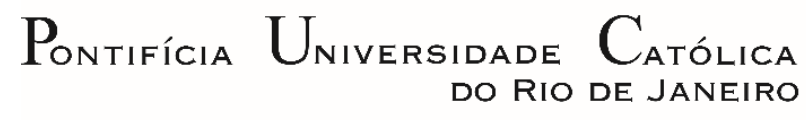

Thiago da Silva Ribeiro

\title{
Aspectos fundamentais da remoção de boro contido em efluentes aquosos por eletrocoagulação
}

\section{Dissertação de Mestrado}

Dissertação apresentada como requisito parcial para obtenção do grau de Mestre pelo Programa de PósGraduação em Engenharia de Materiais e de Processos Químicos e Metalúrgicos do Departamento de Engenharia Química e de Materiais da PUC-Rio.

Orientador: Prof. Maurício Leonardo Torem

Co-Orientador: Dr. Antonio Gutiérrez Merma

Rio de Janeiro 


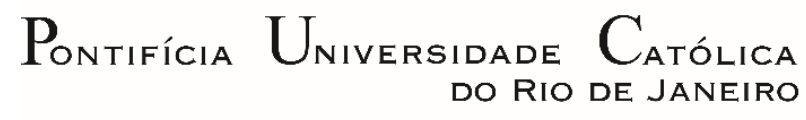

Thiago da Silva Ribeiro

\section{Aspectos fundamentais da remoção de boro contido em efluentes aquosos por eletrocoagulação}

Dissertação apresentada como requisito parcial para obtenção do grau de Mestre pelo Programa de PósGraduação em Engenharia de Materiais e de Processos Químicos e Metalúrgicos do Departamento de Engenharia Química e de Materiais da PUC-Rio. Aprovada pela Comissão Examinadora abaixo assinada.

Prof. Maurício Leonardo Torem

Orientador

Departamento de Engenharia Química e de Materiais - PUC-Rio

Dr. Antonio Gutiérrez Mesma

Co-Orientador

Departamento de Engenharia Química e de Materiais - PUC-Rio

Prof. Brunno Ferreira dos Santos

Departamento de Engenharia Química e de Materiais - PUC-Rio

Prof ${ }^{a}$. Lídia Yokoyama

Universidade Federal do Rio de Janeiro - UFRJ

Prof. Márcio da Silveira Carvalho Coordenador Setorial do Centro Técnico Científico - PUC-Rio

Rio de Janeiro, 11 de Agosto de 2017. 
Todos os direitos reservados. É proibida a reprodução total ou parcial do trabalho sem autorização da universidade, do autor e do orientador.

Thiago da Silva Ribeiro

Graduou-se em Engenharia Ambiental pela Universidade Veiga de Almeida (2015).

Ficha Catalográfica

Ribeiro, Thiago da Silva

Aspectos fundamentais da remoção de boro contido em efluentes aquosos por eletrocoagulação / Thiago da Silva Ribeiro ; orientador: Maurício Leonardo Torem ; coorientador: Antonio Gutiérrez Merma. - 2017.

140 f. : il. color. ; $30 \mathrm{~cm}$

Dissertação (mestrado)-Pontifícia Universidade Católica do Rio de Janeiro, Departamento de Engenharia Química e de Materiais, 2017.

Inclui bibliografia

1. Engenharia de Materiais - Teses. 2. Engenharia Química - Teses. 3. Remoção de boro. 4. Eletrocoagulação. 5. Eletrodos de alumínio. 6. Metodologia de Superfície de Resposta. I. Torem, Maurício Leonardo. II. Gutiérrez Merma, Antonio. III. Pontifícia Universidade Católica do Rio de Janeiro. Departamento de Engenharia Química e de Materiais. IV. Título. 


\section{Agradecimentos}

“Agradecer é reconhecer que não conquistamos nada sozinhos".

Antes de tudo, quero agradecer a Deus pelo presente da vida, pela terra que piso, pelo alento que respiro, pelas pessoas com que convivo...

Aos meus pais, Adão e Neuza, pelo amor incondicional e pela educação baseada em valores fraternais e solidários. Todo o meu agradecimento jamais será suficiente.

Aos meus familiares, longe ou perto, por aqui ou por lá, pelo convívio repleto de carinho e de apoio.

À minha esposa, Déborah Cristina, a minha companheira de todas as horas, pela incansável compreensão, pelo incentivo nas horas certas e incertas e, em especial, pelo amor sempre presente.

Ao meu orientador, Professor Doutor Maurício Torem, pelas importantes e decisivas contribuições para o meu crescimento acadêmico. Agradeço de coração o constante apoio e confiança.

Ao meu coorientador, Doutor Antonio Merma, pelos valiosos conselhos e por me fazer cada vez mais certo de que as perguntas são sempre mais importantes que as respostas. 
Ao Grupo de Tecnologia Mineral e Ambiental da PUC-Rio pela singular oportunidade de aprendizado e convívio enriquecedor.

Aos amigos de mestrado pela indescritível participação nessa caminhada.

Aos professores e funcionários do Departamento de Engenharia Química e de Materiais da PUC-Rio ofereço o meu mais profundo agradecimento. É uma honra estar ao lado de vocês.

Agradeço o suporte financeiro oferecido pela Pontifícia Universidade Católica do Rio de Janeiro, pela Coordenação de Aperfeiçoamento de Pessoal de Nível Superior e pela Fundação Carlos Chagas Filho de Amparo à Pesquisa do Estado do Rio de Janeiro. 


\section{Resumo}

Ribeiro, Thiago da Silva; Torem, Maurício Leonardo; Merma, Antonio Gutiérrez. Aspectos fundamentais da remoção de boro contido em efluentes aquosos por eletrocoagulação. Rio de Janeiro, 2017. 140p. Dissertação de Mestrado - Departamento de Engenharia Química e de Materiais, Pontifícia Universidade Católica do Rio de Janeiro.

Compostos de boro são utilizados na indústria metalúrgica, microeletrônica, de vidros, na agricultura, etc. Esse elemento é um micronutriente essencial no desenvolvimento de microrganismos, plantas, animais e humanos. No entanto, pode ser tóxico em grandes concentrações e por isso necessita ser removido de águas e efluentes. No Brasil, o limite padrão é de $0,5 \mathrm{mg} / \mathrm{L}$ para águas doces de classe I e II, estabelecido pela resolução do Conama 357/2005. Por sua vez, a resolução do Conama 430/2011 estabelece um padrão de lançamento de efluentes de $5 \mathrm{mg} / \mathrm{L}$. A presente dissertação tem como objetivo geral estudar a remoção de boro por eletrocoagulação para o tratamento de águas e efluentes contendo boro, utilizando uma célula com um arranjo de 4 eletrodos de alumínio (2 catodos e 2 anodos) monopolares em paralelo. Os resultados obtidos mostram que o processo de eletrocoagulação é uma alternativa viável para a remoção de boro, e alcança eficiências em torno de $70 \%(\mathrm{em} \mathrm{pH}$ inicial $=4$; densidade de corrente $=$ $18,75 \mathrm{~mA} / \mathrm{cm}^{2}$ e tempo de eletrólise $\left.=90 \mathrm{~min}\right)$. O modelo cinético que melhor descreve a remoção de boro foi o de pseudo-primeira ordem. $\mathrm{O}$ modelo de Langmuir se ajustou muito bem aos dados experimentais obtidos. $\mathrm{O}$ valor de $\mathrm{q}_{\mathrm{m}}$ obtido pelo modelo de Langmuir refletiu a elevada capacidade de adsorção máxima $\left(\mathrm{q}_{\mathrm{m}}=334 \mathrm{mg} / \mathrm{g}\right)$. Através das análises por Microscopia Eletrônica de Varredura (MEV) e por Espectroscopia de Energia Dispersiva (EDS) na superfície dos eletrodos, observou-se a presença de corrosão do tipo localizada nos catodos e a corrosão do tipo uniforme nos anodos. A morfologia do lodo produzido no processo de eletrocoagulação foi analisada por $\mathrm{MEV}$, indicando a presença de uma morfologia heterogênea na superfície, enquanto que a análise por Difração de 
Raios-X (DRX) apresentou picos largos característicos de um material amorfo e a fase de alumínio predominante foi a boehmita, $\mathrm{AlO}(\mathrm{OH})$, finalmente, através da análise por Espectroscopia por Perda de Energia de Elétrons (EELS) foi possível a detecção do boro no lodo, além da detecção de alumínio e de oxigênio. Diante dos resultados obtidos no estudo de otimização a partir da Metodologia de Superfície de Resposta (RSM) constatou-se que o desenvolvimento de um modelo matemático por análise de regressão possibilitou a avaliação do efeito das variáveis independentes (densidade de corrente, $\mathrm{pH}$ inicial e tempo de eletrólise) e as suas interações na remoção de boro.

\section{Palavras-chave}

Remoção de boro; Eletrocoagulação; Eletrodos de alumínio; Metodologia de Superfície de Resposta. 


\section{Abstract}

Ribeiro, Thiago da Silva; Torem, Maurício Leonardo (Advisor); Merma, Antonio Gutiérrez (Co-advisor). Fundamental aspects of boron removal from wastewaters by electrocoagulation method. Rio de Janeiro, 2017. 140p. Dissertação de Mestrado - Departamento de Engenharia Química e de Materiais, Pontifícia Universidade Católica do Rio de Janeiro.

Boron compounds are used in the metallurgical industry, microelectronics, glassware, agriculture, etc. This element is an essential micronutrient in the development of microorganisms, plants, animals and humans. However, it can be toxic in high concentrations and therefore needs to be removed from water and effluent. In Brazil, the standard limit is $0.5 \mathrm{mg} / \mathrm{L}$ for Class I and II freshwaters, established by Conama Resolution 357/2005. In turn, the Conama 430/2011 resolution establishes an effluent discharge standard of $5 \mathrm{mg} / \mathrm{L}$. The present dissertation aims to study the removal of boron by electrocoagulation for the treatment of water and effluents containing boron, using a cell with an arrangement of 4 monopolar aluminum electrodes ( 2 cathodes and 2 anodes) in parallel. The results show that the electrocoagulation process is a viable alternative for the removal of boron and reaches efficiencies around 70\% (at initial $\mathrm{pH}=4$, current density $=18.75 \mathrm{~mA} / \mathrm{cm} 2$ and electrolysis time $=90 \mathrm{~min}$ ). The kinetic model that best describes the removal of boron was pseudo-first order. The Langmuir model fitted very well to the experimental data obtained. The value of $\mathrm{q}_{\mathrm{m}}$ obtained by the Langmuir model reflected the high maximum adsorption capacity $\left(q_{\mathrm{m}}=334 \mathrm{mg} / \mathrm{g}\right)$. Through the analysis by Scanning Electron Microscopy (SEM) and Energy Dispersive Spectroscopy (EDS) on the surface of the electrodes, it was observed the presence of pitting corrosion in the cathodes and uniform corrosion in the anodes. The morphology of the sludge produced in the electrocoagulation process was analyzed by SEM, indicating the presence of a heterogeneous surface morphology, while the X-ray diffraction (XRD) analysis showed broad peaks characteristic of an amorphous material and the predominant 
aluminum phase was boehmite, $\mathrm{AlO}(\mathrm{OH})$, finally, through the Electron Energy Loss Spectroscopy (EELS) analysis, it was possible to detect boron in the sludge, as well as aluminum and oxygen. In view of the results obtained in the optimization study from the Response Surface Methodology (RSM), it was verified that the development of a mathematical model by regression analysis made possible the evaluation of the effect of the independent variables (current density, initial $\mathrm{pH}$ and time of electrolysis) and their interactions in the removal of boron.

\section{Keywords}

Boron Removal; Electrocoagulation; Aluminum Electrodes; Response Surface Methodology. 


\section{Sumário}

$\begin{array}{ll}1 \text { Introdução } & 20\end{array}$

2 Objetivos 23

2.1. Objetivo Geral 23

2.2. Objetivos específicos 23

3 Fundamentos Teóricos $\quad 24$

3.1. Boro 24

3.1.1. Boro no meio ambiente 24

3.1.2. Química do boro 26

3.1.3. Toxicologia do boro e Legislações 29

3.1.4. Métodos de remoção de boro 31

3.2. Eletrocoagulação 34

3.2.1. Eletroquímica 38

3.2.1.1. A interface solução-eletrodo 38

3.2.1.2. Processos Faradaicos e não-Faradaicos 40

3.2.1.3. Termodinâmica eletroquímica 40

3.2.1.4. Cinética eletroquímica 42

3.2.1.5. Sobrepotencial 48

3.2.1.6. Reações na célula de eletrocoagulação 50

3.2.2. Coagulação $\quad 51$

3.2.2.1. Dupla camada elétrica 52

3.2.2.2. Estabilidade Coloidal 53

3.2.2.3. Mecanismos de agregação 56

3.2.2.4. Alumínio(III) como cátion coagulante 58

3.2.2.5. Diagrama Eh-pH 61

3.2.3. Flotação 62

3.3. Considerações sobre o projeto do reator de eletrocoagulação 64

3.4. Parâmetros operacionais da célula de eletrocoagulação 68

3.5. Vantagens e limitações da Eletrocoagulação 73 
4 Materiais e métodos $\quad 75$

4.1. Materiais 75

4.1.1. Reator de eletrocoagulação 75

4.1.2. Reagentes químicos 79

4.2. Métodos experimentais 79

4.2.1. Preparação da solução contendo boro 79

4.2.2. Rotina experimental 79

4.2.3. Planejamento experimental 80

4.2.4. Avaliação microscópica da superfície dos eletrodos de alumínio 82

4.2.5. Caracterização do lodo gerado no processo de eletrocoagulação 83

4.2.6. Determinação da concentração de boro 84

4.2.7. Modelo cinético 85

4.2.8. Isotermas de adsorção 86

5 Resultados e discussão $\quad 87$

5.1. Efeitos dos parâmetros operacionais de eletrocoagulação 87

5.1.1. Efeito do pH inicial 87

5.1.1.1. Avaliação do mecanismo de remoção dominante 93

5.1.2. Efeito da densidade de corrente 100

5.2. Modelo cinético 104

5.3. Isotermas de adsorção 107

5.4. Avaliação microscópica da superfície dos eletrodos de alumínio utilizados no processo de eletrocoagulação 111

5.5. Caracterização do lodo produzido no processo de eletrocoagulação 115

5.6. Otimização das condições experimentais 117

5.6.1. Modelagem e análise estatística 117

5.6.2. Análise das superfícies de resposta 120

$\begin{array}{ll}\text { 5.6.3. Condições ótimas } & 125\end{array}$

6 Conclusões $\quad 126$ 
7 Referências bibliográficas 


\section{Lista de Figuras}

Figura 1 - Estrutura cristalina do ácido bórico (Park et al., 1994).

Figura 2 - Diagrama de especiação do boro com $[B]=0,04 \mathrm{M}$

(Hinz et al., 2015).

Figura 3 - Diagrama de especiação do boro com $[B]=0,4 M$ (Hinz et al., 2015).

Figura 4 - Natureza complexa e interdependente do processo de eletrocoagulação (Adaptado de Holt et al., 2002).

Figura 5 - Diagrama de Venn das três ciências básicas que interagem no processo de eletrocoagulação (Adaptado de Holt et al., 2005).

Figura 6 - llustração da dupla camada elétrica e da variação do potencial elétrico $\left(\psi_{0}\right)$ em função da distância a partir do eletrodo, segundo o modelo de Stern (Adaptado de Goodwin, 2004).

Figura 7 - Etapas básicas de um processo de oxidação ou redução em um eletrodo (Adaptado de Pletcher et al., 1990).

Figura 8 - Balanço dos potenciais de repulsão e atração entre partículas de acordo com a teoria DLVO (Adaptado de Ninham, 1999).

Figura 9 - Mecanismos de desestabilização de partículas coloidais (Di Bernardo et al., 2005).

Figura 10 - Diagrama de especiação do alumínio, obtido através do software Hydra-Medusa (KTH). Elaborada pelo autor.

Figura 11 - Diagrama de solubilidade do hidróxido de alumínio (Wang et al., 2017).

Figura 12 - Diagrama de equilíbrio Eh-pH para o sistema alumínio-água a $25^{\circ} \mathrm{C}$, obtido através do software HSC Chemistry 6.1 (Outotec). Elaborada pelo autor.

Figura 13 - Diagrama esquemático de um reator de eletrocoagulação escala bancada com eletrodos monopolares em paralelo (Adaptado de Mollah et al., 2004). 
Figura 14 - Diagrama esquemático de um reator de eletrocoagulação escala bancada com eletrodos bipolares em paralelo (Adaptado de Mollah et al., 2004).

Figura 15 - Linha experimental de eletrocoagulação. 1- pHmetro (HI 4521 - HANNA); 2- Célula de eletrocoagulação (acrílico); 3Eletrodos de alumínio; 4- Agitador magnético (761-5 FISATOM); 5- Fonte de tensão (PS-1001 - ICEL); 6- Bomba de vácuo. Elaborada pelo autor.

Figura 16 - Célula de eletrocoagulação utilizada para avaliação do processo em batelada. Fotografia do autor.

Figura 17 - Eletrodo de alumínio perfurado. Fotografia do autor. 77

Figura 18 - Arranjo físico dos eletrodos. Fotografia do autor.

Figura 19 - Célula de eletrocoagulação durante a realização de um experimento. Fotografia do autor.

Figura 20 - Evolução do pH da solução durante o processo de eletrocoagulação para $\mathrm{pH}_{0}=3$ em diferentes valores de densidade de corrente $([\mathrm{NaCl}]=15 \mathrm{mM} ; \mathrm{RPM}=250 ; d=10 \mathrm{~mm})$. Elaborada pelo autor.

Figura 21 - Evolução do pH da solução durante o processo de eletrocoagulação para $\mathrm{pH}_{0}=4$ em diferentes valores de densidade de corrente $([\mathrm{NaCl}]=15 \mathrm{mM} ; \mathrm{RPM}=250 ; d=10 \mathrm{~mm})$. Elaborada pelo autor.

Figura 22 - Evolução do pH da solução durante o processo de eletrocoagulação para $\mathrm{pH}_{0}=5$ em diferentes valores de densidade de corrente $([\mathrm{NaCl}]=15 \mathrm{mM} ; \mathrm{RPM}=250 ; d=10 \mathrm{~mm})$. Elaborada pelo autor.

Figura 23 - Evolução do pH da solução durante o processo de eletrocoagulação para $\mathrm{pH}_{0}=6$ em diferentes valores de densidade de corrente $([\mathrm{NaCl}]=15 \mathrm{mM} ; \mathrm{RPM}=250 ; d=10 \mathrm{~mm})$. Elaborada pelo autor.

Figura 25 - Evolução do pH da solução durante o processo de eletrocoagulação para $\mathrm{pH}_{0}=8 \mathrm{em}$ diferentes valores de densidade de corrente $([\mathrm{NaCl}]=15 \mathrm{mM} ; \mathrm{RPM}=250 ; d=10 \mathrm{~mm})$. Elaborada pelo autor. 
Figura 26 - Remoção de boro (\%) em função do tempo de eletrólise para $\mathrm{J}=6,25 \mathrm{~mA} / \mathrm{cm}^{2}$ em diferentes valores de $\mathrm{pH}$ inicial $([\mathrm{NaCl}]=15 \mathrm{mM} ; \mathrm{RPM}=250 ; \mathrm{d}=10 \mathrm{~mm})$. Elaborada pelo autor.

Figura 27 - Remoção de boro (\%) em função do tempo de eletrólise para $\mathrm{J}=12,50 \mathrm{~mA} / \mathrm{cm}^{2}$ em diferentes valores de $\mathrm{pH}$ inicial $([\mathrm{NaCl}]=15 \mathrm{mM} ; \mathrm{RPM}=250 ; \mathrm{d}=10 \mathrm{~mm})$. Elaborada pelo autor.

Figura 28 - Remoção de boro (\%) em função do tempo de eletrólise para $\mathrm{J}=18,75 \mathrm{~mA} / \mathrm{cm}^{2}$ em diferentes valores de $\mathrm{pH}$ inicial $([\mathrm{NaCl}]=15 \mathrm{mM} ; \mathrm{RPM}=250 ; \mathrm{d}=10 \mathrm{~mm})$. Elaborada pelo autor.

Figura 29 - Variação do potencial zeta do ácido bórico em função do pH sem eletrólito suporte. Elaborada pelo autor.

Figura 30 - Comportamento do $\mathrm{pH}$ ao longo do tempo em $\mathrm{pH}_{0}=$ $3\left([\mathrm{NaCl}]=15 \mathrm{mM} ; \mathrm{RPM}=250 ; \mathrm{d}=10 \mathrm{~mm} ; \mathrm{J}=6,25 \mathrm{~mA} / \mathrm{cm}^{2}\right)$.

Elaborada pelo autor.

Figura 31 - Comportamento do $\mathrm{pH}$ ao longo do tempo em $\mathrm{pH}_{0}=$ $4\left([\mathrm{NaCl}]=15 \mathrm{mM} ; \mathrm{RPM}=250 ; \mathrm{d}=10 \mathrm{~mm} ; \mathrm{J}=6,25 \mathrm{~mA} / \mathrm{cm}^{2}\right)$.

Elaborada pelo autor.

Figura 32 - Comportamento do $\mathrm{pH}$ ao longo do tempo em $\mathrm{pH}_{0}=$ $5\left([\mathrm{NaCl}]=15 \mathrm{mM} ; \mathrm{RPM}=250 ; \mathrm{d}=10 \mathrm{~mm} ; \mathrm{J}=6,25 \mathrm{~mA} / \mathrm{cm}^{2}\right)$.

Elaborada pelo autor.

Figura 33 - Comportamento do $\mathrm{pH}$ ao longo do tempo em $\mathrm{pH}_{0}=$ $6\left([\mathrm{NaCl}]=15 \mathrm{mM} ; \mathrm{RPM}=250 ; \mathrm{d}=10 \mathrm{~mm} ; \mathrm{J}=6,25 \mathrm{~mA} / \mathrm{cm}^{2}\right)$.

Elaborada pelo autor.

Figura 34 - Comportamento do $\mathrm{pH}$ ao longo do tempo em $\mathrm{pH}_{0}=$ $7\left([\mathrm{NaCl}]=15 \mathrm{mM} ; \mathrm{RPM}=250 ; \mathrm{d}=10 \mathrm{~mm} ; \mathrm{J}=6,25 \mathrm{~mA} / \mathrm{cm}^{2}\right)$.

Elaborada pelo autor.

Figura 35 - Comportamento do $\mathrm{pH}$ ao longo do tempo em $\mathrm{pH}_{0}=$ $8\left([\mathrm{NaCl}]=15 \mathrm{mM} ; \mathrm{RPM}=250 ; \mathrm{d}=10 \mathrm{~mm} ; \mathrm{J}=6,25 \mathrm{~mA} / \mathrm{cm}^{2}\right)$.

Elaborada pelo autor.

Figura 36 - Efeito da densidade de corrente na remoção de boro (\%) em função dos diferentes valores de pH inicial ([NaCl] 
$=15 \mathrm{mM} ; \mathrm{RPM}=250 ; \mathrm{d}=10 \mathrm{~mm} ; \mathrm{t}=90 \mathrm{~min})$. Elaborada pelo

autor.

Figura 37 - Dissolução total de alumínio em função dos valores de $\mathrm{pH}$ inicial em densidade de corrente de $6,25 \mathrm{~mA} / \mathrm{cm}^{2}$ ([NaCl] $=15 \mathrm{mM} ; \mathrm{RPM}=250 ; \mathrm{d}=10 \mathrm{~mm} ; \mathrm{t}=90 \mathrm{~min})$. Elaborada pelo autor.

Figura 38 - Dissolução total de alumínio em função dos valores de $\mathrm{pH}$ inicial em densidade de corrente de $12,50 \mathrm{~mA} / \mathrm{cm}^{2}([\mathrm{NaCl}]$ $=15 \mathrm{mM} ; \mathrm{RPM}=250 ; \mathrm{d}=10 \mathrm{~mm} ; \mathrm{t}=90 \mathrm{~min}$ ). Elaborada pelo autor.

Figura 39 - Dissolução total de alumínio em função dos valores de $\mathrm{pH}$ inicial em densidade de corrente de $18,75 \mathrm{~mA} / \mathrm{cm}^{2}([\mathrm{NaCl}]$ $=15 \mathrm{mM} ; \mathrm{RPM}=250 ; \mathrm{d}=10 \mathrm{~mm} ; \mathrm{t}=90 \mathrm{~min})$. Elaborada pelo autor.

Figura 40 - Constante cinética em função do pH inicial e da densidade de corrente. Elaborada pelo autor. Figura 41 - Gráfico da regressão não linear dos modelos Langmuir e Freundlich. Elaborada pelo autor.

Figura 42 - Análise por MEV da superfície do catodo, com aumento de 200 vezes. Elaborada pelo autor.

Figura 43 - Análise por MEV da superfície do anodo, com aumento de 200 vezes. Elaborada pelo autor.

Figura 44 - Análise por MEV da superfície do catodo em uma região onde ocorreu a dissolução química do alumínio, com aumento de 2000 vezes. Elaborada pelo autor.

Figura 45 - Análise por EDS da superfície do catodo em uma região onde não houve a dissolução química do alumínio.

Elaborada pelo autor.

Figura 46 - Análise por EDS da superfície do catodo em uma região onde houve a dissolução química do alumínio. Elaborada pelo autor.

Figura 47 - Análise por EDS da superfície do anodo. Elaborada pelo autor.

Figura 48 - Morfologia e composição elementar do lodo 
produzido no processo de eletrocoagulação. Elaborada pelo

autor.

Figura 49 - Difratograma do lodo obtido no processo de

eletrocoagulação. Elaborada pelo autor.

Figura 50 - Espectro de EELS do lodo obtido no processo de

eletrocoagulação. Elaborada pelo autor.

Figura 51 - Gráfico de probabilidade normal dos resíduos para a variável resposta. Elaborada pelo autor.

Figura 52 - Superfície de resposta para o percentual de

remoção de boro $\mathrm{xpH}$ inicial $\mathrm{x}$ densidade de corrente, mantendo o tempo fixo em 90 minutos. Elaborada pelo autor.

Figura 53 - Gráfico de contorno para o percentual de remoção

de boro $\mathrm{xpH}$ inicial $\mathrm{x}$ densidade de corrente, mantendo o tempo fixo em 90 minutos. Elaborada pelo autor.

Figura 54 - Superfície de resposta para o percentual de remoção de boro $x$ tempo $x$ densidade de corrente, mantendo o $\mathrm{pH}$ inicial fixo em 5,5. Elaborada pelo autor.

Figura 55 - Gráfico de contorno para o percentual de remoção de boro $\mathrm{x}$ tempo $\mathrm{x}$ densidade de corrente, mantendo $\mathrm{opH}$ inicial fixo em 5,5. Elaborada pelo autor.

Figura 56 - Superfície de resposta para o percentual de remoção de boro $x$ tempo $x \mathrm{pH}$ inicial, mantendo a densidade de corrente fixa em $18,75 \mathrm{~mA} / \mathrm{cm}^{2}$. Elaborada pelo autor. Figura 57 - Gráfico de contorno para o percentual de remoção de boro $\mathrm{x}$ tempo $\mathrm{xpH}$ inicial, mantendo a densidade de corrente fixa em $18,75 \mathrm{~mA} / \mathrm{cm}^{2}$. Elaborada pelo autor. 


\section{Lista de Tabelas}

Tabela 1 - Características da célula de eletrocoagulação.

Elaborada pelo autor. $\quad 76$

Tabela 2 - Características dos eletrodos. Elaborada pelo autor. $\quad 77$

Tabela 3 - Fatores e níveis aplicados ao experimento.

Densidade de corrente (X1), em $\mathrm{mA} / \mathrm{cm}^{2}, \mathrm{pH}$ inicial (X2) e tempo (X3), em minuto. Elaborada pelo autor.

Tabela 4 - Condições operacionais utilizadas na determinação

de boro por ICPOES. Elaborada pelo autor.

Tabela 5 - Condições experimentais para determinar a constante cinética. Elaborada pelo autor.

Tabela 6 - Condições experimentais para determinar o modelo de isoterma de adsorção. Elaborada pelo autor.

Tabela 7 - Valores das constantes cinéticas e de $R^{2}$ para os modelos cinéticos de pseudo-primeira ordem e de pseudosegunda ordem. Elaborada pelo autor.

Tabela 8 - Valores de $\mathrm{R}^{2}$ ajustado e os parâmetros das isotermas de Langmuir e de Freundlich. Elaborada pelo autor.

Tabela 9 - Constante $q_{m}$ da isoterma de Langmuir para a adsorção de boro em diferentes adsorventes. Elaborada pelo autor.

Tabela 10 - Coeficientes da regressão linear, erro padrão dos coeficientes, valores de t e probabilidade de significância estatística $(p)$ dos coeficientes do modelo referente à remoção de boro. Densidade de corrente $(X 1)$, em $\mathrm{mA} / \mathrm{cm}^{2}, \mathrm{pH}$ inicial (X2) e tempo (X3), em minuto. Elaborada pelo autor. 
"O segredo da sabedoria, do poder e do conhecimento é a humildade"

Ernest Hemingway 


\section{Introdução}

O elemento boro é encontrado na natureza formando compostos com o oxigênio, especialmente boratos. Pode-se detectá-lo nos oceanos, em rochas sedimentares, no carvão, no xisto e em alguns solos. Esses compostos são desprendidos espontaneamente para a atmosfera e para os oceanos, por fluxos de vapor geotermais, erosão de rochas sedimentares ricas em argila e por fontes antropogênicas (Murray, 1995; Howe, 1998; Ayyildiz, 2005).

Em meio aquoso, o boro é encontrado frequentemente como ácido bórico $\left(\mathrm{H}_{3} \mathrm{BO}_{3}\right)$ e íons borato $\left(\left[\mathrm{B}(\mathrm{OH})_{4}\right]^{-}\right)$. A forma dominante de boro inorgânico em sistemas de águas naturais é como o ácido bórico não dissociado (Davidson et al., 2007).

O ácido bórico é um ácido fraco e exclusivamente monoprótico, que, em solução, comporta-se como um aceptor de elétrons permitindo sua complexação com o par de elétrons dos íons hidroxila. A sua constante de ionização é: $\mathrm{Ka}=$ $5,8 \times 10^{-10},(\mathrm{pKa}=9,24)$ a $25^{\circ} \mathrm{C}$. Embora seja uma espécie monoprótica em soluções diluídas, pode-se encontrar espécies poliméricas em concentrações superiores a $0,1 \mathrm{M}$ de $\mathrm{H}_{3} \mathrm{BO}_{3}$, tais como $\left[\mathrm{B}_{2} \mathrm{O}(\mathrm{OH})_{6}\right]^{2-}, \quad\left[\mathrm{B}_{3} \mathrm{O}_{3}(\mathrm{OH})_{4}\right]^{-}$, $\left[\mathrm{B}_{4} \mathrm{O}_{5}(\mathrm{OH})_{4}\right]^{2-}$ e $\left[\mathrm{B}_{5} \mathrm{O}_{6}(\mathrm{OH})_{4}\right]^{-}$(Hosmane, 2011).

Os compostos de boro são utilizados na indústria microeletrônica, na metalúrgica, na de vidros, na agricultura, etc. Esse elemento é um micronutriente fundamental no desenvolvimento de microrganismos, animais, humanos e plantas. Contudo, ele pode ser tóxico em grandes concentrações e, dessa forma, é necessário que seja removido de águas e efluentes (Hermanek, 1992).

A Organização Mundial da Saúde (OMS) aconselha, em sua diretriz, que a concentração de boro para água potável seja de 2,4mg/L. Embora o valor de 2,4mg/L esteja abaixo do nível aceitável de risco à saúde humana, esse ultrapassa a concentração limite em diversos tipos de culturas. Portanto, muitos países ainda implementam seu próprio parâmetro (Wang et al., 2014). 
No Brasil, o limite padrão é de 0,5mg/L para águas doces de classe I e II, estabelecido pela resolução do Conama 357/2005. Por sua vez, a resolução do Conama 430/2011 estabelece um padrão de lançamento de efluentes de 5mg/L, que não se aplica para lançamento em águas salinas. Não há inclusão de limite para padrão de potabilidade na legislação vigente no Ministério da Saúde.

Diversas tecnologias têm sido desenvolvidas para a remoção de boro. Neste estudo, discutiu-se alguns dos principais métodos utilizados para essa operação. A maioria dos processos evoluiu em torno da ideia de utilizar a água do mar ou a água contaminada como uma fonte de água potável ou de irrigação.

A técnica de precipitação é apropriada para a remoção de boro em altas concentrações. Contudo, em baixas concentrações, essa tecnologia requer o controle da temperatura, do $\mathrm{pH}$ ou a utilização de produtos químicos auxiliares que prejudicam o seu emprego (McNeill et al., 1997).

Foram encontrados relatos na literatura de remoção de boro por adsorção com alumina ativada, bauxita, hidróxido de magnésio, hidróxido de ferro, carvão ativado, hidróxido de alumínio, calcita ou combinações desses sólidos (Parks et al., 2007). Os custos com produtos químicos e manejo do lodo gerado estão diretamente ligados à dose de adsorvente, o que pode influenciar a viabilidade dessa tecnologia.

O aperfeiçoamento de resinas específicas para a remoção de boro nos anos 70 levou a uma ampliação do emprego dessa tecnologia (Jacob, 2007). Contudo, o boro adsorvido pela resina é eluído na regeneração, esse processo gera um efluente com alto conteúdo de boro.

Nesse panorama, acentua-se a busca por um processo com alta eficiência de remoção de boro, mas que também possa gerar um subproduto sólido que contenha boro, de manuseio e disposição fáceis para o seu descarte final ou aproveitamento.

O processo de eletrocoagulação é uma tecnologia complexa. Embora tenha sido largamente utilizada por mais de um século, ainda não se tem um domínio dos seus fundamentos. O principal motivo dessa circunstância recai no fato da eletrocoagulação ser uma tecnologia que se localiza na interseção de três tecnologias principais: a eletroquímica, a coagulação e a flotação. Logo, deve-se quantificar e esclarecer as interações chaves entre essas três tecnologias (Holt et al., 2005). 
Mollah et al. (2001) expuseram diversas vantagens do processo de eletrocoagulação em relação ao processo de coagulação tradicional. O equipamento necessário para o processo de eletrocoagulação, por exemplo, é simples e de fácil operação. Dessa forma, poderia ser realizado em instalações de tratamento pequenas e compactas, resultando em um custo relativamente baixo e possibilitando a sua completa automação. Além disso, o processo não tem partes móveis e a maior parte é controlada eletricamente, necessitando, assim, de menos manutenção. Também foi afirmado que a técnica de eletrocoagulação pode ser utilizada em áreas rurais onde a eletricidade não está disponível, pois a energia necessária para o processo poderia ser fornecida por painéis solares (Sharma et al., 2011). Ademais, o processo de eletrocoagulação representa uma alternativa apropriada onde tecnologias de tratamento localizadas são preferíveis em relação a tratamentos centralizados (Holt et al., 2005).

Como em qualquer processo, encontram-se também algumas desvantagens como a troca regular dos anodos, a passivação da superfície dos eletrodos, ocasionando a perda de eficiência da unidade de eletrocoagulação, e o consumo de energia elétrica, em virtude do contínuo aumento da tarifa energética (Vik et al., 1984). Contudo, recentemente, algumas soluções estão sendo empregadas com o objetivo de superar essas limitações. É o caso, por exemplo, da inversão de polaridade dos eletrodos para reduzir o efeito da passivação (Mlakar et al., 2017) e da utilização de energia solar fotovoltaica para suprir a demanda energética do processo (Hussin et al., 2017). 


\section{2}

\section{Objetivos}

\section{1.}

\section{Objetivo Geral}

O objetivo geral do presente trabalho foi estudar a remoção de boro por eletrocoagulação para o tratamento de águas e efluentes que contêm boro.

\section{2.}

\section{Objetivos específicos}

Os objetivos específicos deste trabalho são:

- Avaliar a influência da densidade de corrente, do pH inicial e do tempo de eletrólise na eficiência de remoção de boro pelo processo de eletrocoagulação;

- Determinar o mecanismo de remoção de boro pelo processo de eletrocoagulação;

- Investigar a morfologia da superfície metálica dos eletrodos de alumínio após o tratamento de eletrocoagulação e os elementos químicos presentes por MEV e EDS;

- Determinar o modelo cinético de melhor ajuste aos dados experimentais;

- Obter as isotermas de adsorção visando determinar a capacidade de adsorção dos precipitados de hidróxido de alumínio;

- Caracterizar o lodo com a finalidade de identificar os compostos gerados no tratamento por eletrocoagulação por DRX, MEV, EDS e EELS;

- Realizar a otimização do processo utilizando como ferramenta estatística a RSM. 


\section{3 \\ Fundamentos Teóricos}

3.1.

Boro

Um resumo da literatura sobre a ocorrência de boro, química, problemas relacionados e métodos de remoção é apresentado nas seções a seguir.

\subsection{1.}

\section{Boro no meio ambiente}

O boro elementar nunca é encontrado na natureza, embora seja um elemento ubíquo nos solos e nas águas (Wang et al., 2014). Devido à sua alta afinidade pelo oxigênio, o boro sempre ocorre na natureza ligado ao oxigênio na forma de boratos inorgânicos.

- Boro na litosfera

O boro é amplamente distribuído na litosfera da Terra (Morgan, 1980). Encontra-se em rochas e solos, particularmente em sedimentos marinhos ricos em argila.

A concentração de boro na crosta terrestre varia de 1 a $500 \mathrm{mg} / \mathrm{kg}$, dependendo da natureza da rocha (Aubert et al., 1997). De acordo com Krauskopf (1972), uma média de boro na crosta terrestre é de cerca de 10mg/kg, representando $0,001 \%$ da composição elementar da Terra.

A quantidade de boro nos solos varia de 2 a $100 \mathrm{mg} / \mathrm{kg}$, com uma média de 30mg/kg (Aubert et al., 1997). A maioria dos solos tem baixa concentração de boro $(<10 \mathrm{mg} / \mathrm{kg})$, enquanto que os solos com alta concentração de boro (10$100 \mathrm{mg} / \mathrm{kg}$ ) estão normalmente associados à atividade vulcânica.

O enriquecimento de boro em folhelhos (até $100 \mathrm{mg} / \mathrm{kg}$ ), em comparação com a crosta continental granítica $(9-10 \mathrm{mg} / \mathrm{kg})$, origina-se pela sorção do boro contido na água do mar através da argila e sedimentos orgânicos ao longo de 
vários ciclos de intemperização e deposição (Lemarchand et al., 2005). Outras rochas e formações também podem ser enriquecidas com boro: argilas $(100 \mathrm{mg} / \mathrm{kg}$ ) e rochas carbonáticas (até 350mg/kg) (Turekian et al., 1961).

A quantidade total de boro armazenada na litosfera é estimada como: crostas continentais e oceânicas $\left(10^{18} \mathrm{~kg}\right)$, depósitos de carvão $\left(10^{10} \mathrm{~kg}\right)$, depósitos comerciais de borato $\left(10^{10} \mathrm{~kg}\right)$ e biomassa $\left(10^{10} \mathrm{~kg}\right)$ (Argust, 1998).

Deve-se notar que o boro nunca é encontrado livre na natureza, mas invariavelmente ocorre como o óxido $\mathrm{B}_{2} \mathrm{O}_{3}$ em combinação com os óxidos de outros elementos para formar boratos de maior ou menor complexidade (Parks et al., 2005).

Existem mais de 200 compostos de boro na Terra, mas apenas doze são comercialmente significativos (Adair, 2007). O primeiro minério de boro conhecido na antiguidade é o tetraborato de sódio decahidratado ou bórax $\left(\mathrm{Na}_{2} \mathrm{~B}_{4} \mathrm{O}_{7} \cdot 10 \mathrm{H}_{2} \mathrm{O}\right)$. Os outros minérios importantes que contêm boro são a ulexita $\left(\mathrm{NaCaB}_{5} \mathrm{O}_{9} \cdot 8 \mathrm{H}_{2} \mathrm{O}\right)$, colemanita $\left(\mathrm{Ca}_{2} \mathrm{~B}_{6} \mathrm{O}_{11} .5 \mathrm{H}_{2} \mathrm{O}\right)$ e kernita $\left(\mathrm{Na}_{2} \mathrm{~B}_{4} \mathrm{O}_{7} .4 \mathrm{H}_{2} \mathrm{O}\right)$. Esses fornecem mais de $90 \%$ da demanda mundial de boro (Adair, 2007).

Alguns dos principais usos do boro estão na produção de vidro (borossilicatos), retardadores de fogo e detergentes. A agricultura também consome quantidades significativas de boro como fertilizante (Parks et al., 2005).

Os principais depósitos estão sendo explorados nos Estados Unidos, Turquia, Itália, Espanha, Rússia, Chile e em alguns outros países (Adair, 2007).

- Boro na hidrosfera

A distribuição de boro na hidrosfera foi identificada por Argust (1998) como: oceanos $\left(10^{15} \mathrm{~kg}\right)$, águas subterrâneas $\left(10^{11} \mathrm{~kg}\right)$, gelo $\left(10^{11} \mathrm{~kg}\right)$ e águas superficiais $\left(10^{8} \mathrm{~kg}\right)$.

A maior parte do boro na hidrosfera é encontrada nos oceanos, com uma concentração média de 4,5mg/L, mas possui uma variação de 0,5 a 9,6mg/L (Weast, 1985).

Em condições naturais, a concentração de boro nas águas subterrâneas e superficiais é geralmente pequena ( $<1 \mathrm{mg} / \mathrm{L}$ e $<0,5 \mathrm{mg} / \mathrm{L}$, respectivamente), e é resultado, em especial, da lixiviação de rochas e solos contendo boratos (Jahiruddin et al., 1998). 
A principal fonte antropogênica de boro é a indústria de vidros/ cerâmicas (responsável por $56 \%$ da demanda mundial de boro), seguida da indústria de sabões/ detergentes e da indústria de fertilizantes/ herbicidas (Hebblethwaite et al., 1993).

Os efluentes de águas residuais domésticas também podem ser extremamente enriquecidos em boro, com concentrações variando de várias centenas de $\mu \mathrm{g} / \mathrm{L}$ a vários mg/L (Fox et al., 2000). A razão mais comum para este enriquecimento é a presença de perborato de sódio, utilizado como agente branqueador em detergentes e produtos de limpeza.

Ainda, os fertilizantes contendo boro podem ser uma importante fonte antropogênica devido à sua aplicação generalizada. $\mathrm{O}$ boro é um micronutriente essencial para plantas e, consequentemente, está incluído em muitos fertilizantes em níveis que variam de 0,01 a $0,06 \%$ em peso, mais comumente na forma de bórax (Brady, 2008).

\subsection{2. \\ Química do boro}

Dois isótopos de boro ocorrem naturalmente, ${ }^{10} \mathrm{~B}(20 \%)$ e ${ }^{11} \mathrm{~B}(80 \%)$, sendo ${ }^{11} \mathrm{~B}$ o isótopo predominante (Muetterties, 1967). A forma elementar de boro é instável na natureza, mas, tal como mencionado acima, ele é frequentemente encontrado em combinação com oxigênio formando uma variedade de sais de borato (Ross et al., 1967).

O boro aparece no grupo 13 (IIIA) na tabela periódica e é o único não metal desse grupo. Além disso, seu comportamento químico exibe muitas semelhanças com o do carbono e silício. Assim como esses elementos, o boro apresenta uma forte tendência para formar ligações covalentes, mas difere claramente desses, pois, apesar de ter quatro orbitais de ligação, possui apenas três elétrons externos, de modo que pode ser definido como deficiente em elétrons (Davidson et al., 2007).

A natureza química do boro é influenciada, principalmente, pela sua pequena dimensão (raio covalente de $0,8-1,01 \AA$ ) e alta energia de ionização (344,2kJ/mol) (Greenwood et al., 1973). 
A estrutura eletrônica do elemento é $1 \mathrm{~s}^{2} 2 \mathrm{~s}^{2} 2 \mathrm{p}^{1} \mathrm{e}$, portanto, nos seus compostos mais comuns, tais como óxidos, sulfuretos, nitretos e halogenetos, o boro tem geralmente um número de coordenação de 3 ou 4 (Davidson et al., 2007).

Os sais de boro são geralmente muito solúveis em água, por exemplo, o bórax tem uma solubilidade de $25,2 \mathrm{~g} / \mathrm{L}$, enquanto o trifluoreto de boro é o composto de boro menos solúvel em água, com uma solubilidade de 2,4g/L (Kemp, 1956).

$\mathrm{Na}$ natureza, o boro é liberado das rochas e dos solos, através do intemperismo, e termina, subsequentemente, no ambiente aquoso como ácido bórico, $\mathrm{H}_{3} \mathrm{BO}_{3}$, ou íon tetrahidroxiborato (íon borato), $\left[\mathrm{B}(\mathrm{OH})_{4}\right]^{-}$.

- Ácido bórico

$\mathrm{O}$ ácido bórico cristalino consiste em camadas de moléculas de $\mathrm{H}_{3} \mathrm{BO}_{3}$ mantidas unidas por ligações de hidrogênio (Muetterties, 1967), conforme apresentado na Figura 1.

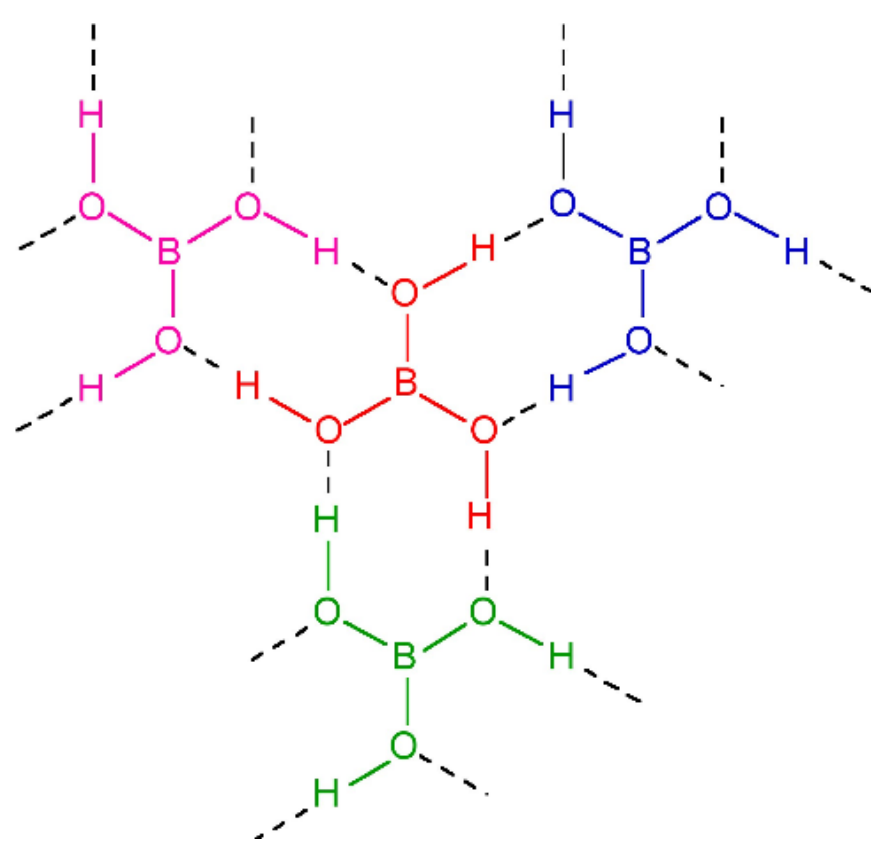

Figura 1 - Estrutura cristalina do ácido bórico (Park et al., 1994).

A solubilidade do ácido bórico, a $25^{\circ} \mathrm{C}$, é de $55 \mathrm{~g} / \mathrm{L}$, essa aumenta com a temperatura à pressão atmosférica (Park et al., 1994). 
O ácido bórico dissolvido apresenta um pequeno tamanho molecular, cujo raio de Stokes é estimado em cerca de $0,155 \mathrm{~nm}$ (que é apenas o dobro da molécula de água) (Park et al., 1994).

Em uma concentração de boro inferior a $216 \mathrm{mg} / \mathrm{L}$, o boro dissolvido é encontrado, principalmente, como as espécies mononucleares de boro, $\mathrm{B}(\mathrm{OH})_{3} \mathrm{e}$ $\left[\mathrm{B}(\mathrm{OH})_{4}\right]^{-}$, conforme apresentado na Figura 2. Em uma concentração mais elevada e com o aumento do $\mathrm{pH}$, espécies polinucleares de boro são formadas, tais como $\left[\mathrm{B}_{2} \mathrm{O}(\mathrm{OH})_{6}\right]^{2-},\left[\mathrm{B}_{3} \mathrm{O}_{3}(\mathrm{OH})_{4}\right]^{-},\left[\mathrm{B}_{4} \mathrm{O}_{5}(\mathrm{OH})_{4}\right]^{2-}$ e $\left[\mathrm{B}_{5} \mathrm{O}_{6}(\mathrm{OH})_{4}\right]^{-}$(Power et al., 1997), conforme apresentado na Figura 3. De acordo com Zeebe et al. (2001), à concentração inferior a 290mg/L, esses íons polinucleares não são predominantes.

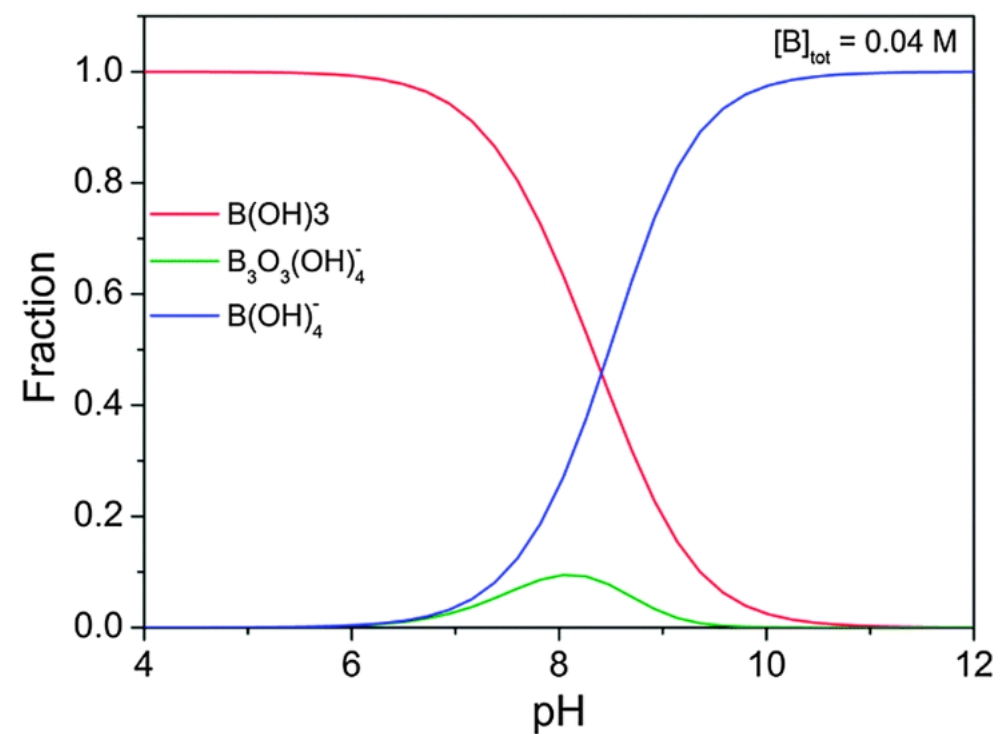

Figura 2 - Diagrama de especiação do boro com [B]=0,04M (Hinz et al., 2015). 


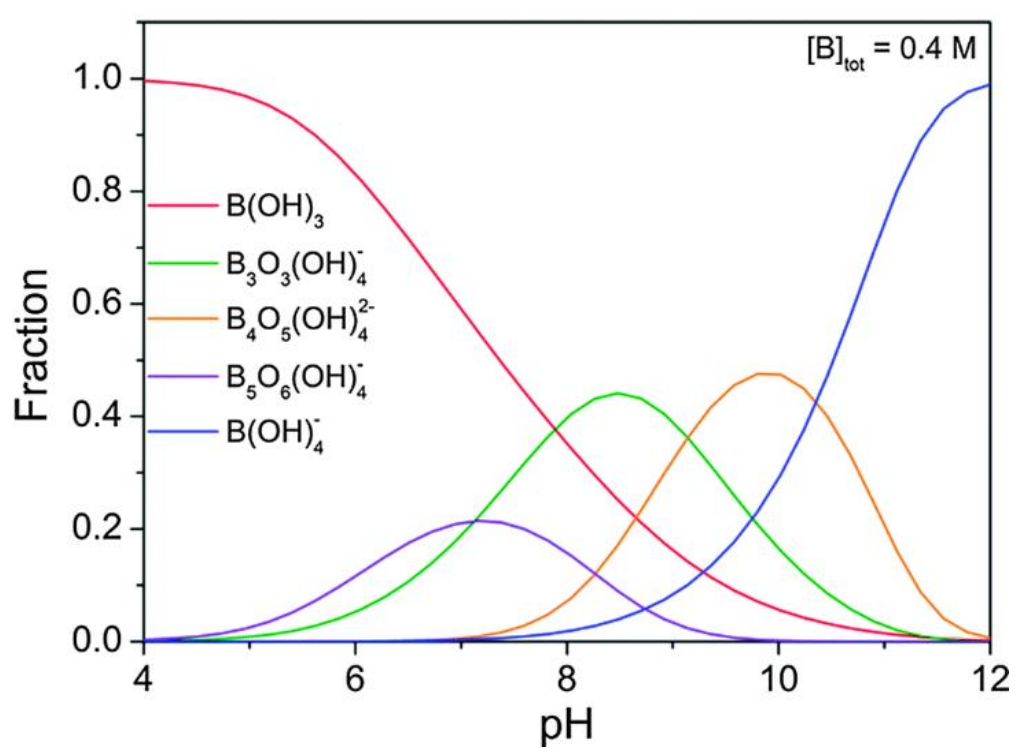

Figura 3 - Diagrama de especiação do boro com [B]=0,4M (Hinz et al., 2015).

A distribuição das duas espécies, ácido bórico e íon borato, depende da constante de dissociação do ácido bórico (pKa). A constante é uma função da temperatura, pressão, $\mathrm{pH}$ e força iônica. $\mathrm{O}$ ácido bórico é fraco e não se dissocia em solução aquosa como um ácido de Bronsted, mas atua como um ácido de Lewis para formar o íon borato (pKa de 9,24) (Jolly, 1984).

\subsection{3.}

\section{Toxicologia do boro e Legislações}

Apesar do boro ser um nutriente essencial para plantas e animais, ele exibe efeitos tóxicos dependendo da concentração e do tempo de exposição.

O boro foi, primeiramente, incluído como parâmetro de potabilidade, em 1984, pela Organização Mundial da Saúde (OMS) (Gupta et al., 1985).

- Humanos e animais

Atualmente, os dados científicos sobre os efeitos específicos do boro na saúde humana são insuficientes e, na sua maioria, inferidos a partir de dados experimentais em animais (Moore, 1997).

O boro apresenta um efeito positivo no metabolismo de vários outros nutrientes, como cálcio, cobre e nitrogênio. A deficiência de boro reduz a 
absorção desses nutrientes. Os mamíferos precisam de boro apenas em quantidades muito pequenas. A Organização Mundial da Saúde definiu em 1$13 \mathrm{mg} /$ dia a dose de boro segura e adequada para um indivíduo saudável (Wolska et al., 2013).

O consumo a longo prazo de água e alimentos com elevada concentração de boro resulta em problemas nos sistemas cardiovascular, nervoso e reprodutivo. Além disso, provoca alterações na composição do sangue, efeitos neurológicos e distúrbios físicos. O excesso de boro pode ser particularmente perigoso para as gestantes, uma vez que aumenta o risco de patologia no feto (Mel'nik et al., 2008).

- Plantas

O boro é um micronutriente essencial para o cultivo de frutas e legumes. A sua deficiência e excesso são prejudiciais para muitas plantas, e a diferença entre esses dois níveis é muito pequena (Wolska et al., 2013).

O boro desempenha um papel importante no crescimento e no funcionamento das plantas, enquanto que a sua deficiência inibe o crescimento do tecido meristemático, interrompe a formação normal das células e atrasa as reações enzimáticas (Nable et al., 1997). Os efeitos visíveis podem ser observados na interrupção do crescimento radicular e foliar, quebra de casca, baixo crescimento e redução da germinação. Quando a quantidade de boro é maior do que a necessária, há sinais de efeitos tóxicos: folhas com pontas amarelas, manchas nos frutos e queda de frutos não maduros. Esses efeitos resultam, em certa medida, na morte das plantas.

A concentração de boro na água de irrigação não deve exceder $0,3-4,0 \mathrm{mg} / \mathrm{L}$, dependendo do tipo de cultura e características do solo (Parks et al., 2005). Na produção agrícola, a toxicidade do boro é mais difícil de controlar do que a sua deficiência, que pode ser evitada pela fertilização apropriada. As plantas apresentam diferentes níveis de tolerância ao excesso de boro. 
- Legislações

Como visto, a concentração recomendada de boro pela diretriz da OMS para água potável é de 2,4mg/L. Embora esse valor esteja abaixo do nível tolerável de risco à saúde humana, esse excede a concentração limite de vários tipos de culturas. Assim sendo, alguns países ainda implementam seu próprio padrão (Wang et al., 2014).

O Departamento de Saúde Pública da Califórnia estabeleceu um limite de 1mg/L, que também é aplicado no Japão (Mane et al., 2009), países da União Europeia e Reino Unido (Busch et al., 2003). Alguns países, como a Austrália $(4 \mathrm{mg} / \mathrm{L})$ e o Canadá $(5 \mathrm{mg} / \mathrm{L})$, regulamentaram valores mais elevados do que a recomendação da OMS por duas razões. Em primeiro lugar, falta de dados que confirmem efeitos adversos à saúde humana. Em segundo lugar, valores inferiores são dificilmente alcançados e economicamente inviáveis (Hilal et al., 2011).

No Brasil, como dito, o limite padrão é de $0,5 \mathrm{mg} / \mathrm{L}$ para águas doces de classe I e II, estabelecido pela resolução do Conama 357/2005. A resolução do Conama 430/2011, por sua vez, estabelece um padrão de lançamento de efluentes de $5 \mathrm{mg} / \mathrm{L}$, que não se aplica para lançamento em águas salinas. Não há inclusão de limite para padrão de potabilidade na legislação vigente no Ministério da Saúde.

\subsection{4.}

\section{Métodos de remoção de boro}

Esta seção revisa métodos convencionais e avançados de remoção de boro. A maioria dos processos desenvolveu-se em torno da ideia de usar a água do mar ou água contaminada como uma fonte de água potável ou de irrigação, uma vez que essas fontes apresentam concentrações de boro que geralmente excedem os limites permitidos (Xu et al., 2008).

\section{- Precipitação}

A precipitação química envolve a transformação de um composto solúvel em uma forma insolúvel através da adição de produtos químicos, de tal modo que 
existe um ambiente supersaturado, isto é, o produto de solubilidade é excedido (Remy, 2005).

A remoção de contaminantes por precipitação é muito vantajosa para o tratamento de água potável ou de águas residuais. Por exemplo, em comparação com a adsorção em que $10-100 \mathrm{~mol}$ de adsorventes, tais como $\mathrm{Fe}(\mathrm{OH})_{3}$ ou $\mathrm{Al}(\mathrm{OH})_{3}$, são normalmente formados por mol de contaminante removido (McNeill et al., 1997), a precipitação pode, tipicamente, remover de 0,3 a $3 \mathrm{~mol}$ de contaminante por mol de cátion adicionado. Esta maior eficiência traduz-se diretamente em custos globais mais baixos, uma vez que as despesas com produtos químicos e o volume de lodo produzido são reduzidos.

Por outro lado, diversos contaminantes são muito solúveis para serem removidos por precipitação (Edwards et al., 1989). Infelizmente, poucos são os compostos de boro com significativa baixa solubilidade.

Remy et al. (2005) sinalizaram a dificuldade da remoção de boro a partir de uma solução diluída. Eles propuseram um novo método utilizando hidróxido de cálcio em pó e, dessa forma, reduziram a concentração de boro de 700 para $50 \mathrm{mg} / \mathrm{L}$, mantendo a temperatura em $90^{\circ} \mathrm{C}$ durante cerca de 2 horas.

Pilipenko et al. (1990) citam a formação de compostos de baixa solubilidade entre zircônio e boro, mas não foram fornecidos os produtos de solubilidade, nem é conhecido se o termo "baixa solubilidade" presente no estudo significou microgramas, miligramas ou gramas por litro de boro solúvel em equilíbrio com o zircónio adicionado.

A precipitação é bem adaptada para remoção de boro em altas concentrações. Contudo, em baixas concentrações, essa tecnologia requer o controle da temperatura, do $\mathrm{pH}$ ou o emprego de produtos químicos auxiliares que dificultam a sua utilização (McNeill et al., 1997).

- Adsorção

A remoção de boro por adsorção com alumina ativada, bauxita, hidróxido de magnésio, hidróxido de ferro, carvão ativado, hidróxido de alumínio, calcita ou combinações destes sólidos foi relatada. No que diz respeito ao tratamento de águas residuais, a adição de hidróxido de magnésio em uma razão molar ( $\mathrm{Mg} / \mathrm{B})$ 
de 20:1 removeu mais de $90 \%$ do boro inicialmente presente na concentração de 500mg/L (Parks et al., 2007).

Em um outro estudo (Bouguerra et al., 2008), a remoção de boro de soluções aquosas foi investigada utilizando alumina ativada. Os autores demonstraram que 0,8 e $5 \mathrm{~g}$ de alumina ativada são capazes de adsorver $40 \%$ e $65 \%$ de boro de soluções aquosas com baixa e alta concentração inicial de boro, respectivamente. De acordo com esta experiência, o tempo de agitação ótimo é de cerca de 30 minutos e o pH deve ser mantido em torno de 8,5 para ambas as concentrações de 5 e $50 \mathrm{mg} / \mathrm{L}$ de boro em solução.

A cinza volante também é relatada como tendo potencial de ser adsorvente para remoção de boro. Uma das vantagens da cinza volante é o fato dessa ser um resíduo de diversas indústrias e, portanto, exibir um menor custo. Ozturk et al. (2005) investigaram a eficácia da cinza volante $(250-400 \mu \mathrm{m})$ para remoção de boro a partir de uma solução aquosa com concentração inicial de boro de $600 \mathrm{mg} / \mathrm{L}$. Em todos os experimentos, a remoção de boro diminuiu com o aumento da temperatura. A remoção máxima de $90 \%$ foi observada a $25^{\circ} \mathrm{C}$ e $\mathrm{pH}$ de 2 , utilizando 4-5 gramas de cinza volante em uma solução de 50mL.

Examinou-se a capacidade do carvão ativado e da cinza volante para remoção de boro da água do mar. Polat et al. (2004) demonstraram que a cinza volante é capaz de reduzir o nível de boro da água do mar em 97\%, enquanto que o carvão ativado possibilitou uma redução em $60 \%$. No entanto, o carvão ativado é uma melhor escolha para o tratamento em fluxo contínuo, uma vez que mantém a sua capacidade de adsorção mesmo após vários ciclos de regeneração.

Os custos com produtos químicos e manejo do lodo produzido estão diretamente relacionados à dose de adsorvente, o que pode afetar a viabilidade desta tecnologia.

\section{- Troca iônica}

O desenvolvimento de resinas específicas para remoção de boro nos anos 70 levou a um aumento na aplicabilidade dessa tecnologia (Jacob, 2007). Quando uma resina de troca iônica não específica é utilizada, todos os ânions são retidos na resina, consequentemente os custos de regeneração tornam-se muito elevados. 
Amberlite IRA-743 é uma resina produzida a partir de copolímero de estireno e divinilbenzeno com grupo funcional metil glucamina, que é essencialmente uma base fraca do tipo amina terciária (Jacob, 2007). A remoção do boro na forma de ânion borato $\left[\mathrm{B}(\mathrm{OH})_{4}\right]^{-}$é representada por um mecanismo de complexação desse com o grupo metil glucamina.

Sahin (1996) estabeleceu o pH de 8 como ótimo para a remoção de boro pela Amberlite IRA-743 e que uma eficiência de remoção de $95 \%$ pode ser obtida quando as águas contêm altos níveis de boro (50-1600mg/L).

Duas fases de regeneração são tipicamente necessárias para a resina específica para boro, incluindo $4 \%$ de $\mathrm{H}_{2} \mathrm{SO}_{4}$ para desorver o boro, seguido por $\mathrm{NaOH}$ a $4 \%$ para neutralizar o ácido. Foi observado que a recuperação do ácido bórico a partir da solução de regeneração não é rentável se estiver em concentração inferior a 1g/L (Pilipenko et al., 1990).

As duas últimas preocupações levantadas por Simonnot et al. (2000) são notáveis. A disposição dos resíduos representa frequentemente até $90 \%$ do custo total com esta tecnologia (Frey et al., 1998) e esta questão não é usualmente considerada na análise de custo para a remoção de boro através de resinas específicas. Simonnot et al. (2000) também observaram que o uso da resina alterou significativamente a composição iônica da solução tratada.

No estudo realizado por Aly et al. (2014), o boro foi encontrado em águas residuais com uma concentração de $9,8 \mathrm{mg} / \mathrm{L}$. O método proposto baseia-se em três tratamentos sucessivos incluindo colunas de cascalho, areia e zeólita natural. Eles descobriram que o método é eficiente e consegue diminuir a concentração de boro em $92,4 \%$, atingindo uma concentração residual de $0,74 \mathrm{mg} / \mathrm{L}$.

\section{2.}

\section{Eletrocoagulação}

A eletrocoagulação apresenta uma longa história, a primeira planta foi construída, em Londres, em 1889, para o tratamento de esgoto (Vik et al., 1984). Apesar de alguns resultados promissores, o sucesso dessa tecnologia encontravase limitado por causa do investimento relativamente alto em comparação à coagulação química e ao alto custo da eletricidade. No entanto, nos últimos anos, tem havido renovado interesse científico, econômico e ambiental nessa tecnologia 
devido, principalmente, à demanda por tecnologias alternativas de tratamento de água. A eletrocoagulação em menor escala encontrou um nicho na indústria de tratamento de água, provando ser uma tecnologia de confiança e eficaz, embora requerendo maior entendimento técnico para seu potencial ser inteiramente explorado (Holt et al, 2002). Tipicamente, estudos empíricos são feitos na eletrocoagulação para definir os principais parâmetros de operação. A tecnologia tem sido otimizada para minimizar o consumo de potência elétrica e para maximizar taxas de remoção de poluentes (Mollah et al., 2001).

Os reatores de eletrocoagulação são células eletroquímicas. Todos esses reatores consistem em um arranjo de eletrodos em contato com a água contaminada, sendo a produção de coagulante in situ sua característica distintiva. Para liberar o coagulante, é necessária a aplicação de uma diferença de potencial através dos eletrodos. Os potenciais requeridos para os eletrodos podem ser deduzidos das reações eletroquímicas de meia-célula que ocorrem em cada eletrodo, o que variará de acordo com o $\mathrm{pH}$ operacional e as espécies presentes no sistema (Holt et al., 2002).

A eletrocoagulação tem a capacidade de remover uma ampla gama de poluentes, incluindo sólidos em suspensão, elementos-traço, corantes, compostos orgânicos, íons, óleos e graxas. As propriedades físico-químicas do poluente influenciam suas interações no reator de eletrocoagulação e, portanto, o caminho de remoção. Por exemplo, os íons são provavelmente eletroprecipitados enquanto que os sólidos em suspensão são adsorvidos aos flocos. A capacidade da eletrocoagulação de remover uma ampla gama de poluentes é o motivo tanto do maior interesse industrial quanto da sua complexidade inerente (Mollah et al., 2004).

A eletrocoagulação envolve três mecanismos principais: (i) geração de coagulantes por oxidação eletrolítica do anodo, (ii) desestabilização dos contaminantes, suspensão particulada e quebra de emulsões e (iii) agregação das fases desestabilizadas para formar um floco (Vasudevan et al., 2013).

Além disso, as seguintes reações físico-químicas também podem ocorrer na eletrocoagulação (Mollah et al., 2004): 
1. Redução catódica das impurezas presentes na solução;

2. Migração eletroforética dos íons em solução;

3. Eletroflotação dos coágulos e flocos por bolhas de $\mathrm{O}_{2}$ e $\mathrm{H}_{2}$ produzidas nos eletrodos;

4. Outros processos (como, por exemplo, a dissolução química).

Assim sendo, a eletrocoagulação é um processo complexo que envolve diversos fenômenos físico-químicos.

Pesquisadores adotaram, em grande parte, uma abordagem empírica para a compreensão da eletrocoagulação (Chen et al., 2000). Ou seja, eles reconheceram a capacidade de remoção de poluentes dessa tecnologia (sob um conjunto de condições operacionais e características do reator), mas não conseguiram extrair (e quantificar) os principais mecanismos subjacentes à remoção de poluentes.

A Figura 4 ilustra a natureza complexa e interdependente do processo de eletrocoagulação (Holt et al., 2002). Claramente, o coagulante e seus produtos de hidrólise podem ter numerosas interações com o poluente, com outras espécies iônicas ou com as bolhas de gases.

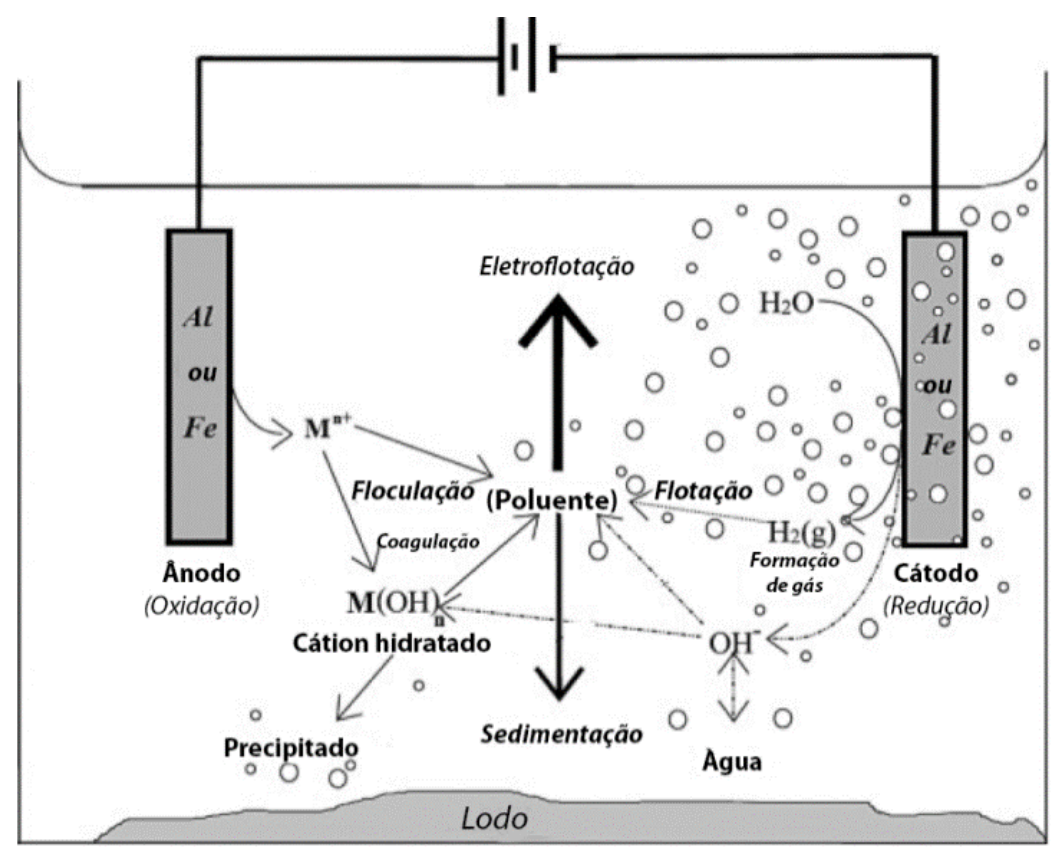

Figura 4 - Natureza complexa e interdependente do processo de eletrocoagulação (Adaptado de Holt et al., 2002). 
É possível identificar três ciências básicas - eletroquímica, coagulação e flotação - que interagem no processo de eletrocoagulação. O fato dessas ciências serem de difícil investigação isoladamente em um reator de eletrocoagulação é um caminho para explicar a ausência de uma literatura técnica detalhada sobre eletrocoagulação (Holt et al., 2005). Essas áreas de conhecimento podem ser conceitualizadas em um diagrama de Venn, em que a combinação das três ciências resulta na eletrocoagulação (Figura 5).

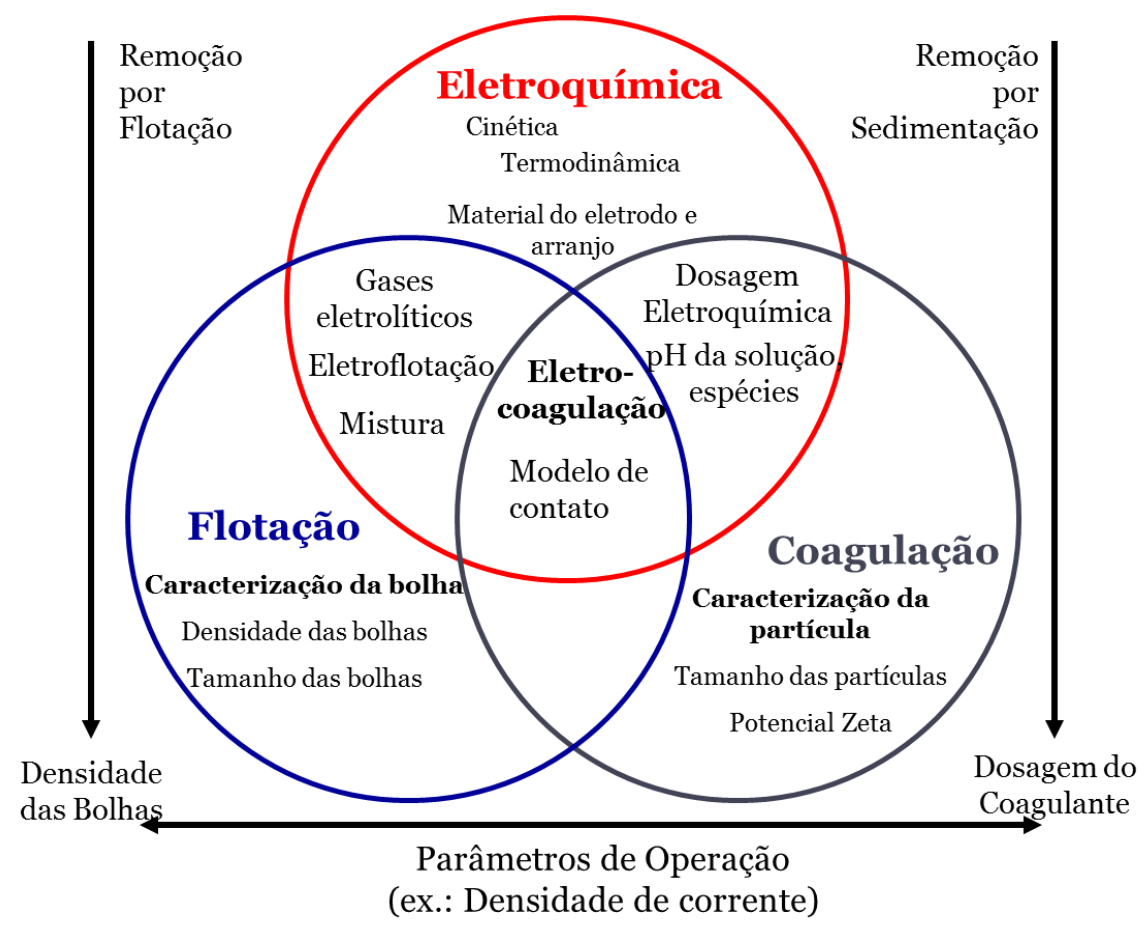

Figura 5 - Diagrama de Venn das três ciências básicas que interagem no processo de eletrocoagulação (Adaptado de Holt et al., 2005).

A perspectiva apresentada na Figura 5 reconhece e define as três bases que subjazem a eletrocoagulação. Cada uma dessas áreas foi pesquisada em profundidade ao longo do último século. Este capítulo resumirá o que cada área tem para oferecer em termos de uma compreensão quantitativa do processo de eletrocoagulação. 


\subsection{1. Eletroquímica}

As reações eletroquímicas que ocorrem na célula de eletrocoagulação determinam o cátion coagulante, tipo de bolhas, entre outros aspectos. Por esse motivo, a eletroquímica é uma das bases da eletrocoagulação (Moreno et al., 2009).

A eletroquímica está relacionada com a transferência de elétrons na interface solução-eletrodo. A maioria dos princípios básicos, no entanto, foram descritos antes da descoberta do elétron por J. J. Thompson, em 1893. Em 1800, Alessandro Volta inventou a primeira bateria, posteriormente conhecida como pilha voltaica, alternando discos de cobre e zinco, esses separados por papel embebido em soluções ácidas. Com a descoberta de uma fonte de corrente elétrica, foi estabelecida a condição para o rápido desenvolvimento de uma área da ciência, atualmente conhecida como eletroquímica. Em 1835, Michael Faraday já havia definido o anodo, catodo, eletrólito e íon: conceitos sem os quais qualquer descrição definitiva da eletroquímica é praticamente impossível (Sawyer et al., 1995).

\subsubsection{1.}

\section{A interface solução-eletrodo}

Em um experimento eletroquímico, o eletrodo atua como fonte ou coletor de elétrons. Quando imerso em uma solução eletrolítica, uma diferença de potencial se desenvolve através da interface como resultado da separação das cargas entre o eletrodo e a solução. Isso faz com que os íons na vizinhança imediata da superfície do eletrodo reorientem-se em um esforço para alcançar o arranjo mais energeticamente estável e para manter a eletroneutralidade. Como resultado, os íons de carga oposta são atraídos para a superfície do eletrodo e os íons de mesma carga são repelidos. Um gradiente de campo elétrico é estabelecido estendendo-se para dentro do seio da solução, sendo esta região denominada de dupla camada elétrica (Bockris et al., 2000).

Houve vários modelos propostos para descrever a estrutura da dupla camada elétrica. Helmholtz (Carnie et al., 2007) primeiro propôs um modelo relativamente simples onde duas camadas rígidas de carga igual e oposta são 
formadas em cada lado da interface solução-eletrodo. O plano externo de Helmholtz é identificado como o plano passando através dos íons solvatados. Nesse modelo, o potencial elétrico muda linearmente entre a superfície do eletrodo e o plano externo de Helmholtz.

Um modelo mais realista foi, então, proposto por Gouy e Chapman (Shaw et al., 1993), que tratou os íons como cargas pontuais e propôs que o potencial decrescesse exponencialmente ao longo de uma camada difusa para dentro do seio da solução. Gouy e Chapman consideraram que o potencial aplicado e a concentração de eletrólito influenciam no valor da capacitância da dupla camada. Assim, a dupla camada não será compacta como no modelo de Helmhotz, mas terá uma espessura variável, estando os íons livres para se movimentarem.

Stern combinou o modelo de Helmholtz com o modelo de Gouy-Chapmann considerando que a dupla camada é formada por uma camada compacta de íons adsorvidos (próximos ao eletrodo), seguida por uma camada difusa que se estende para dentro do seio da solução (Ohshima et al., 1998), conforme apresentado na Figura 6.

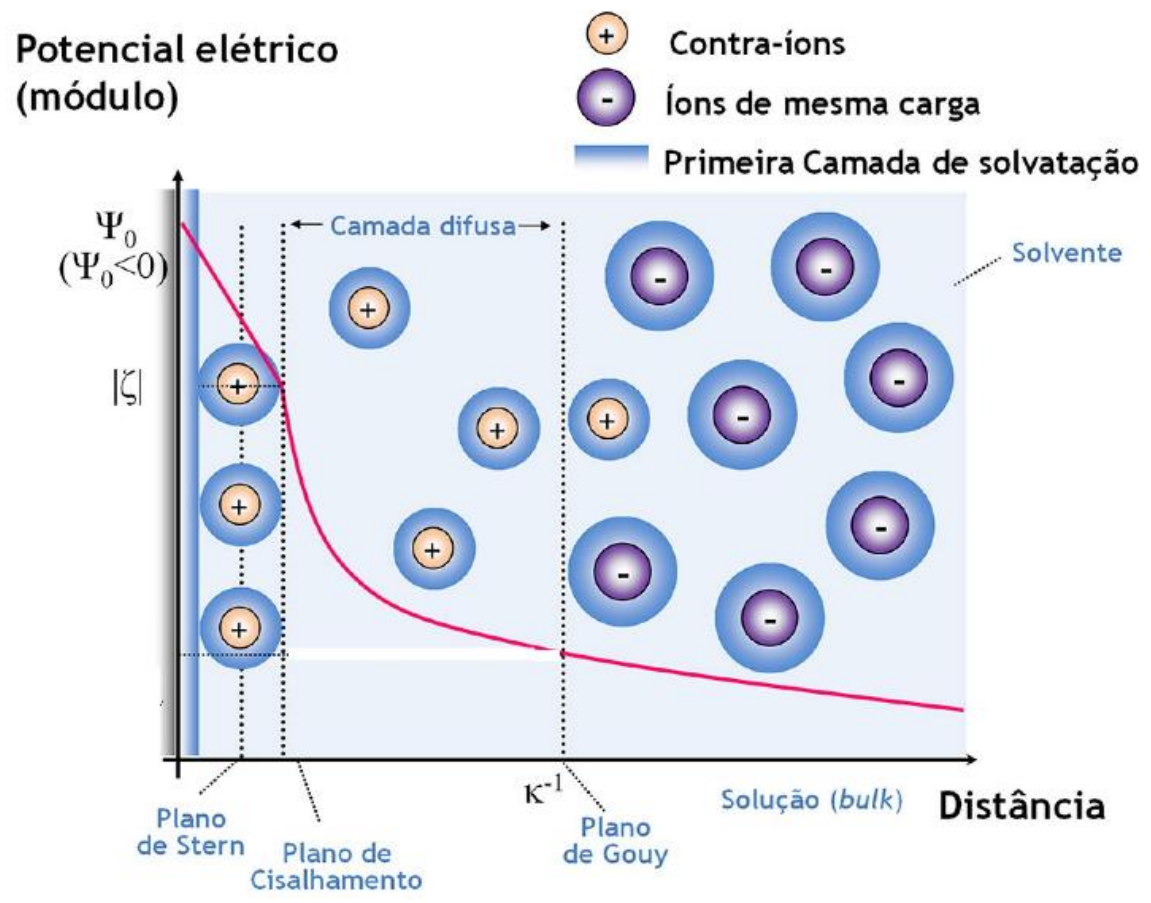

Figura 6 - llustração da dupla camada elétrica e da variação do potencial elétrico $\left(\psi_{0}\right)$ em função da distância a partir do eletrodo, segundo o modelo de Stern (Adaptado de Goodwin, 2004). 


\subsubsection{2.}

\section{Processos Faradaicos e não-Faradaicos}

As reações de transferência de elétrons entre o eletrodo e as espécies eletroativas em solução são chamadas de processos faradaicos. Tais reações são regidas pela lei de Faraday (Bard et al., 1980).

A lei de Faraday afirma que a quantidade (m), em mol, de uma substância consumida ou produzida em um dos eletrodos de uma célula eletroquímica é diretamente proporcional à carga elétrica (q), em coulomb, que passa através do eletrodo. Isto pode se expressar como apresentado na Equação 1.

$m=\frac{q}{n F}=\frac{I t}{n F}$

Onde n e F são o número de mols de elétrons que aparecem na reação de eletrodo e a constante de Faraday (96485C. $\mathrm{mol}^{-1}$ ), respectivamente, m é a quantidade de uma substância consumida ou produzida, em mol, e q é a carga elétrica, em coulomb. A carga elétrica é equivalente ao produto da intensidade de corrente, I, em ampère, e o tempo, $t$, em segundo.

A constante de Faraday apresenta uma relação com outras duas constantes físicas (Bard et al., 1980):

$F=q_{0} N_{A}$

Onde $\mathrm{N}_{\mathrm{A}}$ é a constante de Avogadro com valor de $6,022 \times 10^{23} \mathrm{~mol}^{-1}, \mathrm{q}_{0}$ é a carga elementar com valor de $1,602 \times 10^{-19} \mathrm{C}$ e F é a constante de Faraday.

Outros processos, tais como adsorção e dessorção, podem ocorrer. Esses processos são chamados de processos não-faradaicos (Rubinstein, 1995).

\subsubsection{3.}

\section{Termodinâmica eletroquímica}

Embora o trabalho de Faraday tenha estabelecido a relação entre a carga elétrica e a quantidade de espécies geradas ou consumidas durante uma reação eletroquímica, a dependência entre o potencial de equilíbrio de uma reação 
eletroquímica e as atividades das espécies eletroativas (participantes) permaneceu obscura até o advento da termodinâmica (Perez et al., 2004).

\section{- Equação de Nernst}

Com base nos princípios termodinâmicos, Nernst estabeleceu uma equação para calcular o potencial de equilíbrio de uma reação eletroquímica (Bard et al., 1980).

Uma reação eletroquímica é um processo químico heterogêneo que envolve a transferência de elétrons.

$\mathrm{O}$ trabalho elétrico máximo $\left(\mathrm{W}_{\text {ele }}\right)$ obtido em uma reação eletroquímica à temperatura e pressão constantes é dado pela energia livre de Gibbs da reação eletroquímica (Atkins, 2001), conforme a eq. (3).

$W_{\text {ele }}=-\Delta G=n F E_{\text {eq }}$

Onde $\mathrm{n}$ é o número de mols de elétrons que participam da reação, $\mathrm{F}$ é a constante de Faraday, $\mathrm{E}_{\mathrm{eq}}$ é o potencial de equilíbrio da reação eletroquímica, em volt, $\Delta \mathrm{G}$ é a energia livre de Gibbs da reação eletroquímica, em joule/mol, e $\mathrm{W}_{\text {ele }}$ é o trabalho elétrico máximo, em joule/mol.

Portanto, a equação de Nernst (eq. 4) é utilizada para calcular o potencial de equilíbrio $\left(\mathrm{E}_{\mathrm{eq}}\right)$ para qualquer reação de meia-célula (Bard et al., 1980).

$E_{\text {eq }}=-\frac{\Delta G^{0}}{n F}-\frac{R T}{n F} \sum \mathrm{v}_{i} l n c_{i}$

Onde n é o número de mols de elétrons que participam da reação, F é a constante de Faraday, $\mathrm{R}$ é a constante universal dos gases, $\mathrm{T}$ é a temperatura em escala absoluta, $\Delta \mathrm{G}^{\circ}$ é a variação da energia livre de Gibbs padrão, em joule/mol, v é o coeficiente estequiométrico da espécie i, c é a concentração da espécie i e $\mathrm{E}_{\mathrm{eq}}$ é o potencial de equilíbrio, em volt.

O potencial global para um reator eletroquímico é calculado como a soma dos potenciais - anódico $\left(\mathrm{E}_{\mathrm{a}}\right)$, catódico $\left(\mathrm{E}_{\mathrm{c}}\right)$, solução $\left(\mathrm{E}_{\text {solução }}\right)$ e perda $\left(\mathrm{E}_{\text {perda }}\right)$ 
(Equação 5). O potencial da solução ( $\mathrm{E}_{\text {solução})}$ é uma função da sua condutividade $(\sigma)$, distância entre eletrodos $(\Delta \mathrm{b})$ e intensidade de corrente (I) (Equação 6). O potencial de perda $\left(\mathrm{E}_{\text {perda }}\right)$ é, geralmente, incluído para descrever perdas de potencial, como, por exemplo, a energia necessária para superar a camada de passivação. Esses dois últimos termos evidenciam que (além do requisito de potencial anódico e catódico) o potencial de um reator é ditado pelas características da solução, geometria do eletrodo e a maneira pela qual o reator é operado (Bard et al., 1980).

$$
E_{\text {cểlula }}=E_{c}-E_{\alpha}-E_{\text {soluĝ̣̃o }}-E_{\text {perda }}
$$

Onde $E_{\text {célula }}$ é o potencial global do reator eletroquímico, em volt, $E_{a}$ é o potencial anódico, em volt, $\mathrm{E}_{\mathrm{c}}$ é o potencial catódico, em volt, $\mathrm{E}_{\text {solução é o potencial }}$ da solução, em volt, e $E_{\text {perda }}$ é o potencial da perda, em volt.

$$
E_{\text {solụ̣̂̃o }}=\frac{\Delta b I}{\sigma}
$$

Onde $E_{\text {solução }}$ é o potencial da solução, em volt, $\sigma$ é a condutividade da solução, em (ohm.metro) ${ }^{-1}, \Delta \mathrm{b}$ é a distância entre eletrodos, em metro, e I é a intensidade de corrente, em ampère.

\subsubsection{4.}

\section{Cinética eletroquímica}

Deve-se notar que a termodinâmica apresenta as condições sob as quais várias espécies são estáveis, mas não indica a taxa com a qual as mudanças chegam a atingir o equilíbrio. Portanto, para prever o desempenho de qualquer reator, a cinética da reação deve ser quantificada (Levenspiel, 1999). No caso de um reator de eletrocoagulação, a taxa da adição do coagulante é determinada pela cinética do eletrodo.

As reações de eletrodos são heterogêneas e ocorrem na região interfacial entre o eletrodo e a solução. Existem gradientes de potencial e concentração entre a superfície do eletrodo e o seio da solução. De tal modo, as espécies químicas a 
serem reduzidas ou oxidadas devem difundir do seio da solução para a superfície do eletrodo (através de um processo de transferência de massa) antes que a transferência de elétrons possa ocorrer na superfície. Consequentemente, as reações eletroquímicas são controladas por transferência de elétrons ou transferência de massa. Certamente, em muitos casos práticos, tanto a transferência de elétrons como a de massa são relevantes na determinação da taxa de reação global (Rubinstein, 1995).

Um exemplo das etapas básicas de um processo de oxidação ou redução (O $+\mathrm{ne}^{-}<->\mathrm{R}$, onde $\mathrm{O}$ é a espécie oxidada e $\mathrm{R}$ é a forma reduzida correspondente) em um eletrodo é ilustrado na Figura 7. Essas etapas podem ser resumidas como (Bard et al., 1980):

1. Transporte de massa da espécie $O$ para a superfície do eletrodo onde ocorre a reação $\left(\mathrm{O}+\mathrm{ne}^{-}<->\mathrm{R}\right)$;

2. Na superfície do eletrodo, podem ocorrer etapas adicionais, tais como adsorção, dessorção e formação de fases, essas podem preceder ou suceder a etapa de transferência de elétrons;

3. Transferência de elétrons na superfície do eletrodo;

4. Transporte da espécie $\mathrm{R}$ da superfície do eletrodo para o seio da solução. 


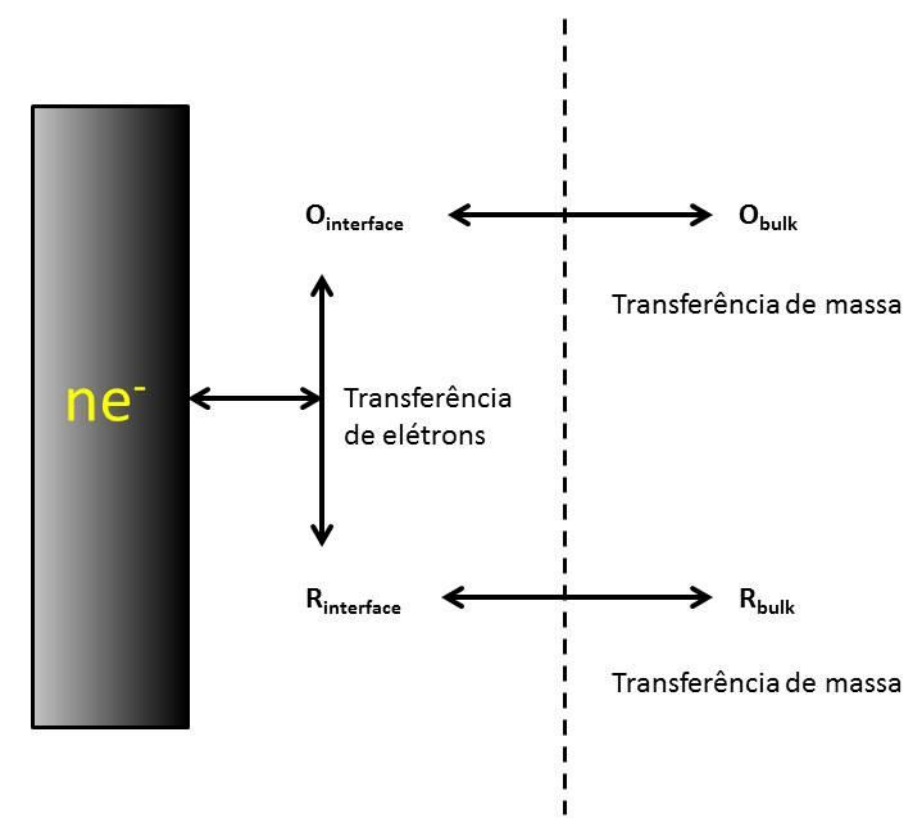

Figura 7 - Etapas básicas de um processo de oxidação ou redução em um eletrodo (Adaptado de Pletcher et al., 1990).

Portanto, é essencial disponibilizar o reagente na superfície do eletrodo e remover o produto formado com a finalidade de se manter uma intensidade de corrente, isto é, assegurar que ocorra a reação de transferência de elétrons (Pletcher et al., 1990).

Uma vez que a taxa de reação global é determinada pela velocidade total das etapas, a etapa mais lenta será a determinante. Portanto, para a compreensão das características das reações eletroquímicas é necessário conhecimento sobre transferência de massa e transferência de elétrons (Levenspiel, 1999).

- Controle por transferência de elétrons

Quando uma reação é controlada pela transferência de elétrons a taxa de reação não depende da concentração da espécie eletroativa na solução e, consequentemente, a variação da concentração em função do tempo será linear.

A transferência de elétrons ocorre entre a camada superficial sólida e as espécies dissolvidas. Uma vez que elétrons são partículas muito leves, quando a distância eletrodo-espécie eletroativa é aproximadamente de $10 \AA$, esses começam 
a tunelar na direção das espécies eletroativas ou vice-versa. No interior dessa camada superficial, no caso de metais, há um potencial constante em que nenhuma localização de elétrons é possível (Vetter, 1967).

A força motriz para essas reações heterogêneas pode ser conseguida variando o potencial do eletrodo. Para os metais, uma vez que possuem uma grande concentração de elétrons móveis em equilíbrio térmico, qualquer mudança no potencial do metal é transmitida ao eletrólito (Formosinho et al., 2003).

A taxa de transferência de elétrons está associada à intensidade de corrente, I, que atravessa o eletrodo. Isto pode se expressar como apresentado na Equação 7.

$I=\frac{q}{t}$

Onde q é a carga elétrica, em coulomb, t é o tempo, em segundo, e I é a intensidade de corrente, em ampère.

Para uma reação fundamental de transferência de elétrons, pode-se escrever o seguinte:

$O+n e^{-} \leftrightarrow R$

Onde $\mathrm{O}$ é a espécie oxidada e $\mathrm{R}$ é a espécie reduzida.

Isso pressupõe que a única reação de eletrodo que pode ocorrer na faixa de potencial em consideração é a conversão reversível de $\mathrm{O}$ e $\mathrm{R}$ (Pletcher et al., 1990).

Como em qualquer sistema químico em equilíbrio, prevalecerá uma situação dinâmica na superfície do eletrodo. Tanto a redução de $\mathrm{O}$ para $\mathrm{R}$ quanto a oxidação de $\mathrm{R}$ para $\mathrm{O}$ ocorrerão, mas essas reações ocorrerão à mesma taxa. Assim, em termos da intensidade de corrente, pode-se escrever (Bard et al., 1980):

$I=I_{a}+I_{c}=0$ 
Onde $I_{a}$ e $I_{c}$ são as intensidades de corrente anódica e catódica, respectivamente, em ampère, e I é a intensidade de corrente líquida, em ampère.

A magnitude das intensidades de corrente anódina e catódica no equilíbrio atua como um parâmetro cinético útil para o par $\mathrm{O} / \mathrm{R}$ e, portanto, é referida como a intensidade de corrente de troca $\left(\mathrm{I}_{0}\right)$ (Bard et al., 1980):

$$
I_{a}=-I_{c}=I_{0}
$$

Onde $I_{a}$ e $I_{c}$ são as intensidades de corrente anódica e catódica, respectivamente, em ampère, e $\mathrm{I}_{0}$ é a intensidade de corrente de troca, em ampère.

A intensidade de corrente de troca é uma medida da atividade de transferência de elétrons no potencial de equilíbrio.

A cinética de transferência de elétrons em eletrodos é geralmente estudada em termos da intensidade de corrente em função do potencial (equação de ButlerVolmer). Quando I = 0, o potencial do eletrodo é o de equilíbrio, $\mathrm{E}_{\text {eq. }}$. A aplicação de um potencial diferente ao de equilíbrio corresponde a uma polarização do eletrodo, cuja magnitude é chamada de sobrepotencial, $\eta$ (Bard et al., 1980). Isto pode se expressar como apresentado na Equação 11.

$$
\eta=E-E_{\text {eq }}
$$

Onde $\mathrm{E}_{\mathrm{eq}}$ é o potencial de equilíbrio do eletrodo, em volt, E é o potencial do eletrodo resultante da polarização, em volt, e $\eta$ é o sobrepotencial, em volt.

A presença de uma intensidade de corrente líquida não nula está sempre associada a um sobrepotencial. No entanto, a dependência entre a intensidade de corrente e o sobrepotencial é complexa em razão da existência das diversas etapas básicas de um processo de oxidação ou redução (Pletcher et al., 1990).

Uma vez que as reações de transferência de elétrons são reações heterogêneas de primeira ordem, a taxa é definida por (Rubinstein, 1995):

$$
\mathrm{v}=\frac{I}{n F A}
$$


Onde $\mathrm{n}$ é o número de mols de elétrons transferidos em cada processo elementar, F é a constante de Faraday, A é a superfície ativa do eletrodo, $\mathrm{em}^{2}{ }^{2}$, I é a intensidade de corrente, em ampère, e $v$ é a taxa da reação de transferência de elétrons, em mol seg ${ }^{-1} \cdot \mathrm{cm}^{-2}$.

A taxa de redução é proporcional à concentração das espécies oxidantes na superfície do eletrodo, $[\mathrm{Ox}]_{\mathrm{s}}$, em um determinado instante de tempo (Bard et al., 1980). Isto pode se expressar como apresentado na Equação 13.

$\mathrm{v}_{r e d}=k_{r e d}[O x]_{0, t}=\frac{I_{c}}{n F A}$

Onde $\mathrm{k}_{\text {red }}$ é a constante da taxa da reação de redução, em $\mathrm{cm} \mathrm{seg}^{-1}$, e $[\mathrm{Ox}]_{0, \mathrm{t}}$ é a concentração das espécies oxidantes na superfície do eletrodo, em $\mathrm{mol} / \mathrm{cm}^{3}$.

De maneira análoga para a reação de oxidação, pode-se escrever:

$\mathrm{v}_{o x}=k_{o x}[R]_{0, t}=\frac{I_{a}}{n F A}$

Onde $\mathrm{k}_{\mathrm{ox}}$ é a constante da taxa da reação de oxidação, em $\mathrm{cm} \mathrm{seg}^{-1}$, e $[\mathrm{R}]_{0, \mathrm{t}}$ é a concentração das espécies redutoras na superfície do eletrodo, em $\mathrm{mol} / \mathrm{cm}^{3}$.

A taxa de reação líquida é a diferença entre a taxa de redução (reação catódica) e a de oxidação (reação anódica) (Bard et al., 1980). Isto pode se expressar como apresentado na Equação 15.

$\mathrm{v}=\mathrm{v}_{r e d}-\mathrm{v}_{o x}=k_{r e d}[O x]_{0, t}-k_{o x}[R]_{0, t}$

Para que ocorra uma transferência de elétron entre o eletrodo e a espécie $(\mathrm{O}$ ou R) em solução e, portanto, que se produza um fluxo de corrente, o nível de energia do elétron deve superar a barreira energética de ativação, ou seja, o nível mínimo de energia que permite uma transferência de elétron. Isso é alcançado aplicando um potencial (Rubinstein, 1995).

No entanto, a transferência de elétrons não é o único fator que pode controlar a reação global, conforme discutiremos na próxima seção. 
- Controle por transferência de massa

De maneira geral é necessário considerar três modos de transporte de massa em sistemas eletroquímicos: i) Por difusão, quando o movimento de espécies ocorre devido a um gradiente de concentração; ii) Por migração, quando o movimento de espécies carregadas ocorre devido a um gradiente de potencial; e iii) Por convecção, quando o movimento de espécies ocorre devido a forças mecânicas (Goodridge, 1995).

Com relação à migração, em muitos casos de interesse prático, usa-se um grande excesso de um eletrólito inerte (também chamado de eletrólito suporte) de maneira que o efeito da migração sobre o transporte de massa total possa ser negligenciado (Goodridge, 1995).

Com relação à convecção, como a velocidade do fluido (eletrólito) na superfície do eletrodo é zero, também pode ser desprezado. Entretanto, deve-se ressaltar que a convecção se torna importante na manutenção da concentração constante dos íons metálicos entre a camada difusa e o seio da solução. Uma maior agitação da solução diminui a espessura da camada difusa (Goodridge, 1995).

Existe um valor de corrente (corrente limite) onde é observada a melhor taxa de reação e eficiência de corrente, sendo o processo controlado exclusivamente pelo transporte de massa da espécie eletroativa do seio da solução para a superfície do eletrodo. O aumento do potencial para valores superiores fará com que a parcela adicional de elétrons fornecida ao sistema seja desviada para reações paralelas, geralmente reações de decomposição do solvente (Goodridge, 1995).

\subsubsection{5. Sobrepotencial}

$\mathrm{Na}$ condição de equilíbrio, a reação eletroquímica dá-se tanto no sentido da oxidação quanto da redução com a mesma velocidade. Estabelece-se um potencial de equilíbrio, $\mathrm{E}_{\mathrm{eq}}($ Newman, 2012). 
Se por um processo qualquer esse potencial for alterado, diz-se que o eletrodo sofreu polarização. O sobrepotencial é o grau de polarização (Newman, 2012).

Quando a intensidade de corrente líquida através do eletrodo não é nula, há uma variação no potencial dos eletrodos a partir da sua posição de equilíbrio. Essa variação representa um sobrepotencial que depende da resistência do eletrólito, da energia de ativação e da concentração (Newman, 2012).

O sobrepotencial é frequentemente considerado como uma soma desses fatores (Newman, 2012):

$\eta=\eta_{\text {ohm }}+\eta_{\text {ati }}+\eta_{\text {cone }}$

Onde $\mathrm{n}_{\mathrm{ohm}}$ é a polarização ôhmica, em volt, $\mathrm{n}_{\mathrm{ati}}$ é o sobrepotencial de ativação, em volt, e $\mathrm{n}_{\text {conc }}$ é o sobrepotencial de concentração, em volt.

E está relacionado ao potencial do eletrodo:

$E=E_{\text {eq }}+\eta_{\text {ohm }}+\eta_{\text {ati }}+\eta_{\text {cone }}$

Onde $\mathrm{n}_{\mathrm{ohm}}$ é a polarização ôhmica, em volt, $\mathrm{n}_{\mathrm{ati}}$ é o sobrepotencial de ativação, em volt, $\mathrm{n}_{\text {conc }}$ é o sobrepotencial de concentração, em volt, e $\mathrm{E}_{\mathrm{eq}}$ é o potencial de equilíbrio do eletrodo, em volt.

$\mathrm{O}$ primeiro fator é devido à resistência do eletrólito entre os eletrodos. No entanto, ao considerar a célula eletroquímica como um todo, outras resistências também são encontradas, tais como a resistência dos próprios eletrodos e da fiação. Todas essas resistências podem ser agrupadas em uma resistência total da célula eletroquímica e representadas através da lei de Ohm (Newman, 2012), conforme apresentado na eq. (18).

$\eta_{o h m}=I R_{\text {cểlula }}$

Onde $\mathrm{R}_{\text {célula }}$ é a resistência total da célula, em ohm, e I é a intensidade de corrente, em ampère. 
O segundo fator é devido à cinética da reação eletroquímica, que está relacionada à energia de ativação da reação. Uma cinética lenta é devida, por exemplo, a uma alta energia de ativação. Para superar a cinética lenta, um aumento da temperatura ou um aumento na tensão aplicada através dos eletrodos poderia ser realizado para alcançar uma intensidade de corrente. O sobrepotencial de ativação também está relacionado ao terceiro fator, o sobrepotencial de concentração (Newman, 2012).

O sobrepotencial de concentração é causado pela diferença de concentração dos portadores de carga da superfície do eletrodo e do eletrólito, ocorrendo quando a reação eletroquímica é suficientemente rápida para reduzir a concentração dos portadores de carga da solução. Assim, a taxa de reação é, então, dependente da capacidade dos portadores de carga de chegar à superfície do eletrodo (Newman, 2012).

\subsubsection{6.}

\section{Reações na célula de eletrocoagulação}

O alumínio, o material de anodo mais utilizado, é apresentado a seguir como exemplo (observe que uma descrição análoga pode ser desenvolvida para outros metais). A eq. (19) apresenta a dissolução anódica do alumínio (Mouedhen, 2008).

$$
A l \leftrightarrow A l^{3+}+3 e^{-} \quad E_{a}^{0}=1,66 \mathrm{~V}
$$

A geração de oxigênio também é possível no anodo, eq. (20) (Mameri et al., 1998), embora isso não tenha sido detectado por Przhegorlinskii et al. (1987).

$$
4 \mathrm{OH}^{-} \leftrightarrow \mathrm{O}_{2}+2 \mathrm{H}_{2} \mathrm{O}+4 e^{-} \quad E_{a}^{0}=-0,40 \mathrm{~V}
$$

Simultaneamente, ocorre uma reação catódica associada, geralmente, à geração de hidrogênio. A reação que ocorre no catodo é dependente do pH. À pH $\leq 7$, o hidrogênio é produzido através da eq. (21) (Canizares et al., 2005). 
$2 \mathrm{H}_{2} \mathrm{O}+2 e^{-} \leftrightarrow 2 \mathrm{OH}^{-}+\mathrm{H}_{2} \quad E_{c}^{0}=-0.83 \mathrm{~V}$

Enquanto que em condições de $\mathrm{pH}>7$, a eq. (22) descreve melhor a geração de hidrogênio no catodo (Canizares et al., 2005).

$2 H^{+}+2 e^{-} \leftrightarrow H_{2} \quad E_{c}^{0}=0 \mathrm{~V}$

Os autores que utilizam anodos e catodos de alumínio relataram repetidamente uma dissolução de alumínio superior a 100\% (Donini et al., 1994), onde os cálculos de eficiência foram com base na dissolução anódica seguindo a lei de Faraday.

Donini et al. (1994) e Przhegorlinskii et al. (1987) indicaram que a fonte da diferença entre a perda de massa observada e a perda de massa calculada (lei de Faraday) é a dissolução química de alumínio ocorrente em ambos os eletrodos.

$\mathrm{O}$ ataque químico em ambos os eletrodos pode ocorrer devido à alcalinidade e acidez produzida na vizinhança deles (Mouedhen, 2008), conforme apresentado nas eq. (23) e (24).

$2 \mathrm{Al}+6 \mathrm{H}^{+} \leftrightarrow 2 \mathrm{Al}^{3+}+3 \mathrm{H}_{2}$

$2 \mathrm{Al}+6 \mathrm{H}_{2} \mathrm{O}+2 \mathrm{OH}^{-} \leftrightarrow 2\left[\mathrm{Al}(\mathrm{OH})_{4}\right]^{-}+3 \mathrm{H}_{2}$

\subsection{2.}

\section{Coagulação}

A coagulação é um processo fundamental de todos os reatores de eletrocoagulação, descrevendo a interação entre o coagulante e qualquer material poluente. O papel do coagulante é desestabilizar a suspensão coloidal, reduzindo as forças atrativas e permitindo que as partículas se agreguem (Letterman et al., 1999). Dependendo das propriedades físico-químicas da solução, do poluente e do coagulante, foram postulados vários mecanismos de coagulação (por exemplo, neutralização das cargas superficiais, compressão da dupla camada elétrica, 
formação de pontes e varredura) (Hiemenz et al., 1986). Para qualquer reator de eletrocoagulação, o mecanismo de coagulação dominante dependerá das condições de operação do reator, do tipo e da concentração de poluente e da concentração de coagulante.

Os poluentes são tipicamente partículas coloidais, que não são facilmente removidas por sedimentação ou flotação devido à sua estabilidade eletrostática. Essas partículas possuem propriedades especiais devido ao pequeno tamanho e à grande área superficial (Everett, 2007).

$\mathrm{Na}$ eletrocoagulação, a estabilidade de um poluente é determinada pelas suas propriedades físico-químicas. Os poluentes com carga superficial semelhante repelem-se mutuamente. Essas forças repulsivas criam um sistema coloidal estável (Everett, 2007).

A carga líquida na superfície da partícula afeta a distribuição de íons na sua vizinhança, aumentando a concentração de contra-íons junto à superfície. Assim, forma-se uma dupla camada elétrica na interface da partícula com a solução (Hunter, 1993).

\subsubsection{1. \\ Dupla camada elétrica}

A carga superficial atua na distribuição dos íons no meio polar, de maneira que as partículas sólidas ficam rodeadas por uma nuvem de íons. Sabemos que os íons de carga oposta (contra-íons) são atraídos pela superfície e os íons de carga de mesmo sinal são repelidos para mais longe da superfície, assegurando, assim, a eletroneutralidade da suspensão. A teoria da dupla camada elétrica explica a distribuição dos íons e, consequentemente, a intensidade dos potenciais elétricos gerados pela superfície carregada (Shaw, 1992).

A constituição da dupla camada elétrica abrange duas regiões: uma camada externa difusa chamada de camada de Gouy-Chapman e uma camada interna compacta denominada de camada de Stern (Hunter, 1993).

O modelo elaborado por Gouy e Chapman oferece uma exposição quantitativa simples da distribuição de íons na camada difusa, segundo a influência de forças elétricas e do movimento térmico. $\mathrm{O}$ modelo proposto por Gouy e Chapman tem como base alguns critérios, a saber: a superfície é plana, 
infinita e com cargas elétricas distribuídas de maneira uniforme; os íons são cargas pontuais localizadas de acordo com a distribuição de Boltzmann; o solvente possui o mesmo valor de constante dielétrica por toda a camada difusa; o eletrólito é isolado e simétrico (Shaw, 1992).

Conforme o modelo proposto por Stern, haveria um plano que separaria as camadas interna e externa. A camada interna seria composta por íons ligados à superfície por forças eletrostáticas e/ou de van der Waals fortes o bastante para superar o movimento térmico e manter os íons relativamente imóveis. Já para a camada externa, Stern se apropria da teoria proposta por Gouy-Chapman (Everett, 2007).

A peculiaridade da espessura da dupla camada $\left(K^{-1}\right)$ é fortemente influenciada pela concentração de íons na solução. Sendo assim, pode-se dizer que quanto maior for a concentração de eletrólito no meio, menor será a distância na qual ainda existe potencial eletrostático relevante e, dessa forma, propiciam a agregação de partículas. Além disso, íons de maiores valências ocasionam uma diminuição da distância na qual ainda existe potencial eletrostático considerável e, portanto, beneficiam a agregação das partículas (Shaw, 1992).

Em uma circunstância dinâmica, onde há o movimento relativo entre as partículas e o meio, a camada difusa é rompida em um plano chamado de plano de cisalhamento, cujo potencial é denominado de potencial zeta $(\zeta)$ ou potencial eletrocinético. Tal potencial é de suma importância, pois ele pode ser medido experimentalmente e, na maioria dos casos, serve como uma boa aproximação do potencial superficial que não é mensurável (Hunter, 1993). De acordo com Kim et al. (1995), não se conhece a localização exata desse plano, mas considera-se que esse seja adjacente ao plano de Stern.

\subsubsection{2.}

\section{Estabilidade Coloidal}

Os coloides são estáveis em soluções aquosas. A capacidade dos coloides de manter um estado disperso e permanecer como entidades separadas é conhecida como estabilidade. Essa estabilidade é o resultado de forças interfaciais, que são consequência tanto da presença de uma carga superficial na interface entre a 
partícula e a solução quanto da hidratação das camadas superficiais do coloide (Hunter, 1993).

O tamanho dos coloides $(0,01$ a $1 \mu \mathrm{m})$ evita que as forças de atração entre partículas superem as forças de repulsão que surgem da dupla camada elétrica. A influência dos fenômenos interfaciais é mais importante do que a influência da gravidade quando se trata de coloides (Bratby, 2006).

No caso dos coloides hidrofílicos, a atração que esses possuem por moléculas de água é o que os torna estáveis. A afinidade partícula-solvente promove a estabilidade, principalmente por meio mecânico, o que pode ser considerado em termos da variação positiva da energia livre de desolvatação que acompanha a agregação das partículas (Shaw, 1992).

As partículas hidrofóbicas, por outro lado, são estáveis por meio da carga superficial que apresentam (Hunter, 1993).

Em águas residuais, os coloides apresentam, geralmente, uma carga superficial líquida negativa. Isso resulta da ionização de grupos funcionais ácidos presentes na superfície do coloide e da adsorção iônica (Maximova et al., 2006).

\section{- Teoria DLVO}

Deryagin e Landau (Deryagin et al., 1941) e Verwey e Overbeek (Verwey et al., 1948) desenvolveram uma teoria, mais conhecida como teoria DLVO, explicando as interações entre as partículas. A estabilidade dos coloides é analisada em termos da variação da energia que ocorre quando as partículas se aproximam. A teoria engloba aproximações da energia de repulsão resultante da sobreposição das duplas camadas elétricas e da energia de atração de London-van der Waals. Essas energias em conjunto resultam na energia de interação total em função da distância entre as partículas (Ninham, 1999), conforme apresentado na Figura 8. 


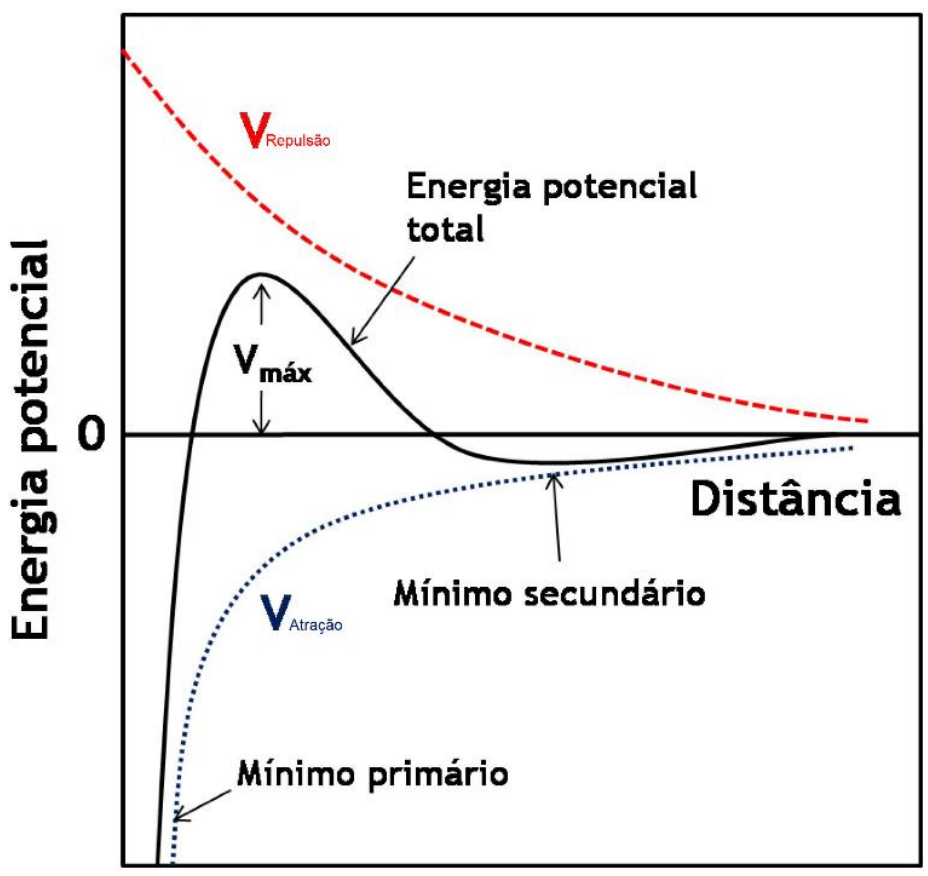

Figura 8 - Balanço dos potenciais de repulsão e atração entre partículas de acordo com a teoria DLVO (Adaptado de Ninham, 1999).

Uma análise qualitativa da curva da energia de interação total em função da distância entre as partículas pode ser feita a partir das particularidades das duas forças, onde verifica-se que a energia de atração diminui com o inverso da distância ao passo que a energia de repulsão diminui exponencialmente com a distância. Sendo assim, observa-se que, em distâncias longas e curtas, a energia de interação total é dominada pela energia de atração de London-van der Waals e, em distâncias intermediárias, a energia de repulsão da dupla camada elétrica predomina (Shaw, 1992).

Denomina-se de mínimo primário o mínimo a uma distância muito pequena entre as partículas. Diz-se, então, que o sistema é instável, visto que tão logo as partículas fiquem próximas o suficiente, elas se agregam de forma irreversível (Ohshima, 2010).

Localizado a uma distância intermediária entre as partículas, tem-se o mínimo secundário. Neste ponto, a agregação entre as partículas é mais fraca, podendo ser desfeita por agitação moderada, causando redispersão do sistema. Normalmente pode-se observar tal fenômeno em soluções eletrolíticas concentradas e/ou com partículas relativamente mais grosseiras (Butt et al., 2010). 
Para que a agregação ocorra no mínimo primário, é necessário que as partículas superem a barreira energética repulsiva. Uma barreira de energia suficientemente alta tem capacidade para impedir que as partículas alcancem o mínimo primário. Ou seja, caso a barreira seja intransponível pela energia térmica fornecida ao sistema, as partículas mantêm-se dispersas e o sistema estável. A altura dessa barreira está vinculada à força iônica do sistema e ao potencial zeta. Quanto maior for a concentração de eletrólitos, isto é, a força iônica da solução, menor será a barreira energética, em razão da compressão da espessura da dupla camada elétrica (Shaw, 1992).

\subsubsection{3. \\ Mecanismos de agregação}

A desestabilização de partículas coloidais ocorre através da compressão da camada dupla elétrica, neutralização de carga, floculação por varredura e formação de pontes (Faust et al., 1998), conforme apresentado na Figura 9.

Vários desses mecanismos ocorrem simultaneamente, mas o mecanismo dominante depende de vários parâmetros, como a concentração e o caráter do poluente, pH da solução e tipo de coagulante (Edzwald, 1993). Os mecanismos desestabilizadores estão descritos abaixo.
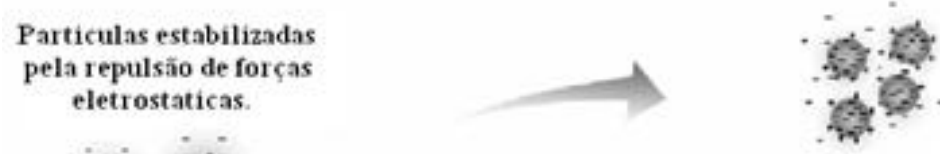

Compressío da dupla canada por incremento da força ionica
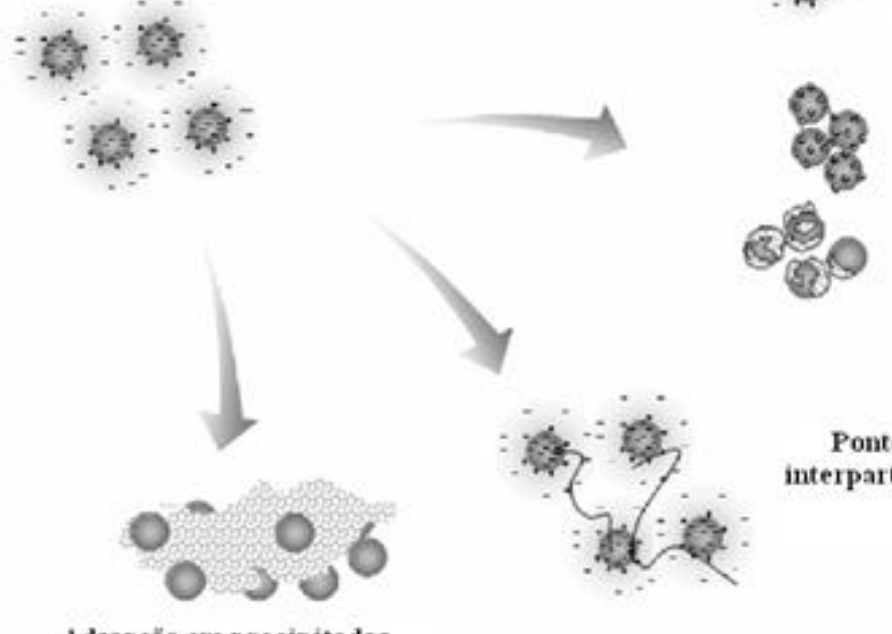

Neutralização de carga, por adsorçăo de ions. ou precipitaça.

Adsorçăo em precipitados

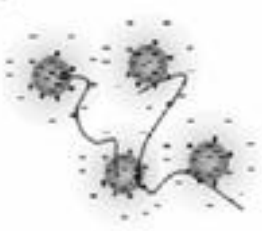

Ponte

interparticular

Figura 9 - Mecanismos de desestabilização de partículas coloidais (Di Bernardo et al., 2005). 
- Compressão da dupla camada elétrica

O aumento da força iônica no seio da solução, quando a interação é exclusivamente eletrostática, promove uma compressão da dupla camada elétrica e, consequentemente, uma diminuição da energia de repulsão entre as partículas (Bratby, 2006).

A desestabilização através desse mecanismo ocorre na presença de eletrólitos indiferentes, pois o contra-íon não adsorve na superfície da partícula, mas apenas aumenta a força iônica do sistema.

Esse efeito desestabilizador aumenta com o aumento da valência do contraíon de acordo com a regra de Schulze-Hardy, isto é, uma menor concentração de contra-íons de maior valência induz o mesmo efeito desestabilizador que uma maior concentração de contra-íons de menor valência (Edzwald, 1993).

Esse mecanismo exige uma alta concentração de contra-íons para que a coagulação possa ocorrer (Faust et al., 1998).

- Neutralização de carga

Considera-se que a neutralização de carga é o mecanismo de desestabilização predominante para partículas coloidais (Duan et al., 2003). A adsorção de contra-íons multivalentes na superfície de uma partícula pode induzir a neutralização de carga e subsequente coagulação.

Em concentrações acima da necessária para coagulação, observou-se uma inversão de carga em razão da adsorção de contra-íons em excesso, e as partículas foram reestabilizadas (Faust et al., 1998).

- Floculação por varredura

Em condições adequadas de concentração de coagulante e pH, os coagulantes metálicos podem combinar-se com os hidróxidos disponíveis na solução formando precipitados de hidróxidos metálicos que se precipitam. Esses hidróxidos metálicos gerados no processo de coagulação são precipitados amorfos, uma vez que as formas cristalinas são formadas muito lentamente (Duan et al., 2003). 
Os hidróxidos metálicos são bastante insolúveis e, nesse caso, precipitam-se de forma polimerizada, formando moléculas de peso molecular elevado (Bratby, 2006).

Ao se precipitarem esses complexos insolúveis aprisionam partículas coloidais que se sedimentam conjuntamente. Esse mecanismo é denominado floculação por varredura.

- Formação de pontes

Os polieletrólitos, além de cadeia longa, possuem agrupamentos de cargas elétricas distribuídos de forma assimétrica ao longo da molécula. Uma carga situada ao longo da cadeia do polímero pode adsorver um coloide, enquanto que o restante da molécula se estenderá pela solução podendo adsorver outros coloides em outros pontos (Bratby, 2006).

O saldo de carga poderá ser positivo (polieletrólitos catiônicos), negativo (polieletrólitos aniônicos) ou nulo (polieletrólitos não iônicos), mas, de qualquer forma, os coloides são removidos em pontos específicos de suas moléculas e a estrutura se sedimenta (Faust et al., 1998).

\subsubsection{4. \\ Alumínio(III) como cátion coagulante}

O alumínio é o material do anodo mais empregado em um reator de eletrocoagulação. O cátion de alumínio possui uma variedade de mecanismos disponíveis (dependendo das propriedades do poluente, do $\mathrm{pH}$ da solução e da concentração), tais como interação direta com o poluente, hidrólise para formar um complexo ou precipitação. Assim, a especiação do cátion é vital para a compreensão do processo de eletrocoagulação (Mouedhen et al., 2008).

A termodinâmica é utilizada para determinar (e quantificar) as espécies aquosas estáveis. Utilizando o alumínio como exemplo, os complexos mononucleares são formados inicialmente como descritos pelas Equações 25, 26, 27 e 28 (Sposito, 1995).

$\mathrm{Al}^{3+}+\mathrm{H}_{2} \mathrm{O} \leftrightarrow \mathrm{AlOH}^{2+}+\mathrm{H}^{+}$ 
$\mathrm{AlOH}{ }^{2+}+\mathrm{H}_{2} \mathrm{O} \leftrightarrow \mathrm{Al}(\mathrm{OH})_{2}^{+}+\mathrm{H}^{+}$

$\mathrm{Al}(\mathrm{OH})_{2}^{+}+\mathrm{H}_{2} \mathrm{O} \leftrightarrow \mathrm{Al}(\mathrm{OH})_{3}+\mathrm{H}^{+}$

$$
\mathrm{Al}(\mathrm{OH})_{3}+\mathrm{H}_{2} \mathrm{O} \leftrightarrow \mathrm{Al}(\mathrm{OH})_{4}^{-}+\mathrm{H}^{+}
$$

Considerando apenas a especiação mononuclear, as concentrações das diferentes espécies de alumínio presentes na solução a um determinado $\mathrm{pH}$ podem ser calculadas através dos equilíbrios termodinâmicos das reações.

A Figura 10 apresenta o diagrama de especiação do alumínio que depende da concentração total de alumínio e do $\mathrm{pH}$ da solução, obtido através do software Hydra-Medusa (School of Chemical Science and Engineering, KTH). Observa-se no diagrama que a espécie $\mathrm{Al}^{3+}$ é predominante até $\mathrm{pH}$ em torno de 5. Os compostos $\mathrm{AlOH}^{2+}$ e $\left[\mathrm{Al}(\mathrm{OH})_{2}\right]^{+}$assumem comportamento semelhante, nota-se que a presença desses ocorre em uma pequena faixa de $\mathrm{pH}$, os quais deixam de estar presentes na solução em $\mathrm{pH}$ próximo de 5. Já o hidróxido de alumínio, $\mathrm{Al}(\mathrm{OH})_{3}$, possui sua formação e concentração máxima em meio ácido, e com o aumento da alcalinidade da solução se estabiliza e torna-se a espécie predominante.

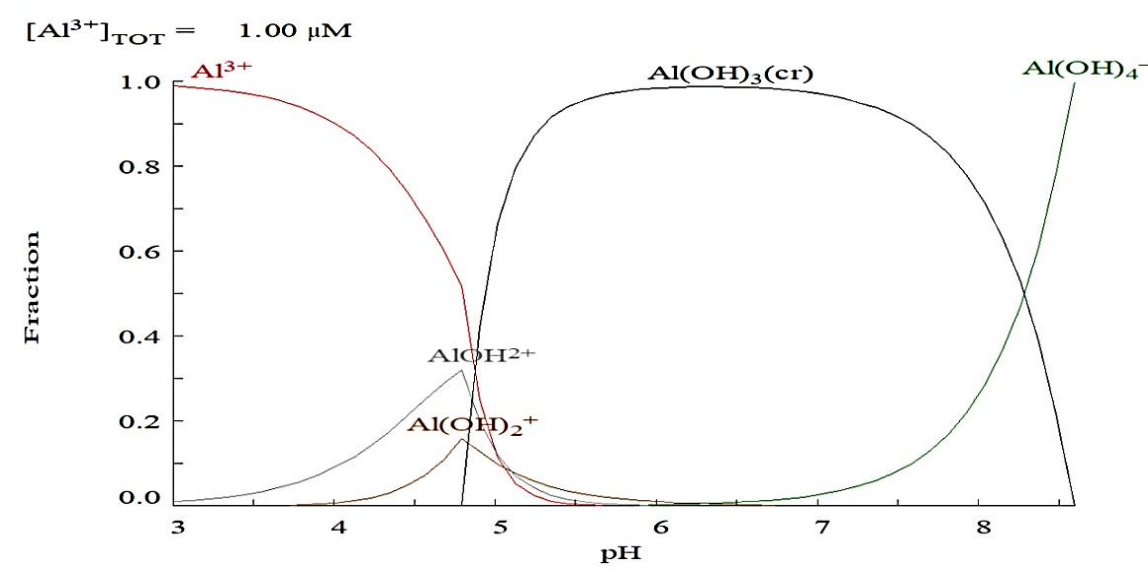

Figura 10 - Diagrama de especiação do alumínio, obtido através do software HydraMedusa (KTH). Elaborada pelo autor. 
No diagrama de solubilidade do hidróxido de alumínio, $\mathrm{Al}(\mathrm{OH})_{3(\mathrm{~s})}$, o limite de solubilidade denota o equilíbrio termodinâmico que existe entre as espécies dominantes de alumínio em solução a um determinado pH e o hidróxido de alumínio sólido. A solubilidade mínima $(0,03 \mathrm{mg}-\mathrm{Al} / \mathrm{L})$ ocorre a $\mathrm{pH} 6,3$, a solubilidade aumenta à medida que a solução se torna mais ácida ou alcalina (Letterman et al., 1999), conforme apresentado na Figura 11.

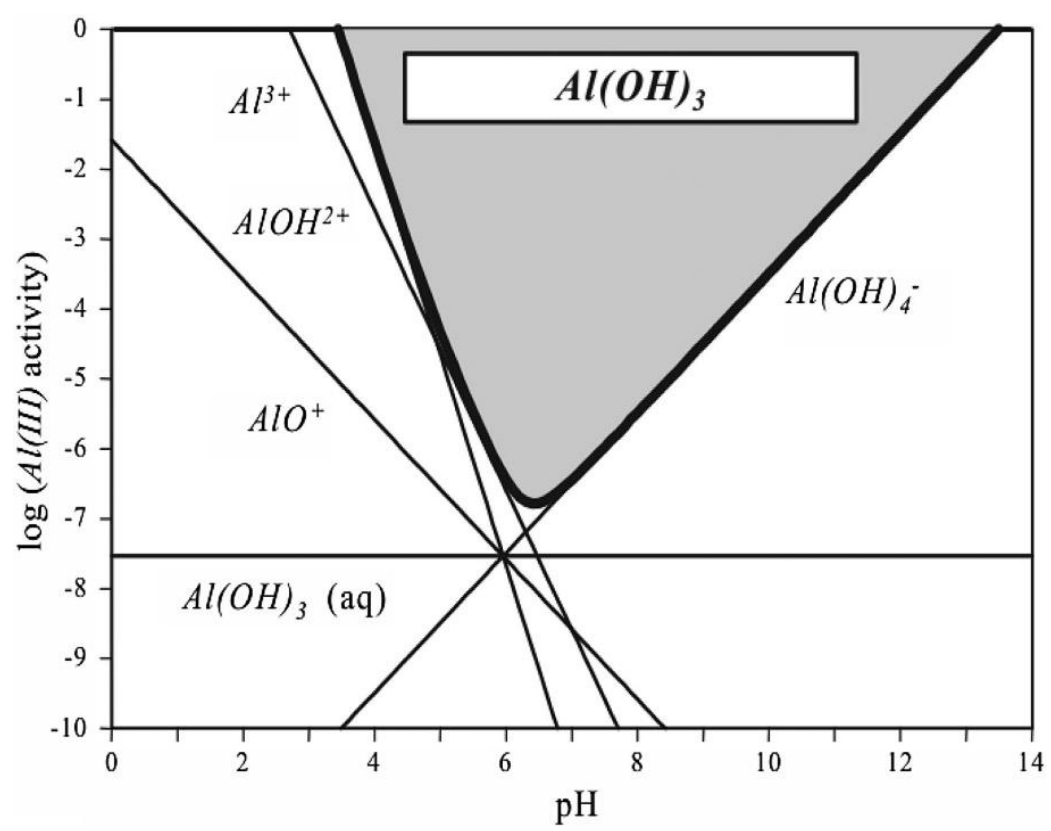

Figura 11 - Diagrama de solubilidade do hidróxido de alumínio (Wang et al., 2017).

Portanto, o cátion metálico (produzido no anodo) reage com os íons hidroxila (produzidos no catodo) para formar um hidróxido metálico amorfo que atua como floculante, formando agregados maiores que podem sedimentar ou serem transportados para a superfície através das bolhas de gases eletrolíticos. Desta forma, este precipitado sólido de hidróxido de alumínio é um precursor para a remoção de poluentes através da floculação por varredura. O diagrama de solubilidade fornece uma visão da importância desse último mecanismo para a remoção de poluentes (Holt et al., 2005).

Para qualquer solução aquosa, as espécies dominantes e os limites de solubilidade podem ser calculados com base em cálculos termodinâmicos. À medida que a concentração total de alumínio aumenta, formam-se complexos de alumínio polinucleares. Os pacotes de modelagem termodinâmica computacional (incluindo HSC, MINTEAQ2 e PHREEQC) auxiliam no cálculo da especiação no 
equilíbrio, mas são limitados pela precisão dos dados disponíveis. É necessária uma melhor compreensão da cinética de especiação do alumínio para modelar os processos nos reatores de eletrocoagulação (Holt et al., 2005).

\subsubsection{5.}

\section{Diagrama Eh-pH}

Conforme observado, a termodinâmica define a relação entre eletroquímica e especiação, como articulado pela equação de Nernst. O diagrama Eh-pH mapeia as regiões das espécies termodinamicamente estáveis, descrevendo, assim, a estabilidade de metais a diferentes ambientes aquosos (Pourbaix, 1964). Portanto, esse é mais um exemplo da sobreposição das áreas de conhecimento conceitualizadas no diagrama de Venn (Figura 5).

A eletrocoagulação requer a corrosão do alumínio. $\mathrm{O}$ equilíbrio eletroquímico para o sistema alumínio-água é apresentado em um diagrama EhpH, onde são identificadas regiões de imunidade, passivação (isto é, formação de uma camada de óxido) e corrosão, conforme apresentado na Figura 12. Assim, as condições ótimas de corrosão para o alumínio (isto é, o pH e os potenciais sob os quais o alumínio é oxidado) são facilmente visualizadas em tal diagrama (Revie et al., 2008).

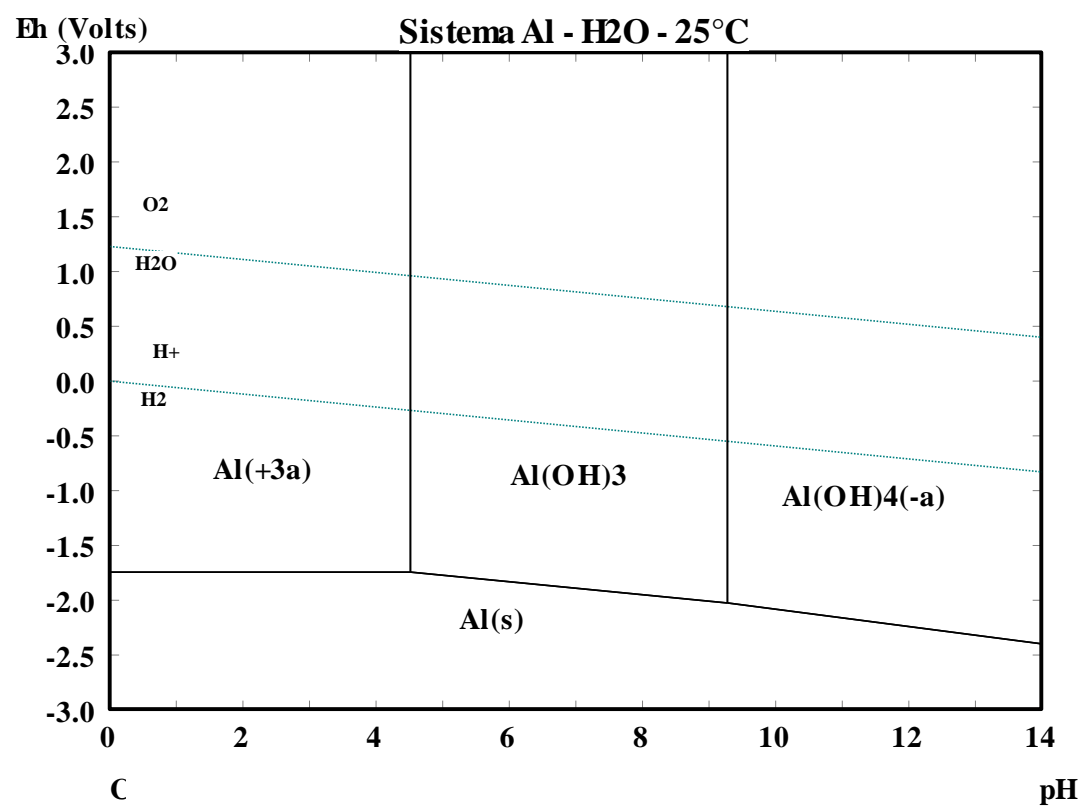

Figura 12 - Diagrama de equilíbrio Eh-pH para o sistema alumínio-água a $25^{\circ} \mathrm{C}$, obtido através do software HSC Chemistry 6.1 (Outotec). Elaborada pelo autor. 
Nesse contexto, a passivação reduz o desempenho da eletrocoagulação ao inibir a corrosão. A passivação dos eletrodos de alumínio tem sido amplamente observada e reconhecida como prejudicial ao desempenho do reator (Novikova et al., 1982). Essa formação de uma camada inibidora, geralmente um óxido, na superfície do eletrodo, evita a dissolução do metal e a transferência de elétrons, limitando, assim, a adição do cátion coagulante à solução.

Essa camada costuma ser dissolvida em soluções ácidas ou alcalinas (dissolução química). No entanto, quando o pH da solução se situa entre 4 e 8,5, essa camada é estável, porém sofre ataque localizado (corrosão do tipo localizada) em presença de íons halogênio, especialmente os íons cloreto $\left(\mathrm{Cl}^{-}\right)$(Revie et al., 2008).

Novikova et al. (1982) investigaram vários métodos de prevenção e/ou controle da passivação dos eletrodos - incluindo a mudança de polaridade, introdução de agentes inibidores e limpeza mecânica. Concluiu-se que o método mais eficiente e confiável foi a limpeza mecânica dos eletrodos.

A coagulação é a segunda base em que a eletrocoagulação está fundamentada. A partir desse momento, o poluente está pronto para separação.

\subsection{3.}

\section{Flotação}

A produção de gases é um subproduto inevitável da eletrocoagulação como descrito pelas Equações 29, 30, 31 e 32. Esses gases transportam os flocos para a superfície da solução ao mesmo tempo que estimulam o contato entre as partículas poluentes e os flocos. Dessa forma, proporcionam uma ação de mistura (Holt et al., 1999).

$$
\begin{aligned}
& 4 \mathrm{OH}^{-} \leftrightarrow \mathrm{O}_{2}+2 \mathrm{H}_{2} \mathrm{O}+4 e^{-} \quad E_{a}^{0}=-0,40 \mathrm{~V} \\
& 2 \mathrm{H}_{2} \mathrm{O}+2 e^{-} \leftrightarrow 2 \mathrm{OH}^{-}+H_{2} \quad E_{c}^{0}=-0,83 \mathrm{~V} \\
& 2 \mathrm{H}^{+}+2 e^{-} \leftrightarrow \mathrm{H}_{2} \quad E_{c}^{0}=0 \mathrm{~V}
\end{aligned}
$$


A principal diferença entre a flotação eletrolítica e as técnicas de flotação convencionais é o método de geração de bolhas e o seu tamanho resultante. A experiência de outras técnicas de flotação, incluindo flotação por ar dissolvido, pode ser empregada para compreender o processo de flotação em reatores de eletrocoagulação. A eletroquímica determina a taxa e o tipo de geração de bolhas. Essa sinergia é representada pela sobreposição das áreas de flotação e eletroquímica no diagrama de Venn (Figura 5) (Chen et al., 2010).

Uma das principais vantagens da flotação por gases eletrolíticos é o menor tamanho das bolhas geradas (Matis et al., 1995). Utilizando eletrodos inertes, como platina ou aço inoxidável, o gás hidrogênio é produzido no catodo e o gás oxigênio no anodo (Belongia et al., 1999). Para esses sistemas, Matis et al. (1995) estudaram a interação das bolhas com o poluente, mostrando que as bolhas eletrolíticas são tipicamente pequenas (inferiores a $50 \mu \mathrm{m}$ de diâmetro). O diâmetro de bolha menor resulta em uma maior área superficial e maior densidade de bolhas, aumentando, assim, a probabilidade de colisão e a capacidade de remoção de partículas finas (Matteson et al., 1995). Além disso, como observado, a evolução das bolhas eletrolíticas melhora a mistura da solução.

O movimento da bolha dentro do reator é função da densidade de bolhas, do caminho e do tempo de residência da bolha. A intensidade de corrente determina a taxa de produção de gás eletrolítico e, portanto, a densidade de bolhas, enquanto que a geometria do reator (volume, área ativa e posicionamento do eletrodo) determina o caminho da bolha. O tempo médio que uma bolha permanece no reator é referido como o seu tempo de residência, sendo função do diâmetro de bolha e do comprimento do percurso (o último sendo amplamente determinado pelo grau de mistura da solução e a profundidade na qual os eletrodos estão imersos) (Chen et al., 2010).

A operação em baixa intensidade de corrente produz poucas bolhas, resultando em uma agitação suave - condições ideais para o crescimento do agregado e floculação. À medida que a densidade de corrente aumenta, a 
quantidade de bolhas também aumenta, dessa forma, alterando o comportamento hidrodinâmico do reator e o grau de mistura (Chen et al., 2010).

A eletroquímica, coagulação e flotação formam, assim, as três bases para a eletrocoagulação. Cada componente é uma tecnologia bem compreendida em suas áreas de conhecimento. No entanto, a partir da literatura publicada, torna-se claro que existe uma demanda por uma compreensão da forma como essas tecnologias interagem em um sistema de eletrocoagulação, como será demonstrado na seção a seguir sobre projeto do reator de eletrocoagulação.

\section{3. \\ Considerações sobre o projeto do reator de eletrocoagulação}

Os reatores de eletrocoagulação são construídos em diversas configurações. Cada sistema tem seu próprio conjunto de vantagens e desvantagens.

A chave geral para o entendimento do desenho do reator são as interações entre as espécies presentes, sendo requerido um contato entre elas para uma efetiva agregação (Holt et al., 2005).

É importante projetar a célula de eletrocoagulação de tal modo que a sua eficiência máxima possa ser alcançada. A fase de projeto deve considerar as seguintes questões:

- Eletrodos

O desenho dos eletrodos determina a liberação do coagulante e o tipo das bolhas. Portanto, influencia na flotação, na mistura, na transferência de massa e na remoção do poluente (Mouedhen et al., 2008).

○Configuração dos Eletrodos

Os eletrodos podem ser arranjados de modo monopolar ou bipolar, conectados em série ou em paralelo. Essas diferentes configurações exercem impacto na eficiência do sistema (Golder et al., 2007).

Os eletrodos monopolares conectados em paralelo consistem, basicamente, em um par de placas metálicas condutíveis (eletrodos de sacrifício) colocadas 
entre dois eletrodos paralelos e uma fonte de tensão, conforme a Figura 13. A corrente é dividida entre todos os eletrodos de acordo com a resistência oferecida por cada célula. Portanto, é requerida uma menor diferença de potencial na conexão em paralelo, se comparada com a conexão em série (Wang et al., 2009).

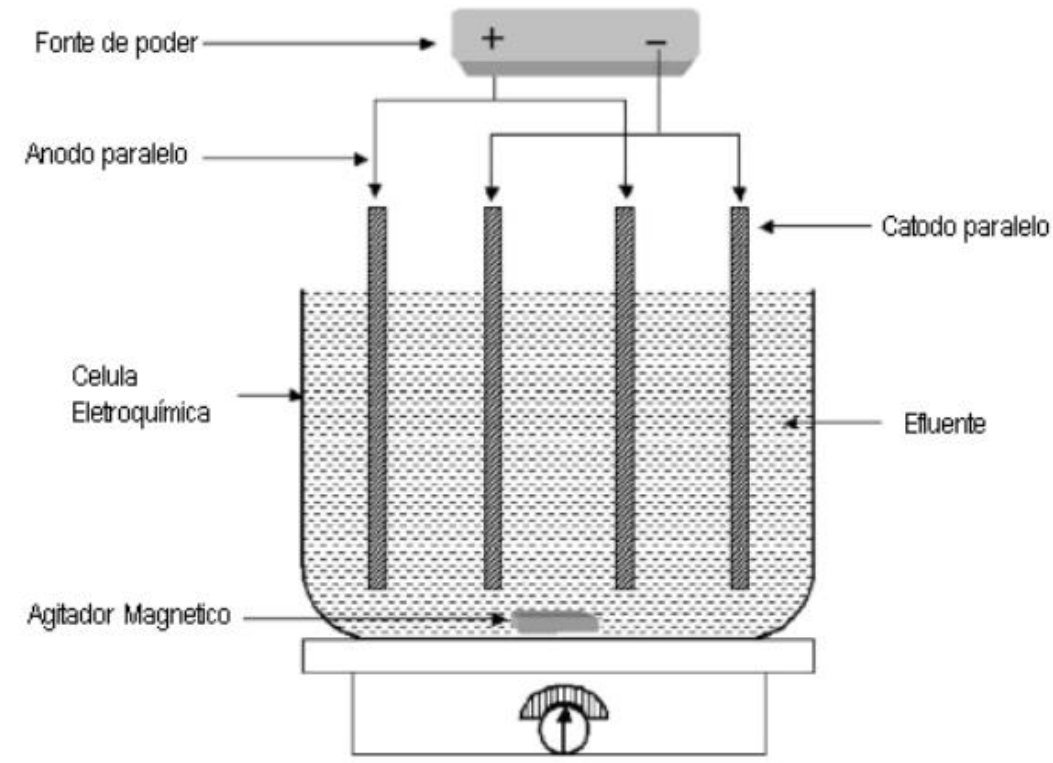

Figura 13 - Diagrama esquemático de um reator de eletrocoagulação escala bancada com eletrodos monopolares em paralelo (Adaptado de Mollah et al., 2004).

Quando os eletrodos monopolares estão conectados em série, cada par de eletrodos de sacrifício é conectado internamente com o outro, não tendo contato com os eletrodos exteriores. Uma maior diferença de potencial é requerida para uma dada corrente, devido ao somatório das tensões das células (Wang et al., 2009).

No caso de eletrodos bipolares, os eletrodos de sacrifício são colocados entre os dois eletrodos paralelos sem conexão elétrica nenhuma. Somente os dois eletrodos monopolares são conectados à fonte de tensão, conforme apresentado na Figura 14. Quando uma corrente elétrica é passada através dos dois eletrodos, os lados neutros da placa condutora são transformados em lados carregados, que têm carga oposta à carga do lado paralelo ao lado dela (Mollah et al., 2001). 


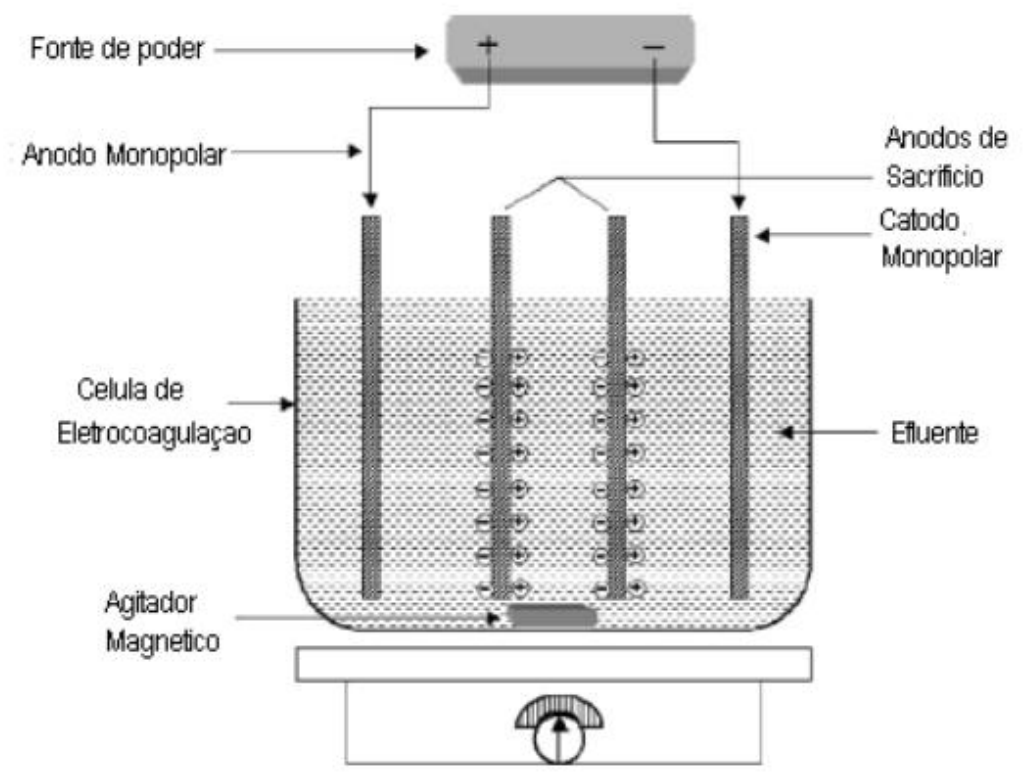

Figura 14 - Diagrama esquemático de um reator de eletrocoagulação escala bancada com eletrodos bipolares em paralelo (Adaptado de Mollah et al., 2004).

As eficiências de remoção de poluentes e os custos operacionais do arranjo monopolar em paralelo e bipolar foram comparados em diferentes estudos (Ghosh et al., 2008). Os resultados poderiam ser resumidos de modo que o arranjo monopolar em paralelo apresentou custos operacionais inferiores, mas uma maior remoção de poluentes foi possível com a configuração bipolar.

\section{○ Material dos Eletrodos}

A seleção do material apropriado é importante para assegurar a eficiência da remoção durante o tratamento por eletrocoagulação. Vários materiais têm sido utilizados, tais como alumínio, ferro, grafite, carbono, zinco e aço inoxidável (Liu et al., 2010). No entanto, os materiais mais empregados como eletrodo de sacrifício são o alumínio e o ferro, uma vez que apresentam baixo custo, elevada disponibilidade e comprovada eficácia (Bayramoglu et al., 2007). Existem também alguns estudos que se utilizaram de combinações de eletrodos de alumínio e ferro (Katal et al., 2011).

A seleção do material ótimo depende dos poluentes a serem removidos e das propriedades químicas do eletrólito. Em geral, o alumínio é superior ao ferro quando apenas a eficiência da remoção é considerada. Possivelmente, devido à 
alta capacidade de adsorção dos hidróxidos de alumínio. No entanto, deve-se notar que o alumínio apresenta um maior custo do que o ferro (Emamjomeh et al., 2009).

Embora diferentes materiais forneçam diferentes graus de remoção, a maioria dos estudos concorda que o alumínio é o melhor material a ser utilizado como anodo e catodo no processo de eletrocoagulação. Isso é confirmado pela maior eficiência da remoção e pelo menor custo operacional acumulado do tratamento em comparação com outros materiais (Akyol, 2012).

- Processo de fluxo continuo ou de batelada

O reator de fluxo contínuo é inerentemente dinâmico em operação e estável em eficácia. A carga poluidora pode ser verificada a diferentes vazões do efluente. A resistência à deposição de flocos no anodo (Mahesh et al., 2006) e a dissolução desses é uma vantagem do reator de fluxo continuo. Os níveis de passivação e corrosão dos eletrodos também podem ser monitorados com o tempo.

O reator de batelada é mais apropriado para a compreensão do comportamento dependente do tempo, sendo o anodo dissolvido continuamente em uma forma capaz de coagular os poluentes. Consequentemente, as concentrações do poluente, coagulante e $\mathrm{pH}$ variam ao longo do tempo. Portanto, é esse comportamento dinâmico inerente, juntamente com a interação entre os aspectos termodinâmicos e cinéticos, que torna os reatores de batelada tão difíceis de serem modelados matematicamente (Holt et al., 2005).

No entanto, a otimização dos parâmetros de processo através de ensaios em batelada serve como diretriz para a operação dos reatores de eletrocoagulação de fluxo contínuo (Holt et al., 2005).

- Geometria do reator

A geometria do reator afeta parâmetros operacionais. Os projetos de eletrodos relatados são numerosos - incluindo grânulos de alumínio em um reator de leito fluidizado (Barkley et al., 1993), eletrodos em malha (Matteson et al., 1995), bem como eletrodos de placas verticais/horizontais, tubos perfurados, tubos sólidos, entre outros (Mollah et al., 2004). 
Cada sistema tem seu próprio conjunto de vantagens e desvantagens, entre as quais estão variadas aptidões para diferentes tratamentos que são de extrema importância.

Os sistemas de eletrocoagulação apresentam, tipicamente, eletrodos de placas e o fluxo da solução ocorre através do espaço entre os eletrodos (Chen, 2004).

- Velocidade de mistura

A principal função da agitação é transferir eficientemente o coagulante que é gerado nos eletrodos. Se o coagulante não é disperso no reator de forma eficiente, o conteúdo do reator não será homogêneo. A velocidade de mistura também pode influenciar na homogeneização das variáveis do sistema, como temperatura e $\mathrm{pH}$. Contudo, altas velocidades de mistura podem destruir os flocos formados no reator e tornar difícil a remoção do contaminante (Bayar et al., 2011).

- Escalonamento do reator

O parâmetro S/V - razão da área ativa dos eletrodos pelo volume do reator é um parâmetro que afeta significativamente o escalonamento. A área dos eletrodos influencia na densidade de corrente e na taxa de liberação dos cátions, bem como na produção de bolhas (Holt et al., 2005). Hansen et al. (2007) relataram que à medida que a razão S/V aumenta, a densidade de corrente ótima diminui.

\section{4.}

\section{Parâmetros operacionais da célula de eletrocoagulação}

Existem vários parâmetros que exibem efeito sobre o processo de eletrocoagulação. Os mais relevantes são apresentados a seguir. 
- Passivação dos eletrodos

Um dos principais desafios operacionais na eletrocoagulação é a passivação dos eletrodos. A passivação dos eletrodos, em específico aqueles de alumínio, tem sido amplamente observada e reconhecida como prejudicial para o desempenho do processo. A formação de uma camada inibidora, usualmente um óxido, na superfície do eletrodo, impede a dissolução do metal e a transferência de elétrons, limitando, assim, a adição de coagulante à solução. Ao longo do tempo, a espessura desta camada aumenta, reduzindo a eficiência do processo de eletrocoagulação (Liu et al., 2010).

O uso de novos materiais, diferentes tipos de arranjos (Pretorius et al., 1991) e estratégias operacionais mais sofisticadas (como a reversão periódica da polaridade dos eletrodos) possibilitaram, certamente, reduções da passivação dos eletrodos. Além disso, a adição de ânions também reduz a passivação. O efeito positivo apresentou-se como: $\mathrm{Cl}^{-}>\mathrm{Br}^{-}>\mathrm{I}^{-}>\mathrm{F}^{-}>\left[\mathrm{ClO}_{4}\right]^{-}>\mathrm{OH}^{-}>\left[\mathrm{SO}_{4}\right]^{2-}$. Especialmente, a adição de $\mathrm{Cl}^{-}$na solução inibirá o processo de passivação do eletrodo. Em muitos casos, também é necessário realizar uma limpeza mecânica na superfície dos eletrodos (Kabdasl et al., 2012).

- pH da solução

Um dos principais parâmetros do tratamento por eletrocoagulação é o pH da solução. O pH afeta a condutividade da solução, dissolução dos eletrodos, especiação do cátion e o potencial zeta dos poluentes (Vepsäläinen et al., 2012).

O alumínio eletrodissolvido pode formar hidroxi-complexos monoméricos e poliméricos dependendo da faixa de $\mathrm{pH}$ e da concentração de alumínio (Gürses et al., 2002). Geralmente, o pH do meio tende a aumentar durante o processo devido à geração de íons hidroxila no catodo (Kobya et al., 2006).

No caso de anodos de alumínio, o mecanismo de remoção predominante em pH 4 a 6 é a neutralização de carga. Quando o pH se encontra entre 6 e 8, o mecanismo de remoção predominante torna-se a floculação por varredura. A especiação do alumínio em solução aquosa depende do $\mathrm{pH}$, além da concentração total de alumínio. A taxa de dissolução química do alumínio tem um valor mínimo 
quando o pH da solução é neutro. Já com valores básicos, essa taxa aumenta em várias magnitudes (Mollah et al., 2001).

Conforme explicado por Kobya et al. (2006), a mudança dos valores de pH durante o processo de tratamento depende do $\mathrm{pH}$ inicial da solução e do tipo de material do eletrodo. $\mathrm{O}$ pH do efluente após o tratamento por eletrocoagulação incrementará quando o $\mathrm{pH}$ inicial tiver valores ácidos, mas diminuirá quando o $\mathrm{pH}$ inicial for alcalino - uma vantagem do processo. $\mathrm{O}$ incremento do $\mathrm{pH}$ foi atribuído à geração de íons hidroxila no catodo, como consequência do processo de geração de gases de hidrogênio (Cañizares et al., 2006). Além da geração do hidrogênio, a formação de $\mathrm{Al}(\mathrm{OH})_{3}$, próximo ao anodo, liberaria íons $\mathrm{H}^{+}$ permitindo uma diminuição do $\mathrm{pH}$. Também existe a reação de geração de gases do oxigênio, o que permite uma diminuição do $\mathrm{pH}$.

- Densidade de corrente e tempo de tratamento

Densidade de corrente é a intensidade de corrente fornecida por área ativa do eletrodo. A densidade de corrente determina diretamente a dosagem de coagulante, taxa de geração de bolhas e influencia fortemente tanto a mistura da solução como a transferência de massa nos eletrodos. Em um sistema de eletrocoagulação, o eletrodo ou conjunto de eletrodos é normalmente ligado a uma fonte de tensão externa. A quantidade de metal dissolvido ou depositado depende da quantidade de corrente. Segundo Daneshvar et al. (2007), quando o tempo de eletrólise aumenta, a concentração de íons e seus flocos de hidróxidos aumentam.

A densidade de corrente é o parâmetro operacional chave, afetando não apenas o tempo de resposta do sistema, mas também influenciando o modo dominante de separação dos poluentes. A maior densidade de corrente admissível pode não ser o modo mais eficiente de operação do reator. É conhecido que a densidade de corrente ótima envolverá invariavelmente um trade-off entre os custos operacionais e a utilização eficiente do coagulante gerado durante o processo de eletrocoagulação (Liu et al., 2010).

Conforme resumido por Chen (2004), a intensidade de corrente fornecida ao sistema determina a quantidade de íons liberados dos eletrodos. Para que o sistema de eletrocoagulação funcione durante um longo período de tempo sem manutenção, a densidade de corrente sugerida é de $20-25 \mathrm{~A} / \mathrm{m}^{2}$, a menos que 
medidas sejam tomadas para limpeza periódica da superfície dos eletrodos. A escolha da densidade de corrente ótima deve ser feita em conjunto com outros parâmetros operacionais, como pH e temperatura, para garantir uma alta eficiência de corrente.

A eficiência de corrente do eletrodo de alumínio pode ser de 120-140\% enquanto que a de ferro é de cerca de $100 \%$. A eficiência de corrente, que é superior a $100 \%$, do eletrodo de alumínio é atribuída ao efeito de corrosão, especialmente quando há presença de íons de cloro. A eficiência de corrente depende da densidade de corrente e dos tipos de ânions presentes na solução (Kovatcheva et al., 1999).

- Distância entre eletrodos

Dentre os mecanismos de transporte de massa, a difusão e a migração são especialmente afetados quando alteramos a distância entre os eletrodos (Aoudj et al., 2010).

Quanto maior a distância entre os eletrodos, maior deverá ser o potencial aplicado, pois a solução possui resistividade à passagem de corrente elétrica. De acordo com as características do efluente, a eficiência do processo pode ser melhorada variando-se a distância dos eletrodos (Crespilho et al., 2004).

Quando a distância entre eletrodos aumenta, a eficiência de remoção aumenta. Esta mudança provavelmente ocorre porque os efeitos eletrostáticos dependem da distância entre eletrodos, então, quando esta aumenta, o movimento dos íons produzidos seria mais lento e eles teriam maior oportunidade de produzir e agregar flocos. Além disso, estes flocos são capazes de adsorver mais moléculas (Daneshvar et al., 2004).

Para que não exista diferença na eficiência de remoção com a alteração do espaçamento entre os eletrodos, a solução a ser tratada deve ter um valor mínimo de condutividade elétrica (Mollah et al., 2001).

- Condutividade

O aumento da força iônica da solução provoca um aumento da densidade de corrente a uma mesma tensão aplicada. Portanto, é necessário investigar o efeito 
da condutividade da solução em termos da remoção de poluentes por eletrocoagulação. A condutividade da solução depende do tipo e concentração do eletrólito. Existem diferentes tipos de eletrólitos disponíveis, tais como $\mathrm{NaCl}$, $\mathrm{BaCl}_{2}, \mathrm{KCl}, \mathrm{Na}_{2} \mathrm{SO}_{4}$ e KI (Sahu et al., 2014).

$\mathrm{O}$ cloreto de sódio $(\mathrm{NaCl})$ é geralmente utilizado para aumentar a condutividade da solução. A condutividade afeta a eficiência de corrente, tensão aplicada e, consequentemente, o consumo de energia do reator de eletrocoagulação (Mollah et al., 2001).

Por outro lado, uma quantidade excessiva de $\mathrm{NaCl}$ induz um maior consumo dos eletrodos de alumínio devido à corrosão (Kabdaşl1 et al., 2012). Esta é a razão pela qual a adição de $\mathrm{NaCl}$ deve ser limitada e otimizada. Os sais de íons monovalentes parecem ser os melhores eletrólitos. Em comparação com nenhuma adição de eletrólito, a adição de $\mathrm{NaCl}$ na faixa de $\mathrm{g} / \mathrm{L}$ provoca uma importante diminuição dos custos operacionais, uma vez que a tensão aplicada diminui com o aumento da condutividade à densidade de corrente constante (Chen, 2004).

- Temperatura

O efeito da temperatura da solução na remoção de boro por eletrocoagulação foi estudado na faixa de 293-333K (Yilmaz et al., 2008). Quando a temperatura aumentou de $293 \mathrm{~K}$ para $333 \mathrm{~K}$, a eficiência de remoção de boro aumentou de $84 \%$ para $96 \%$. O efeito oposto foi relatado quando águas residuais de uma fábrica de celulose foram tratadas a temperaturas entre $293 \mathrm{~K}$ e 333K (Katal et al., 2011). A remoção de cor, DQO e fenol diminuiu 10-20\% quando a temperatura aumentou de $293 \mathrm{~K}$ para $333 \mathrm{~K}$. É possível que o efeito da temperatura dependa do mecanismo de remoção dominante.

Vasudevan et al. (2009) concluíram que, a baixas temperaturas, a dissolução do ânodo ocorre a uma taxa mais lenta. Foi sugerido que, quando a temperatura é mais elevada, há um encolhimento dos grandes poros presentes no $\mathrm{Al}(\mathrm{OH})_{3}$, o que provoca a formação de flocos densos que são mais propensos à sedimentação. $\mathrm{O}$ acréscimo da temperatura também ocasiona um aumento da solubilidade do alumínio (Chen, 2004).

A taxa de reação eletroquímica, como a maioria das taxas de reação química, aumenta quando a temperatura da solução aumenta. A razão pode ser 
que com o aumento da temperatura, a mobilidade e, portanto, a colisão do contaminante com os precipitados de hidróxido de alumínio aumentem (Song et al., 2007).

- Concentração inicial do contaminante

A remoção do poluente com frequência diminui com o aumento da sua concentração.

Esse comportamento pode ser justificado em razão da escassez de sítios de adsorção disponíveis para as espécies do contaminante em excesso (Missaoui et al., 2013), uma vez que a quantidade de coagulante gerado ao longo do processo de eletrocoagulação permanece constante.

\section{5. \\ Vantagens e limitações da Eletrocoagulação}

Mollah et al. (2001) relataram várias vantagens do processo de eletrocoagulação em comparação com o processo de coagulação tradicional. Por exemplo, o equipamento necessário para o processo de eletrocoagulação é simples e fácil de operar. Como consequência, pode ser realizado em instalações de tratamento pequenas e compactas, resultando em um custo relativamente baixo e possibilitando a automação completa. Além disso, o processo não tem partes móveis e a maior parte do processo é controlada eletricamente e, portanto, requer menos manutenção. Também foi afirmado que a técnica de eletrocoagulação pode ser utilizada em áreas rurais onde a eletricidade não está disponível. A energia necessária para o processo pode ser fornecida por painéis solares (Sharma et al., 2011). Além disso, o processo de eletrocoagulação representa uma escolha adequada na qual tecnologias de tratamento localizadas são preferíveis em relação a tratamentos centralizados (Holt et al., 2005).

Em relação aos flocos produzidos ao longo do processo de eletrocoagulação, eles são similares aos formados por coagulação química, exceto que os flocos de eletrocoagulação são mais largos, tendo menos conteúdo de água, mais estáveis em meio ácido, portanto, podem ser separados mais rapidamente por filtração. Além disso, as bolhas de gás produzidas durante a eletrólise podem carregar o 
poluente até o topo da solução, onde é concentrado, coletado e removido (Mollah et al., 2001).

Como em qualquer processo, existem também algumas desvantagens como a troca regular dos anodos, a passivação da superfície dos eletrodos, o que causa a perda de eficiência da unidade de eletrocoagulação e o consumo de energia elétrica, em razão do contínuo aumento da tarifa energética (Vik et al., 1984). Contudo, recentemente algumas soluções estão sendo empregadas com o objetivo de superar essas limitações. É o caso, por exemplo, da inversão de polaridade dos eletrodos para reduzir o efeito da passivação (Mlakar et al., 2017) e da utilização de energia solar fotovoltaica para suprir a demanda energética do processo (Hussin et al., 2017). 


\section{4}

\section{Materiais e métodos}

Neste capitulo são apresentados os materiais, reagentes e equipamentos utilizados no estudo do processo de remoção de boro por eletrocoagulação, assim como a metodologia experimental desenvolvida para o estudo em questão.

\section{1.}

\section{Materiais}

A linha experimental de eletrocoagulação é composta dos equipamentos apresentados na Figura 15.

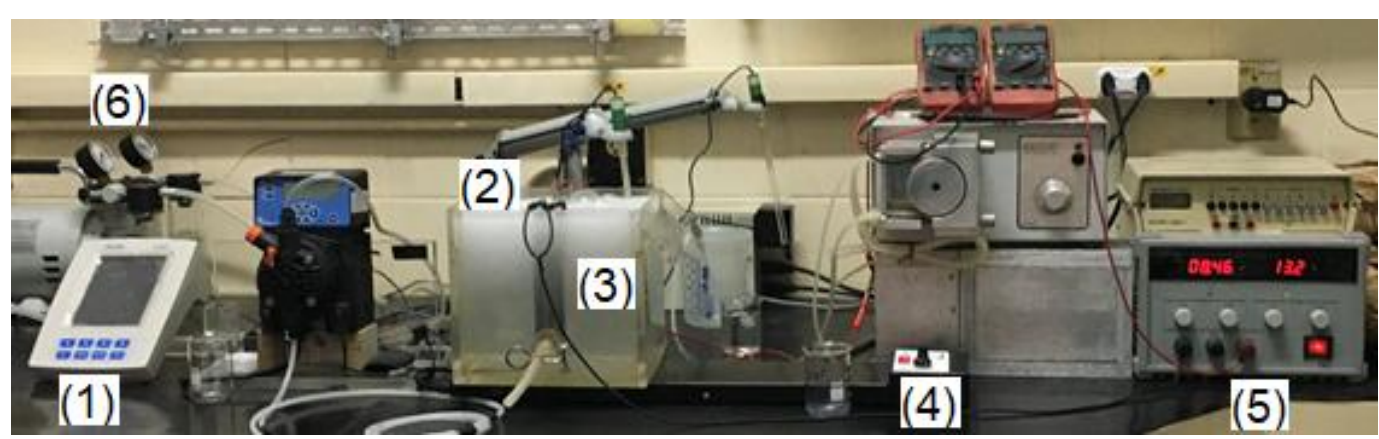

Figura 15 - Linha experimental de eletrocoagulação. 1- pHmetro (HI 4521 - HANNA); 2Célula de eletrocoagulação (acrílico); 3- Eletrodos de alumínio; 4- Agitador magnético (761-5 - FISATOM); 5- Fonte de tensão (PS-1001 - ICEL); 6- Bomba de vácuo. Elaborada pelo autor.

Os materiais e equipamentos utilizados serão descritos de acordo com a metodologia experimental seguida neste trabalho.

\subsection{1.}

\section{Reator de eletrocoagulação}

O desempenho da técnica de eletrocoagulação foi investigado com a utilização de uma célula de eletrocoagulação em batelada, conforme ilustrado na 
Figura 16. As características da célula de eletrocoagulação são apresentadas na Tabela 1.

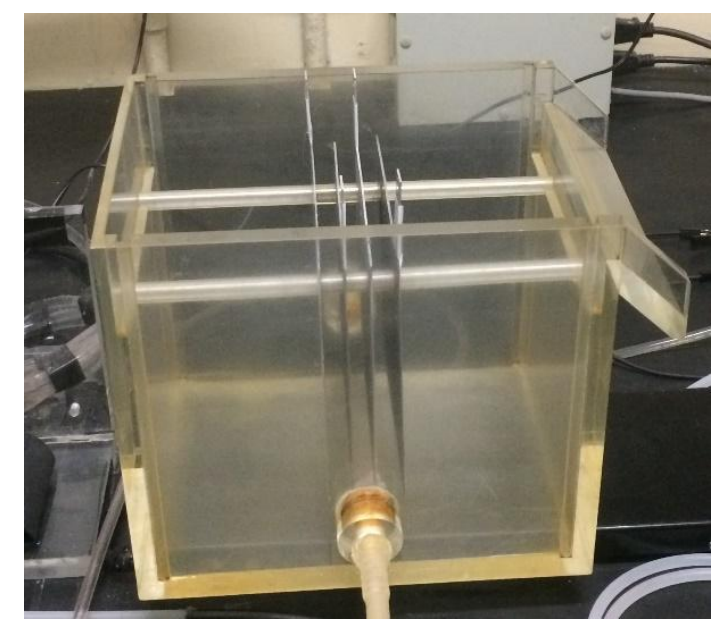

Figura 16 - Célula de eletrocoagulação utilizada para avaliação do processo em batelada. Fotografia do autor.

Tabela 1 - Características da célula de eletrocoagulação. Elaborada pelo autor.

\begin{tabular}{|c|c|}
\hline \multicolumn{2}{|c|}{ Características da célula } \\
\hline Material & Acrílico \\
\hline Dimensões & \\
\hline$\circ \quad$ Altura & $170 \mathrm{~mm}$ \\
\hline$\circ \quad$ Comprimento & $150 \mathrm{~mm}$ \\
\hline$\circ \quad$ Largura & $190 \mathrm{~mm}$ \\
\hline$\circ \quad$ Espessura das paredes & $10 \mathrm{~mm}$ \\
\hline Volume de trabalho & $5,5 \mathrm{~L}$ \\
\hline
\end{tabular}

Foram empregados eletrodos de forma retangular com as características apresentadas na Tabela 2. Os eletrodos foram perfurados com furos de $5 \mathrm{~mm}$ de diâmetro em toda a superfície, como mostra a Figura 17, de modo a aumentar o transporte de massa e evitar o sobreaquecimento da solução, além de facilitar a liberação dos gases gerados. Os eletrodos empregados apresentavam uma área superficial de $149,94 \mathrm{~cm}^{2}$. 
Tabela 2 - Características dos eletrodos. Elaborada pelo autor.

\begin{tabular}{|c|c|}
\hline \multicolumn{2}{|c|}{ Características dos eletrodos } \\
\hline Material & \\
\hline$\circ$ Anodo & Alumínio \\
\hline$\circ$ Catodo & Alumínio \\
\hline Dimensões & \\
\hline$\circ \quad$ Altura & $130 \mathrm{~mm}$ \\
\hline$\circ \quad$ Comprimento & $120 \mathrm{~mm}$ \\
\hline$\circ \quad$ Espessura & $5 \mathrm{~mm}$ \\
\hline Disposição & Verticais - Paralelo \\
\hline
\end{tabular}

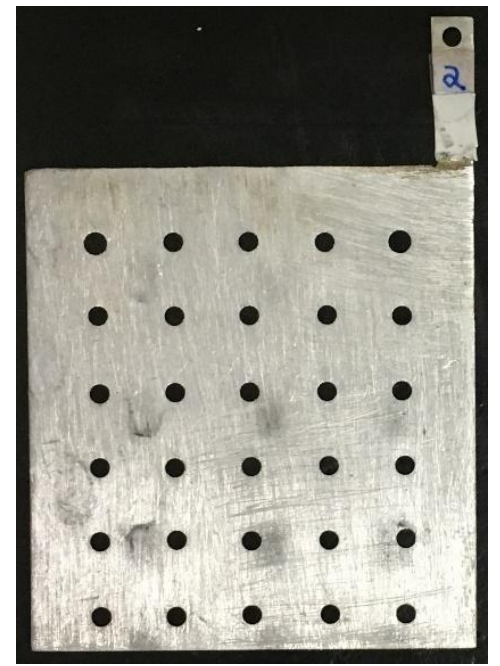

Figura 17 - Eletrodo de alumínio perfurado. Fotografia do autor.

A configuração de eletrodos utilizada foi composta por 4 eletrodos de alumínio, sendo 2 anodos e 2 catodos, em um arranjo monopolar em paralelo, ilustrado na Figura 18. 


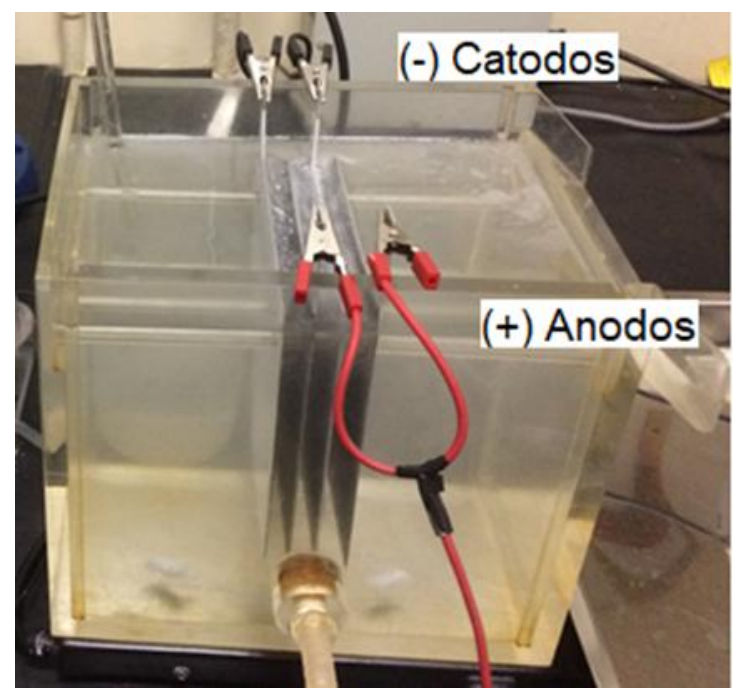

Figura 18 - Arranjo físico dos eletrodos. Fotografia do autor.

A célula de eletrocoagulação empregada apresentava um ponto de amostragem lateral, conforme ilustrado na Figura 19, por onde eram retiradas amostras da solução, visando a análise da concentração de boro em diferentes tempos de tratamento.

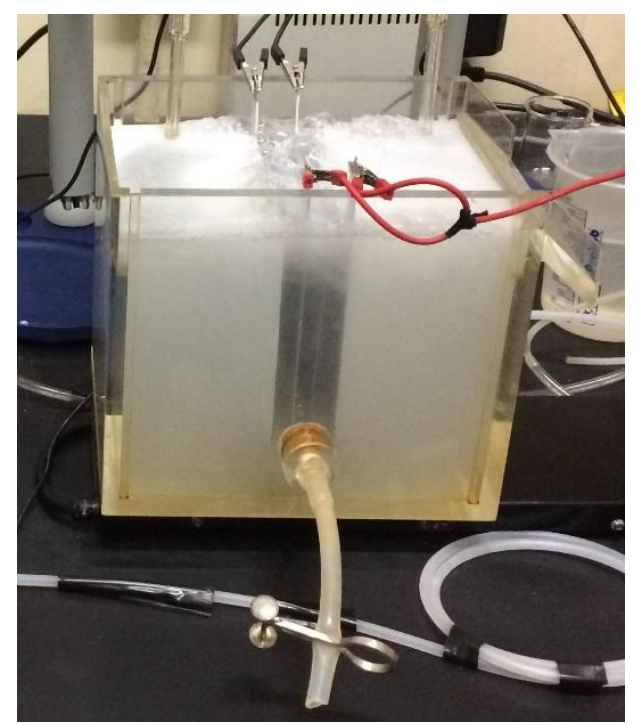

Figura 19 - Célula de eletrocoagulação durante a realização de um experimento. Fotografia do autor. 


\subsection{2.}

\section{Reagentes químicos}

Todos os reagentes apresentavam pureza analítica (P.A.) e foram adquiridos da Proquimios Comércio e Indústria Ltda. Os reagentes químicos, utilizados na condução das experiências de eletrocoagulação, foram:

- Ácido bórico $\left(\mathrm{H}_{3} \mathrm{BO}_{3}\right)$;

- Cloreto de sódio $(\mathrm{NaCl})$;

- Solução de ácido clorídrico (HCl);

- Solução de hidróxido de sódio $(\mathrm{NaOH})$.

\section{2. \\ Métodos experimentais}

\subsection{1. \\ Preparação da solução contendo boro}

As soluções sintéticas foram preparadas com água deionizada nas concentrações de boro de $12,50 \mathrm{mg} / \mathrm{L}, 25 \mathrm{mg} / \mathrm{L}, 50 \mathrm{mg} / \mathrm{L}$ e $100 \mathrm{mg} / \mathrm{L}$ a partir do ácido bórico $\left(\mathrm{H}_{3} \mathrm{BO}_{3}\right)$ fornecido pela Proquimios.

\subsection{2.}

\section{Rotina experimental}

As soluções sintéticas previamente preparadas foram supridas à célula de eletrocoagulação por meio de sua abertura superior. Foram utilizados agitadores magnéticos com agitação constante de 250 rotações por minuto para promover a mistura do sistema reacional. Adicionou-se $\mathrm{NaCl}$ como eletrólito suporte do sistema para atingir a concentração de $15 \mathrm{mM}$ na célula de eletrocoagulação. $\mathrm{O}$ pH foi ajustado com alíquotas de $\mathrm{NaOH} 1 \mathrm{M}$ ou de $\mathrm{HCl} 1 \mathrm{M}$ até um determinado valor, em função do tipo de experimento. Em seguida, foram colocados os eletrodos (previamente pesados). O espaçamento entre os eletrodos foi assegurado constante 
em 10mm por meio de separadores de acrílico. A corrente elétrica foi, então, ajustada para um determinado valor, em função do tipo de experimento, e mantida constante ao longo do processo.

Ao longo de todos os experimentos não foi feita nenhuma adição de reagentes químicos, sendo, então, permitido que o valor de $\mathrm{pH}$ variasse espontaneamente, sem qualquer interferência externa, conforme poderá ser visualizado posteriormente, quando da análise das curvas de variação do $\mathrm{pH}$ em função do tempo.

Foram tomadas alíquotas de $50 \mathrm{~mL}$ durante o decorrer do experimento, em intervalos regulares de tempo, sendo tomada a amostra do tempo "zero" no momento antes de ligar a fonte de tensão. Imediatamente tomadas as amostras, essas eram filtradas em papel Millipore $(0,45 \mu \mathrm{m})$. Em seguida, as amostras foram analisadas para determinação da concentração de boro por um espectrômetro de Plasma Indutivamente Acoplado a Espectrometria de Emissão Ótica (ICPOES). Ao fim do tempo de eletrólise (90 minutos), os eletrodos foram pesados para a determinação da quantidade de alumínio dissolvido.

Com o objetivo de evitar qualquer interferência e garantir a reprodutibilidade da superfície dos eletrodos, esses foram preparados da seguinte forma: ao final de cada experimento, os eletrodos eram polidos mecanicamente com papel abrasivo, seguido de imersão em solução de $\mathrm{HCl} 0,1 \mathrm{M}$ durante 2 minutos. Por fim, os eletrodos eram enxaguados com água deionizada e secos com papel absorvente.

\subsection{3.}

\section{Planejamento experimental}

No processo de eletrocoagulação, vários fatores, tais como pH inicial, densidade de corrente e tempo de eletrólise, influenciam na eficiência de remoção de contaminantes (Mollah et al., 2001). A metodologia de otimização clássica ou univariada, embora simples e de fácil interpretação, apresenta a desvantagem de possibilitar a otimização de um fator ou parâmetro por vez, fixando-se um determinado valor de um fator e variando os níveis dos outros fatores envolvidos no processo (Anderson et al., 2000). Com o objetivo de ultrapassar essa limitação, faz-se a utilização da otimização multivariada, na qual os recursos matemáticos e 
estatísticos são envolvidos. Através dessa metodologia é possível que todos os fatores sejam variados simultaneamente, de forma que se houver alguma interação entre eles, esta será reconhecida (Montgomery, 2017).

Inicialmente realizou-se uma pesquisa bibliográfica avaliando-se diversos estudos que aplicaram a eletrocoagulação na remoção de diferentes contaminantes, com o intuito de verificar quais as variáveis que mais influenciam o processo.

Diante da revisão bibliográfica realizada, os parâmetros densidade de corrente, $\mathrm{pH}$ inicial e tempo de eletrólise destacaram-se dentre os parâmetros citados como interferentes do processo de eletrocoagulação.

Experimentos desenhados em esquemas fatoriais são aqueles que envolvem combinações entre os níveis de dois ou mais fatores (Box et al., 2005). Um planejamento será considerado completo quando possuir todas as combinações possíveis, entre todos os níveis de cada fator (Anderson et al., 2000).

Nesse sentido, a matriz experimental foi desenvolvida aplicando o planejamento fatorial completo $3 \times 6 \times 7$, isto é, três fatores, sendo o primeiro fator com três níveis, o segundo fator com seis níveis e o terceiro fator com sete níveis, apresentados pela Tabela 3. Todos os experimentos foram realizados em duplicata.

Tabela 3 - Fatores e níveis aplicados ao experimento. Densidade de corrente (X1), em $\mathrm{mA} / \mathrm{cm}^{2}, \mathrm{pH}$ inicial (X2) e tempo (X3), em minuto. Elaborada pelo autor.

\begin{tabular}{|c|c|c|}
\hline Fator & Níveis & Valores \\
\hline $\mathbf{X 1}$ & 3 & 6,$25 ; 12,50 ; 18,75$ \\
\hline $\mathbf{X 2}$ & 6 & $3 ; 4 ; 5 ; 6 ; 7 ; 8$ \\
\hline $\mathbf{X 3}$ & 7 & $5 ; 10 ; 15 ; 20 ; 40 ; 60 ; 90$ \\
\hline
\end{tabular}

O experimento consistiu na análise dos efeitos dos fatores sobre o parâmetro resposta avaliado (percentagem de remoção de boro).

A partir dos resultados experimentais (em duplicata), foi possível a elaboração dos modelos matemáticos através do método dos mínimos quadrados. Este método é utilizado para estimar os coeficientes do modelo utilizado na modelagem da resposta, de tal forma que a soma dos quadrados dos resíduos seja a menor possível (Myers et al., 2016). 
Para a representação dos dados experimentais da variável de resposta, foi proposto um modelo matemático de regressão (função resposta) apresentado pela eq. (33) (Myers et al., 2016). Os modelos empíricos são polinômios de segunda ordem.

$y=\beta_{0}+\sum_{i=1}^{k} \beta_{i} x_{i}+\sum_{i=1}^{k} \beta_{i i} x_{i}^{2}+\sum_{i=1}^{k-1} \quad \sum_{j>i}^{k} \beta_{i j} x_{i} x_{j}$

Onde y é a função resposta, os valores de x são os parâmetros do reator de eletrocoagulação (densidade de corrente, $\mathrm{pH}$ inicial e tempo de eletrólise) e os valores de $\beta$ são os coeficientes significativos do modelo.

O modelo de regressão, obtido por meio das análises estatísticas, faz a correlação entre a função resposta (percentual de remoção de boro) e os fatores (densidade de corrente, $\mathrm{pH}$ inicial e tempo), juntamente com as interações entre eles. A validade do modelo matemático gerado foi comprovada pela análise de variância (ANOVA).

Após a verificação das variáveis significativas para o percentual de remoção de boro, aplicou-se a Metodologia de Superfície de Resposta (RSM). A RSM, dentre as diversas técnicas multivariadas de otimização, apresenta importante aplicabilidade por causa de sua alta eficiência, poder de modelagem e capacidade de exploração dos sistemas estudados (Myers et al., 2016).

\subsection{4.}

Avaliação microscópica da superfície dos eletrodos de alumínio

A Microscopia Eletrônica de Varredura (MEV) é uma técnica utilizada para análise morfológica e estrutural da superfície do material, possibilitando, ainda, a realização de microanálise composicional da amostra (Reichelt, 2007). Um feixe de elétrons colimado, que varre a amostra ponto-a-ponto, interage com o material gerando diversos tipos de sinais, dentre os quais são comumente utilizados os elétrons secundários, os retroespalhados e os raios-X característicos. Os elétrons secundários fornecem imagem de topografia da superfície da amostra e são os responsáveis pela obtenção das imagens de alta resolução, já os retroespalhados fornecem imagem característica de variação de composição. Os raios-X característicos dão informação composicional do material em cada ponto da 
varredura, deste modo, podem ser utilizados para análise composicional pontual, além de permitir avaliação de perfis de composição e formação de imagens de mapeamento dos elementos químicos presentes (Goldstein et al., 2012).

Para a realização deste ensaio, utilizou-se um Microscópio Eletrônico de Varredura (MEV), JEOL-FEG JSM-7100F, operado a 20kV, com detector de Dispersão de Energia de Raios-X acoplado. Os corpos de prova foram extraídos dos eletrodos de alumínio após vários ciclos de experimentos.

O microscópio utilizado está localizado no Laboratório Multiusuário de Nanociência e Nanotecnologia - LabNano, CBPF-RJ.

\subsection{5.}

\section{Caracterização do lodo gerado no processo de eletrocoagulação}

Utilizou-se diferentes técnicas com o objetivo de identificar as fases cristalinas, avaliar a morfologia e determinar os elementos químicos presentes no lodo gerado no processo de eletrocoagulação. Essas técnicas são a Difração de Raios-X (DRX), a Microscopia Eletrônica de Varredura (MEV) e a Espectroscopia por Perda de Energia de Elétrons (EELS).

Anteriormente às análises, o lodo gerado no processo de eletrocoagulação foi seco em estufa a $100^{\circ} \mathrm{C}$ durante 24 horas. As análises foram realizadas na amostra gerada no experimento com as seguintes condições: $\mathrm{pH}_{\mathrm{o}}=4$; densidade de corrente $=18,75 \mathrm{~mA} / \mathrm{cm}^{2}$ e tempo $=90 \mathrm{~min}$.

Os raios-X são ondas eletromagnéticas de comprimentos de onda entre 0,05nm e 0,25nm que ocupam uma posição intermediária entre o ultravioleta e a radiação gama no espectro eletromagnético (Klug et al., 1954). São produzidos quando partículas carregadas com alta energia cinética são desaceleradas rapidamente. A radiação gerada no processo pode ser empregada para fazer uma análise química do material já que a resposta do material à incidência da radiação X pode ser análoga a uma "impressão digital” do material (Whittig et al., 1986).

A determinação da(s) fase(s) cristalina(s) foi realizada em Difratometro de Raios-X D8 Advance (Bruker AXS). As condições das análises foram: faixa de varredura $(2 \theta)$ de $10^{\circ}$ a $80^{\circ}$, passo de varredura de $0,02^{\circ}$ e tempo por passo de $2 \mathrm{~s}$.

Para a análise da morfologia e da composição química do lodo gerado no processo de eletrocoagulação utilizou-se um Microscópio Eletrônico de Varredura 
(MEV), JEOL JSM-6490LV, operado a $15 \mathrm{kV}$, com detector de Dispersão de Energia de Raios-X acoplado.

A Espectroscopia por Perda de Energia de Elétrons é a análise da distribuição de energia dos elétrons que saem da amostra, produto da interação do feixe incidente com a estrutura interna do material. Esses elétrons podem sofrer ou não perda de energia (espalhamento inelástico). Esses eventos de perda de energia trazem informação valiosa da composição química da amostra (Ahn, 2006). A EELS tem sido utilizada como um complemento para a EDS por possibilitar melhor informação, assim como detecção de elementos de baixo número atômico como o boro (Von Harrach et al., 2010).

Para a técnica por Espectroscopia por Perda de Energia de Elétrons (EELS) utilizou-se um Microscópio Eletrônico de Transmissão (MET) no modo varredura/transmissão, operado a 200kV.

Os microscópios utilizados estão localizados no Laboratório Multiusuário de Nanociência e Nanotecnologia - LabNano, CBPF-RJ.

\subsection{6. \\ Determinação da concentração de boro}

As análises das amostras filtradas contendo boro foram realizadas em um Espectrômetro de Emissão Ótica com Plasma Indutivamente Acoplado (ICPOES) da marca PerkinElmer, modelo Optima 7300 DV, equipado com câmara ciclônica Glass Expansion (Twinnabar) e nebulizador de fluxo cruzado.

A técnica de ICPOES é baseada na medida da intensidade da radiação emitida, quando um átomo ou íon excitado pelo plasma retorna ao seu estado fundamental. A excitação da espécie ocorre quando seus elétrons mais externos têm seu nível de energia aumentado, passando do estado fundamental para o excitado, devido à colisão com elétrons ou íons argônio existentes no plasma. O elétron não é estável em níveis mais altos de energia, portanto, retorna a seu estado fundamental, emitindo a energia que foi absorvida sob a forma de energia luminosa (Olesik, 1991). A técnica de ICPOES é uma técnica multielementar, executa grande número de determinações em muito pouco tempo, além de poder ser aplicada a diferentes concentrações (Montaser et al., 1992). 
As condições operacionais utilizadas na determinação de boro estão apresentadas na Tabela 4 .

Tabela 4 - Condições operacionais utilizadas na determinação de boro por ICPOES. Elaborada pelo autor.

\begin{tabular}{|c|c|}
\hline Parâmetro & Valores \\
\hline Potência aplicada $(\mathrm{W})$ & 1400 \\
\hline Ar plasma (L/min) & 15 \\
\hline Ar auxiliar (L/min) & 1,0 \\
\hline Ar de nebulização (L/min) & 0,60 \\
\hline Taxa de aspiração da amostra (mL/min) & 1,5 \\
\hline Modo de detecção & Área de pico \\
\hline Visão & Radial \\
\hline
\end{tabular}

\subsection{7.}

\section{Modelo cinético}

Foi estudada a cinética do processo de remoção de boro por eletrocoagulação através de experimentos com a utilização de diferentes concentrações iniciais de boro $(12,5 \mathrm{mg} / \mathrm{L}, 25 \mathrm{mg} / \mathrm{L}, 50 \mathrm{mg} / \mathrm{L}$ e $100 \mathrm{mg} / \mathrm{L})$, diferentes valores de $\mathrm{pH}$ inicial $(3,4,5,6,7$ e 8$)$ e diferentes valores de densidade de corrente $\left(6,25 \mathrm{~mA} / \mathrm{cm}^{2}, 12,50 \mathrm{~mA} / \mathrm{cm}^{2}\right.$ e $\left.18,75 \mathrm{~mA} / \mathrm{cm}^{2}\right)$. Essas condições experimentais são apresentadas na Tabela 5. Os experimentos foram ajustados aos modelos de pseudo-primeira ordem e de pseudo-segunda ordem (Levenspiel, 1999), os valores de $\mathrm{R}^{2}$ foram utilizados para avaliar a qualidade dos ajustes.

Tabela 5 - Condições experimentais para determinar a constante cinética. Elaborada pelo autor.

\begin{tabular}{|c|c|}
\hline Parâmetros & Valor \\
\hline Concentração inicial de boro $(\mathbf{m g} / \mathbf{L})$ & $12,5,25,50,100$ \\
\hline pH inicial & $3,4,5,6,7$ e 8 \\
\hline Densidade de corrente $\left(\mathbf{m A} / \mathbf{c m}^{2}\right)$ & $6,25,12,50$ e 18,75 \\
\hline Tempo $(\mathbf{m i n})$ & $5,10,15,20,40,60$ e 90 \\
\hline
\end{tabular}




\subsection{8.}

Isotermas de adsorção

Para a obtenção das isotermas de adsorção, foram realizados experimentos à temperatura constante de $25^{\circ} \mathrm{C}$, através de experimentos com a utilização de diferentes concentrações iniciais de boro $(12,5 \mathrm{mg} / \mathrm{L}, 25 \mathrm{mg} / \mathrm{L}, 50 \mathrm{mg} / \mathrm{L}$ e $100 \mathrm{mg} / \mathrm{L})$. Essas condições experimentais são apresentadas na Tabela 6. Os modelos avaliados foram os de Langmuir e Freundlich (Redlich et al., 1959).

Tabela 6 - Condições experimentais para determinar o modelo de isoterma de adsorção. Elaborada pelo autor.

\begin{tabular}{|c|c|}
\hline Parâmetros & Valor \\
\hline Concentração inicial de boro $\mathbf{( m g / L )}$ & $12,5,25,50,100$ \\
\hline $\mathbf{p H}$ inicial & $\mathrm{pH}_{0}=4$ \\
\hline Densidade de corrente $\left(\mathbf{m A} / \mathbf{c m}^{2}\right)$ & 12,50 \\
\hline
\end{tabular}




\section{5 \\ Resultados e discussão}

Neste capítulo são apresentados os resultados obtidos ao longo da pesquisa, referentes aos efeitos dos parâmetros operacionais de eletrocoagulação, determinação do modelo cinético, estudos de equilíbrio da adsorção do boro, avaliação microscópica da superfície dos eletrodos de alumínio, caracterização do lodo produzido no processo de eletrocoagulação e a otimização das condições experimentais através da modelagem e análise estatística.

\section{1.}

\section{Efeitos dos parâmetros operacionais de eletrocoagulação}

Nesta seção, os seguintes parâmetros operacionais foram investigados: $\mathrm{pH}$ inicial $\left(\mathrm{pH}_{0}\right)$ e densidade de corrente $(\mathrm{J})$. Foram discutidos os efeitos de interação entre esses parâmetros, assim como o efeito do tempo de eletrólise no processo de eletrocoagulação.

\subsection{1.}

\section{Efeito do pH inicial}

$\mathrm{O}$ pH inicial é um parâmetro que afeta fortemente o desempenho do processo de eletrocoagulação, sobretudo a especiação do cátion $\mathrm{Al}^{3+}$ (Mouedhen et al., 2008). O pH se incrementa durante o processo de eletrocoagulação devido à geração de ânions hidroxila no catodo, que compensam a acidez dos cátions de alumínio gerados no anodo. Consequentemente, o intervalo de valores de $\mathrm{pH}$ que a solução exibe ao longo do tempo de eletrólise desempenha um papel fundamental (Mollah et al., 2001).

As Figuras 20 a 25 apresentam a evolução do pH da solução durante o processo de eletrocoagulação para diferentes valores de $\mathrm{pH}$ inicial $(3,4,5,6,7$ e 8) e de densidade de corrente $\left(6,25 \mathrm{~mA} / \mathrm{cm}^{2}, 12,50 \mathrm{~mA} / \mathrm{cm}^{2}\right.$ e $\left.18,75 \mathrm{~mA} / \mathrm{cm}^{2}\right)$. Observa-se que o efeito da densidade de corrente sobre a evolução do $\mathrm{pH}$ da solução ao longo do processo de eletrocoagulação é mínimo. Isso porque o 
aumento da densidade de corrente promove tanto o acréscimo da quantidade de ânions hidroxila produzidos no catodo quanto a maior geração dos cátions de alumínio (ácido de Lewis) no anodo. Além disso, quando o $\mathrm{pH}_{0}<6$ a evolução do $\mathrm{pH}$ ao longo do tempo de eletrólise apresenta um aumento acentuado, enquanto que nas soluções com o $\mathrm{pH}_{0}>6$ o aumento é mais moderado.

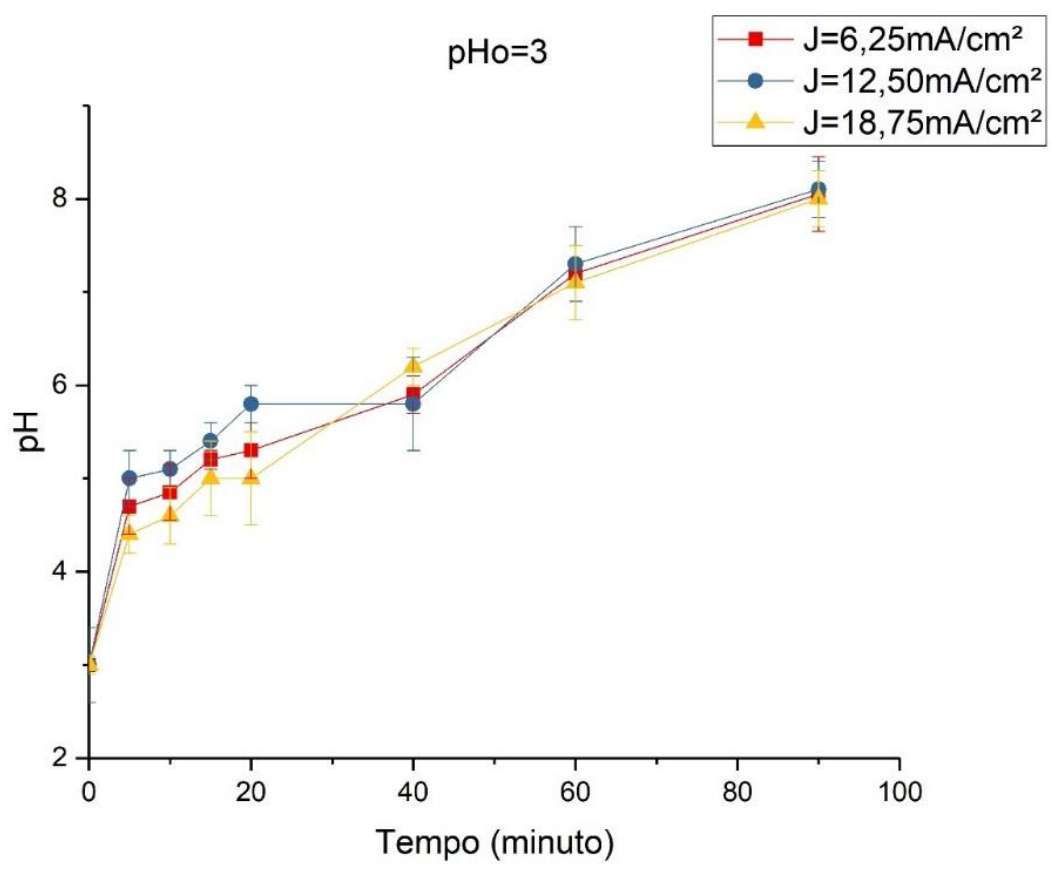

Figura 20 - Evolução do pH da solução durante o processo de eletrocoagulação para $\mathrm{pH}_{0}$ $=3$ em diferentes valores de densidade de corrente $([\mathrm{NaCl}]=15 \mathrm{mM} ; \mathrm{RPM}=250 ; \mathrm{d}=$ $10 \mathrm{~mm})$. Elaborada pelo autor. 


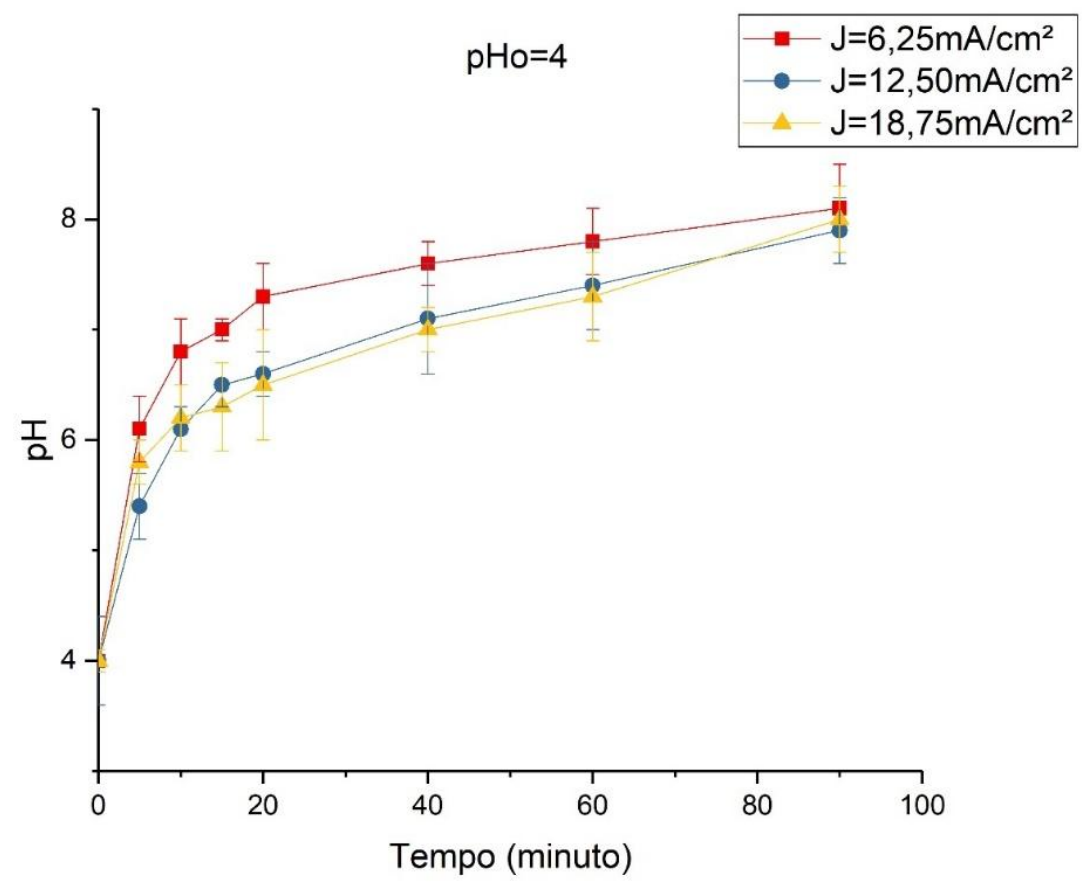

Figura 21 - Evolução do pH da solução durante o processo de eletrocoagulação para $\mathrm{pH}_{0}$ $=4$ em diferentes valores de densidade de corrente $([\mathrm{NaCl}]=15 \mathrm{mM} ; \mathrm{RPM}=250 ; \mathrm{d}=$ $10 \mathrm{~mm})$. Elaborada pelo autor.

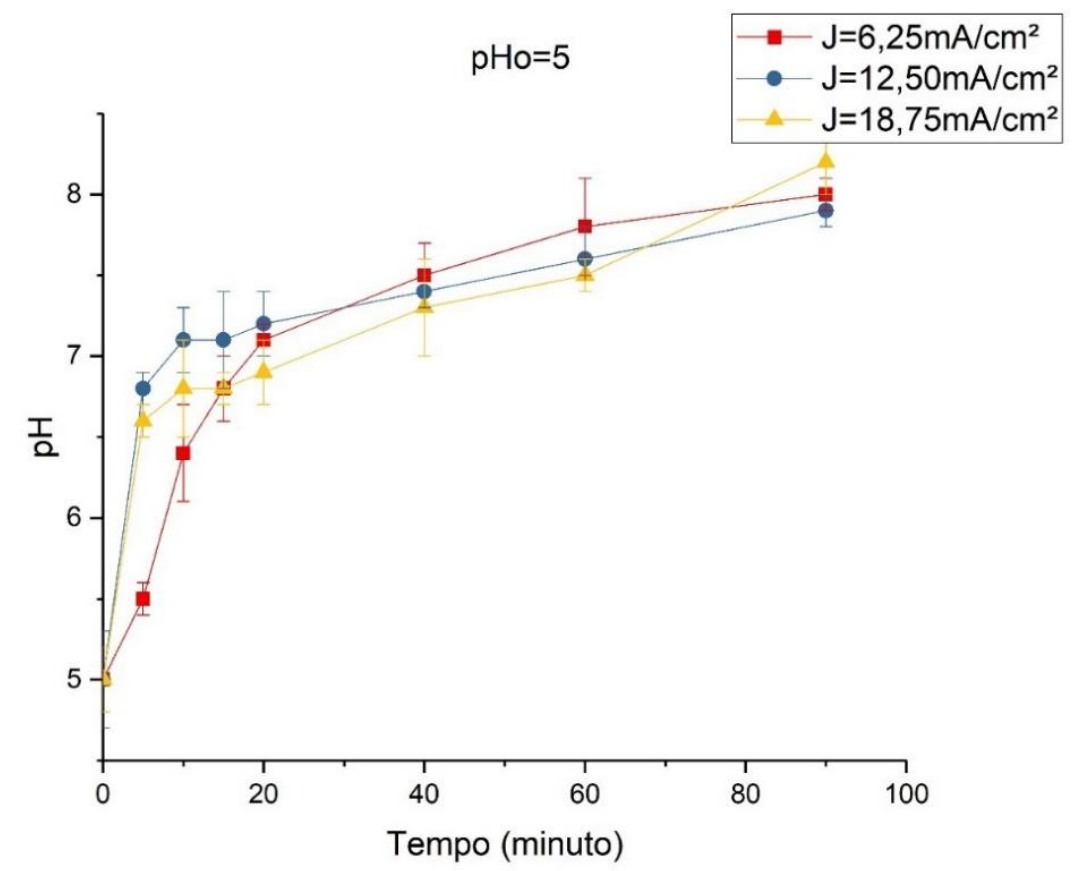

Figura 22 - Evolução do pH da solução durante o processo de eletrocoagulação para $\mathrm{pH}_{0}$ $=5$ em diferentes valores de densidade de corrente $([\mathrm{NaCl}]=15 \mathrm{mM} ; \mathrm{RPM}=250 ; \mathrm{d}=$ $10 \mathrm{~mm})$. Elaborada pelo autor. 


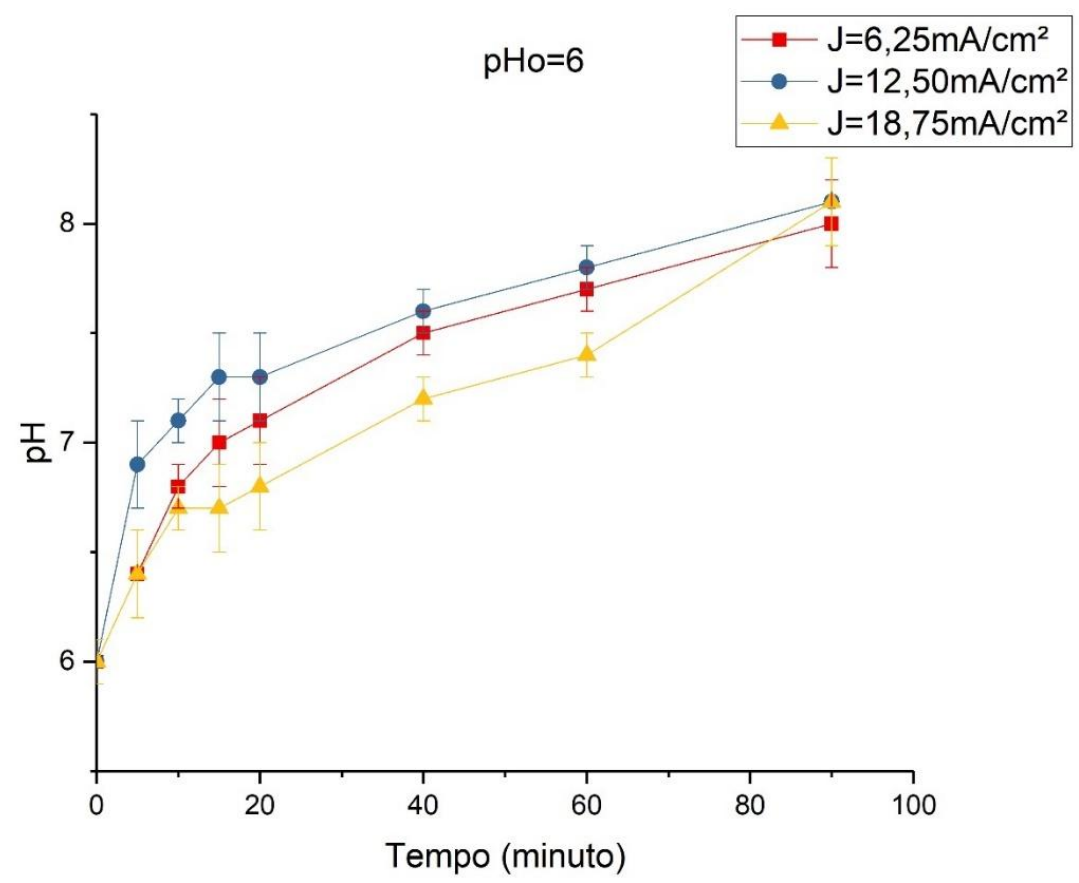

Figura 23 - Evolução do pH da solução durante o processo de eletrocoagulação para $\mathrm{pH}_{0}$ $=6$ em diferentes valores de densidade de corrente $([\mathrm{NaCl}]=15 \mathrm{mM} ; \mathrm{RPM}=250 ; \mathrm{d}=$ $10 \mathrm{~mm})$. Elaborada pelo autor.

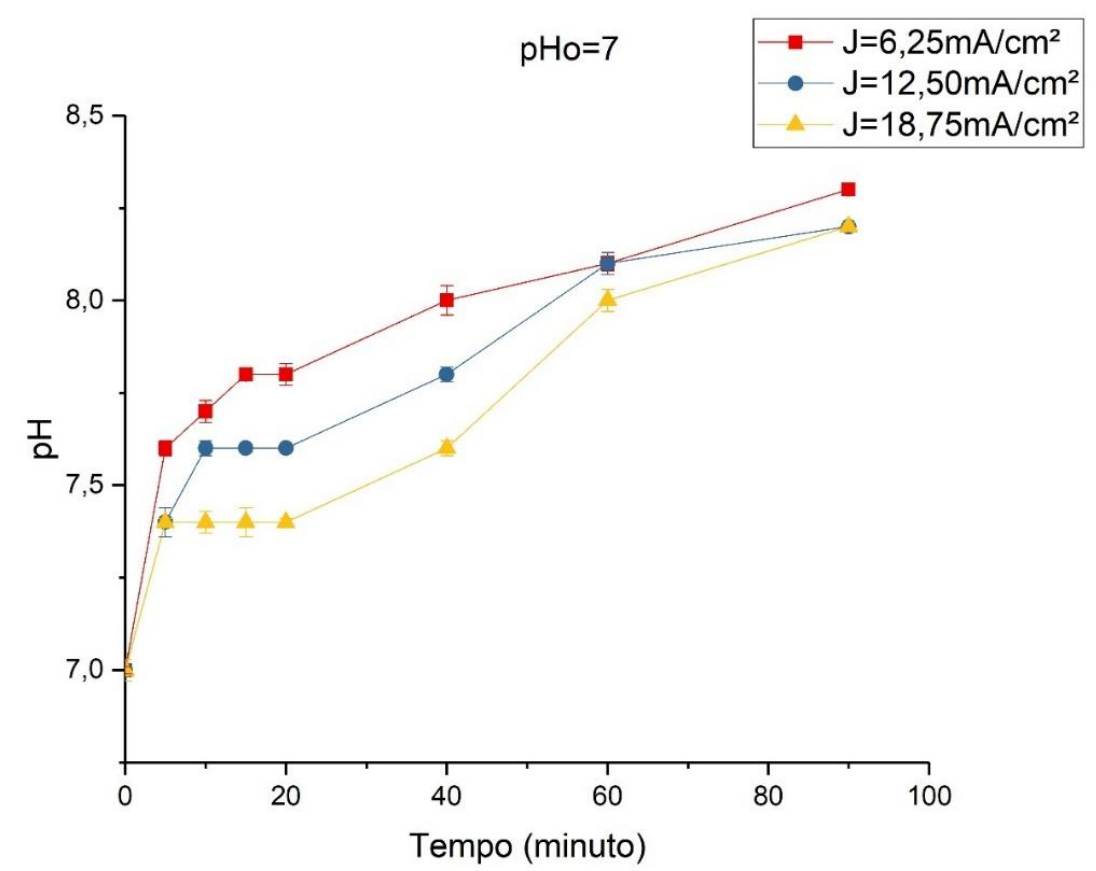

Figura 24 - Evolução do pH da solução durante o processo de eletrocoagulação para $\mathrm{pH}_{0}$ $=7$ em diferentes valores de densidade de corrente $([\mathrm{NaCl}]=15 \mathrm{mM} ; \mathrm{RPM}=250 ; \mathrm{d}=$ $10 \mathrm{~mm})$. Elaborada pelo autor. 


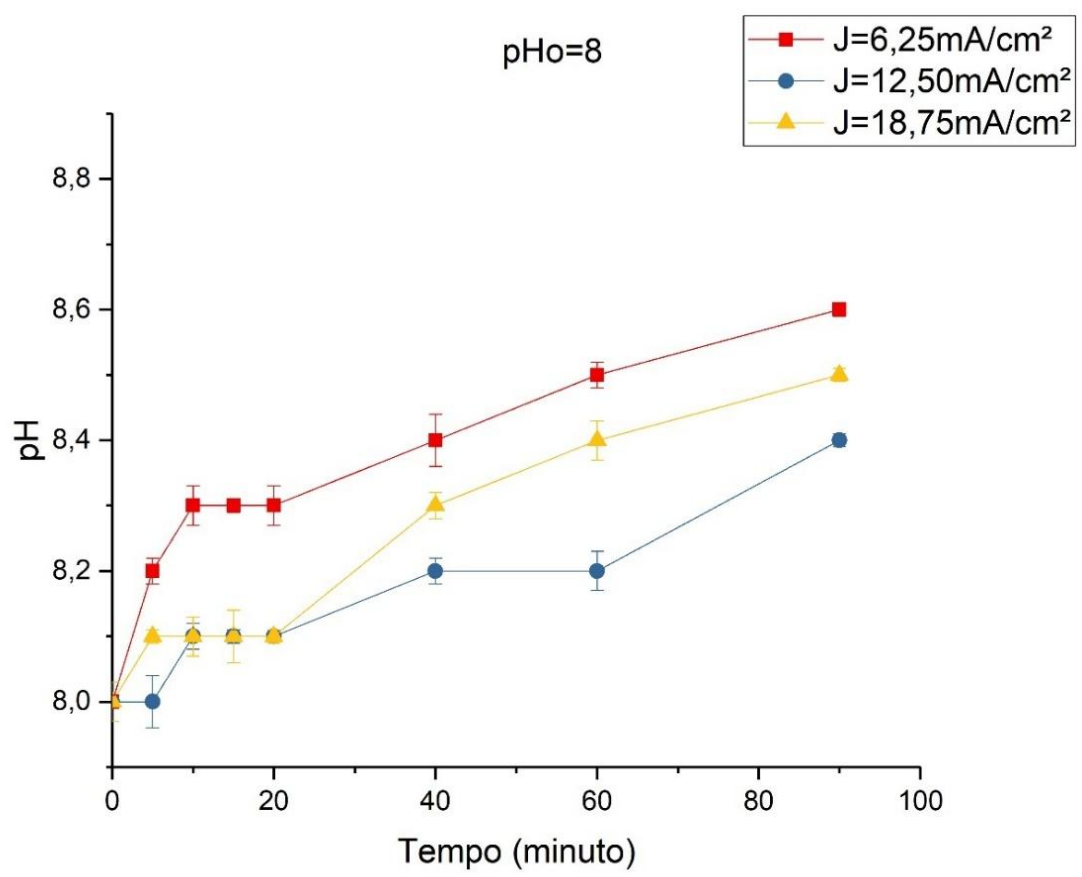

Figura 25 - Evolução do $\mathrm{pH}$ da solução durante o processo de eletrocoagulação para $\mathrm{pH}_{0}$ $=8$ em diferentes valores de densidade de corrente $([\mathrm{NaCl}]=15 \mathrm{mM} ; \mathrm{RPM}=250 ; \mathrm{d}=$ $10 \mathrm{~mm})$. Elaborada pelo autor.

As Figuras 26, 27 e 28 apresentam a remoção de boro (\%) em função do tempo de eletrólise para diferentes valores de $\mathrm{pH}$ inicial $(3,4,5,6,7$ e 8$)$ e de densidade de corrente $\left(6,25 \mathrm{~mA} / \mathrm{cm}^{2}, 12,50 \mathrm{~mA} / \mathrm{cm}^{2}\right.$ e $\left.18,75 \mathrm{~mA} / \mathrm{cm}^{2}\right)$. Observa-se que a maior remoção de boro foi alcançada em $\mathrm{pH}_{0}=4$. Diversos autores (Yilmaz et al., 2005; Isa et al., 2014) encontraram em $\mathrm{pH}_{0}=7$ a maior eficiência de remoção de boro. Essa divergência pode ser justificada em razão da diferente condição experimental, uma vez que os autores mantiveram o pH da solução constante ao longo do processo de eletrocoagulação. 


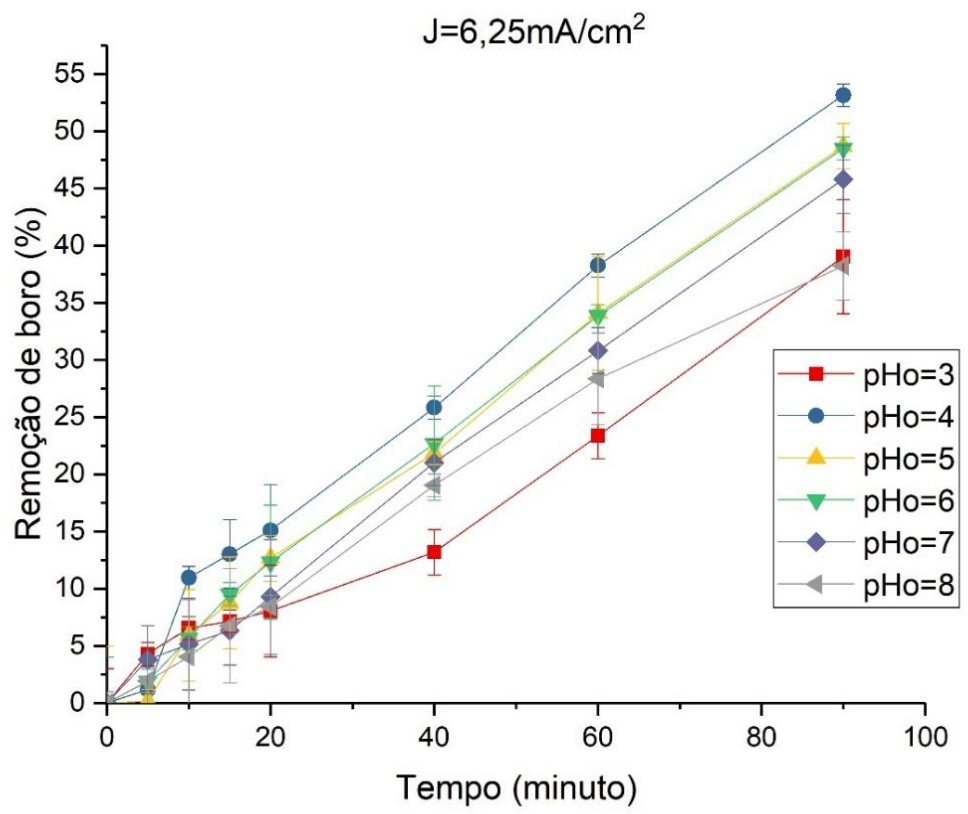

Figura 26 - Remoção de boro (\%) em função do tempo de eletrólise para $\mathrm{J}=6,25 \mathrm{~mA} / \mathrm{cm}^{2}$ em diferentes valores de $\mathrm{pH}$ inicial $([\mathrm{NaCl}]=15 \mathrm{mM} ; \mathrm{RPM}=250 ; \mathrm{d}=10 \mathrm{~mm})$. Elaborada pelo autor.

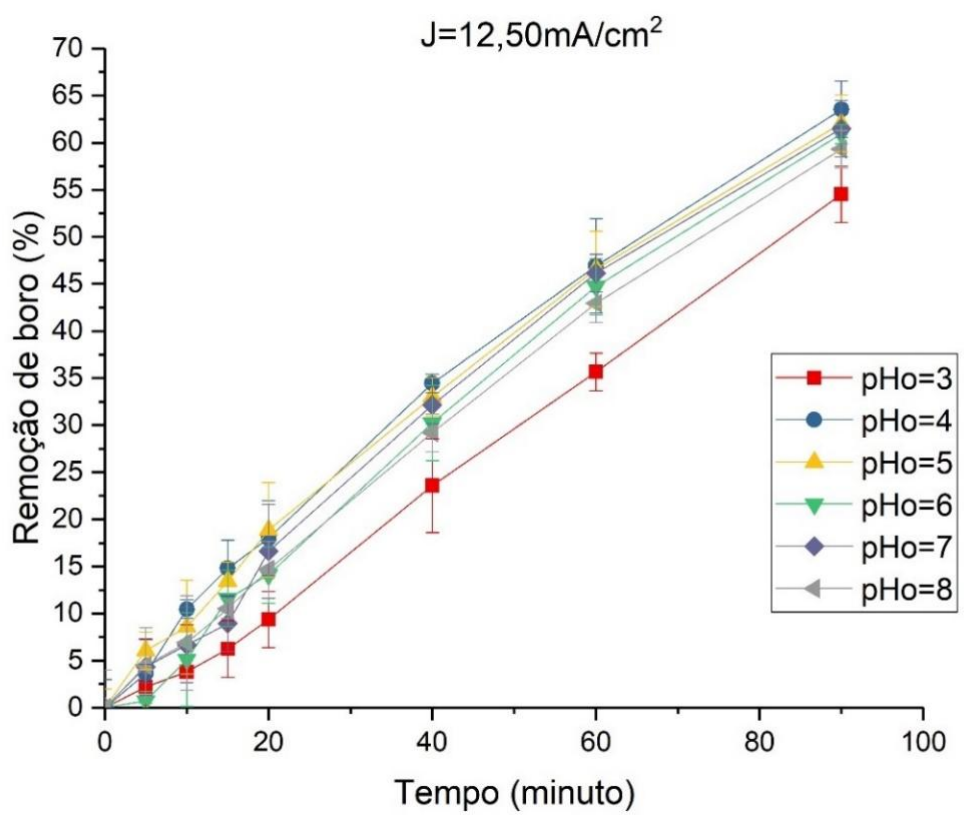

Figura 27 - Remoção de boro (\%) em função do tempo de eletrólise para $\mathrm{J}=$ $12,50 \mathrm{~mA} / \mathrm{cm}^{2}$ em diferentes valores de $\mathrm{pH}$ inicial $([\mathrm{NaCl}]=15 \mathrm{mM} ; \mathrm{RPM}=250 ; \mathrm{d}=$ $10 \mathrm{~mm})$. Elaborada pelo autor. 


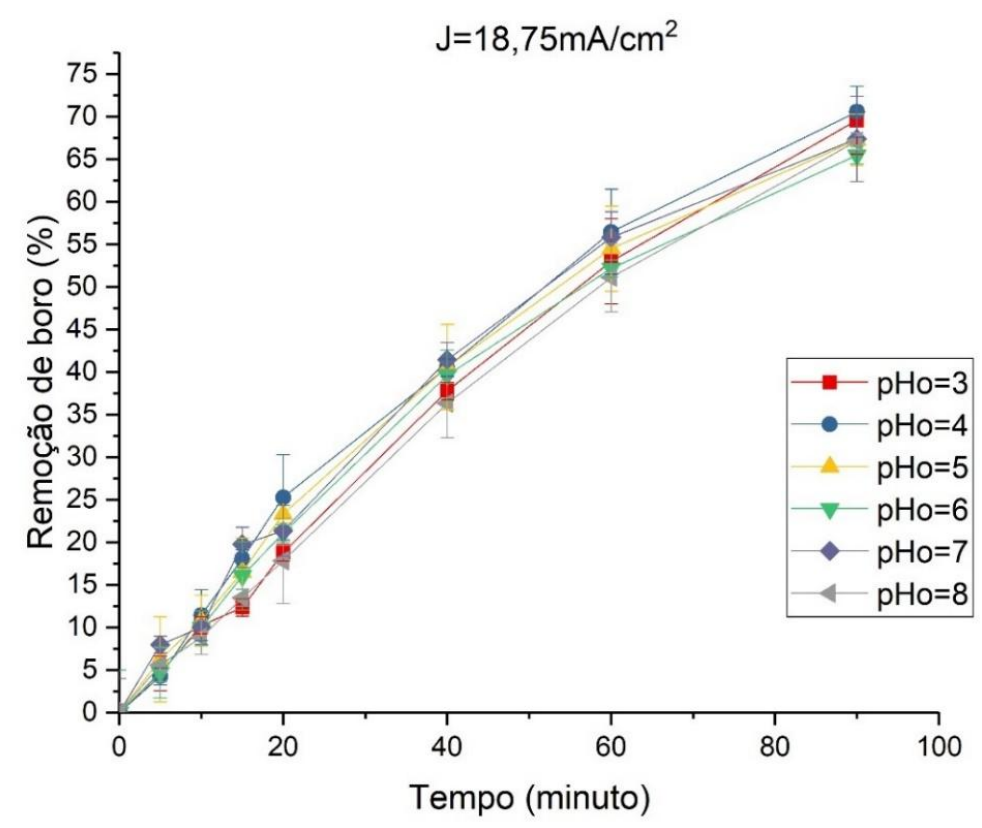

Figura 28 - Remoção de boro (\%) em função do tempo de eletrólise para $\mathrm{J}=$ $18,75 \mathrm{~mA} / \mathrm{cm}^{2}$ em diferentes valores de $\mathrm{pH}$ inicial $([\mathrm{NaCl}]=15 \mathrm{mM} ; \mathrm{RPM}=250 ; \mathrm{d}=$ $10 \mathrm{~mm})$. Elaborada pelo autor.

$\mathrm{O}$ efeito do $\mathrm{pH}$ na remoção de boro pode ser compreendido em função da especiação do alumínio. É sabido que a especiação do alumínio em solução aquosa também depende do $\mathrm{pH}$, além da concentração total de alumínio (Canizares et al., 2005). Portanto, a análise da evolução do pH ao longo do processo de eletrocoagulação mostra-se fundamental para uma verdadeira compreensão dos fenômenos envolvidos e, consequentemente, do mecanismo de remoção dominante.

\subsubsection{1.}

\section{Avaliação do mecanismo de remoção dominante}

A avaliação do mecanismo de remoção dominante requer a identificação das espécies hidrolisadas do cátion metálico e a compreensão da natureza do contaminante, em especial, o seu valor de potencial zeta.

Em relação à identificação das espécies hidrolisadas, Cañizares et al. (2005) caracterizaram as espécies hidrolisadas do alumínio, geradas durante a eletrodissolução do anodo, utilizando uma técnica espectrofotométrica. Esses 
autores mostraram que em $\mathrm{pH}<5$ os cátions monoméricos de hidroxialumínio são as espécies predominantes. $\mathrm{O}$ aumento do $\mathrm{pH}$ provoca um declínio das espécies catiônicas monoméricas de hidroxialumínio e um aumento dos precipitados de hidróxido de alumínio, que representam a espécie predominante de alumínio em 5 $<\mathrm{pH}<8$. Em $\mathrm{pH}>8$ o precipitado dissolve-se para formar espécies aniônicas monoméricas de hidroxialumínio em solução.

Em relação à compreensão da natureza do contaminante, é sabido que o processo de coagulação e, consequentemente, os mecanismos de remoção são limitados pelo potencial zeta, a coagulação ocorre à medida que esse potencial é reduzido (Hunter, 2013). O potencial zeta do ácido bórico foi medido em uma solução sem eletrólito suporte e variando o pH com o auxílio de soluções de $\mathrm{NaOH}$ e de $\mathrm{HCl}$. Nessas condições, obteve-se os valores apresentados na Figura 29.

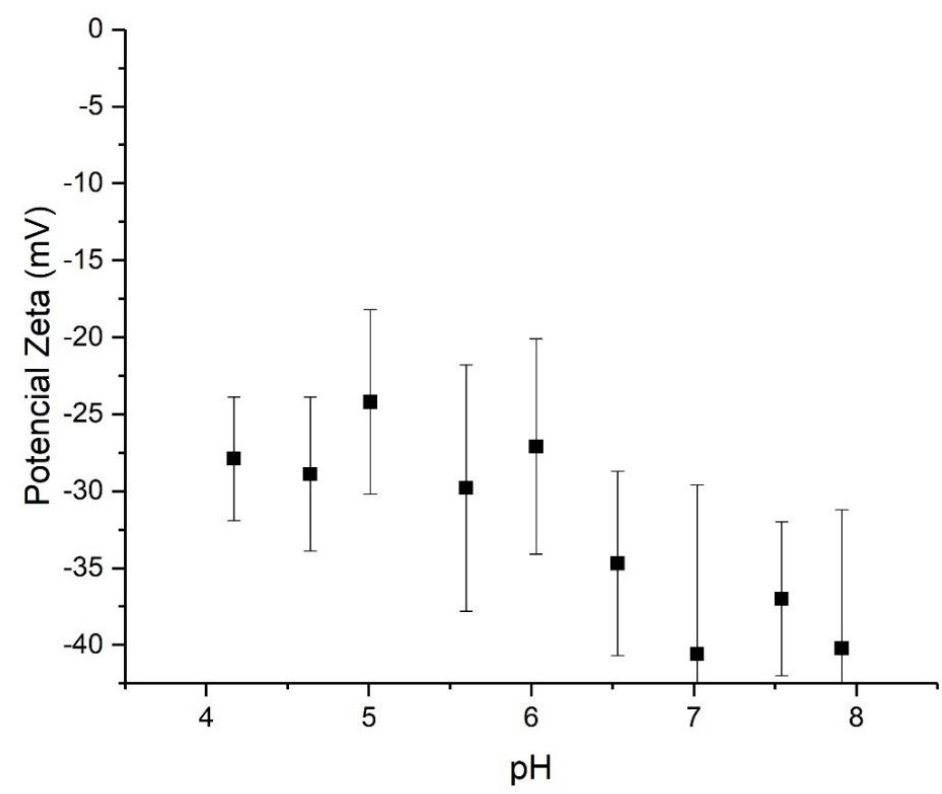

Figura 29 - Variação do potencial zeta do ácido bórico em função do pH sem eletrólito suporte. Elaborada pelo autor.

Em toda a extensão do $\mathrm{pH}$ analisado, o ácido bórico apresenta potencial zeta negativo, portanto a dispersão coloidal permanece estabilizada. Esse resultado 
indica que para uma melhor coagulação é necessário que ocorra a desestabilização das partículas.

A remoção de boro (\%) em função do tempo de eletrólise e da evolução do $\mathrm{pH}$ ao longo do processo de eletrocoagulação para diferentes valores de $\mathrm{pH}$ inicial (3, 4, 5, 6, 7 e 8), mantendo fixa a densidade de corrente em $6,25 \mathrm{~mA} / \mathrm{cm}^{2}$, é apresentada nas Figuras 30 a 35. Além disso, observa-se, nessas Figuras, as espécies presentes na solução com base no diagrama de especiação do alumínio para as condições experimentais.

- Mecanismo de remoção dominante em $\mathrm{pH}_{0}=3$

Na Figura 30, em $\mathrm{pH}_{0}=3$, observa-se, com base no cálculo dos equilíbrios termodinâmicos, a predominância dos cátions monoméricos durante os primeiros 10 minutos do processo. A predominância do hidróxido de alumínio ocorre a partir dos 10 minutos e continua até o término do processo de eletrocoagulação.

Ao longo dos primeiros 10 minutos do processo, os cátions monoméricos, que representam a espécie predominante, servem para neutralizar a carga negativa do ácido bórico e, então, microflocos são formados, em um mecanismo de neutralização de carga (Edzwald, 1993). Os microflocos são agregados para formar flocos maiores que possibilitam a remoção por sedimentação ou por flotação. Esse mecanismo de remoção foi observado como predominante em $\mathrm{pH}<$ 5 por Uduman et al. (2011), na remoção de biomassa de algas por eletrocoagulação, e por El-Taweel et al. (2015), na remoção de $\operatorname{Cr}(\mathrm{VI})$ por eletrocoagulação.

Após os primeiros 10 minutos do processo, o mecanismo de remoção dominante altera-se para envolver os precipitados de hidróxido de alumínio, que representam a espécie predominante, em um mecanismo de floculação por varredura (Duan et al., 2003). Esse mecanismo de remoção foi observado como predominante em $5<\mathrm{pH}<8$ por Amani-Ghadim et al. (2013), na remoção de corantes azo por eletrocoagulação, e por Zaroual et al. (2006), no tratamento de um efluente têxtil por eletrocoagulação.

A baixa eficiência de remoção de boro nesse $\mathrm{pH}$ inicial pode estar relacionada ao fenômeno de reversão de carga. O mecanismo de neutralização de carga permite a reestabilização das partículas coloidais quando se aplica uma 
superdosagem do coagulante, através da reversão de carga superficial (Edzwald, 1993). A reversão de carga superficial em razão da superdosagem de coagulante foi observada por Kiliç et al. (2009) na remoção de partículas ultrafinas de quartzo.

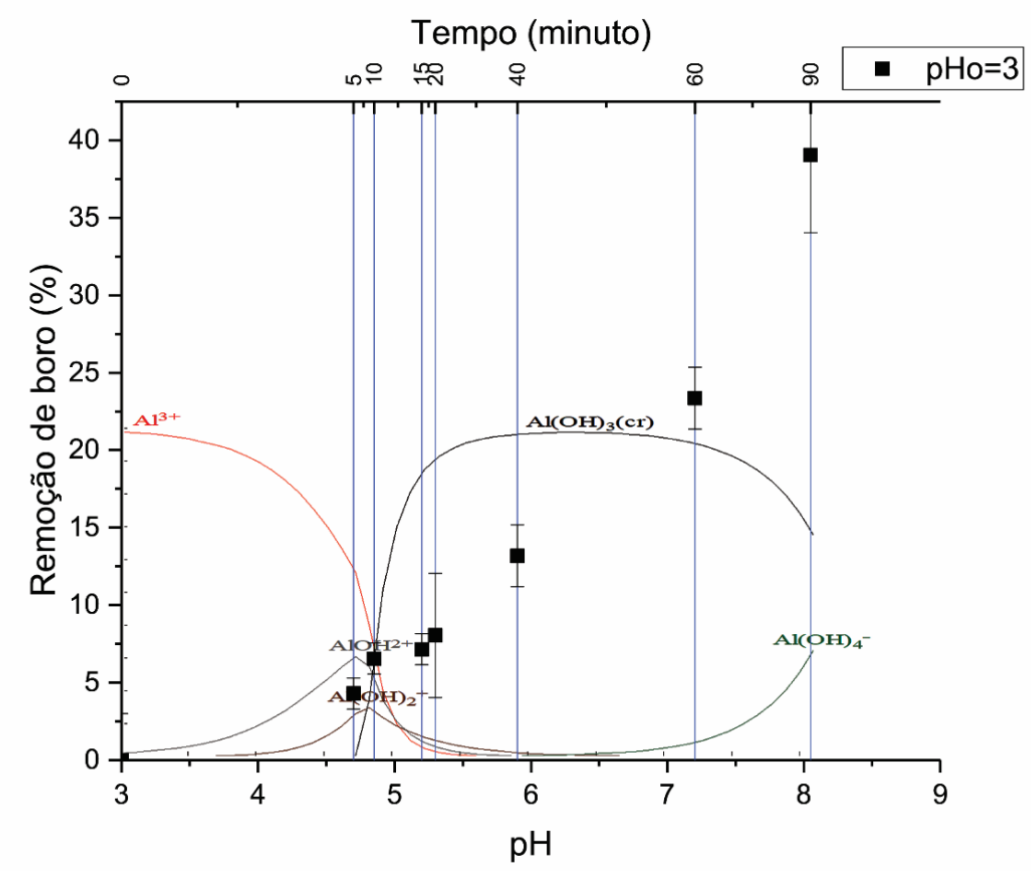

Figura 30 - Comportamento do $\mathrm{pH}$ ao longo do tempo em $\mathrm{pH}_{0}=3([\mathrm{NaCl}]=15 \mathrm{mM} ; \mathrm{RPM}$ $\left.=250 ; d=10 \mathrm{~mm} ; \mathrm{J}=6,25 \mathrm{~mA} / \mathrm{cm}^{2}\right)$. Elaborada pelo autor.

- Mecanismo de remoção dominante em $\mathrm{pH}_{0}=4$

Na Figura 31, em $\mathrm{pH}_{0}=4$, observa-se, com base no cálculo dos equilíbrios termodinâmicos, a predominância dos cátions monoméricos durante os primeiros instantes do processo $(\mathrm{t}<5 \mathrm{~min})$. A predominância do hidróxido de alumínio ocorre a partir dos 5 minutos e continua até o término do processo de eletrocoagulação.

Nesse pH inicial atinge-se a melhor eficiência de remoção de boro. Observa-se que a remoção de boro em 5 minutos é mínima; e após, o mecanismo de remoção dominante, durante todo o processo, é a floculação por varredura.

É provável que ocorra uma ação conjunta, inicialmente, com a desestabilização das partículas de ácido bórico através das interações com os 
cátions monoméricos presentes na solução e, posteriormente, com a adsorção dessas partículas no precipitado de hidróxido de alumínio. Essa interação entre os dois mecanismos foi observada por Dominguez et al. (2007) no tratamento de um efluente de processamento de cortiça.

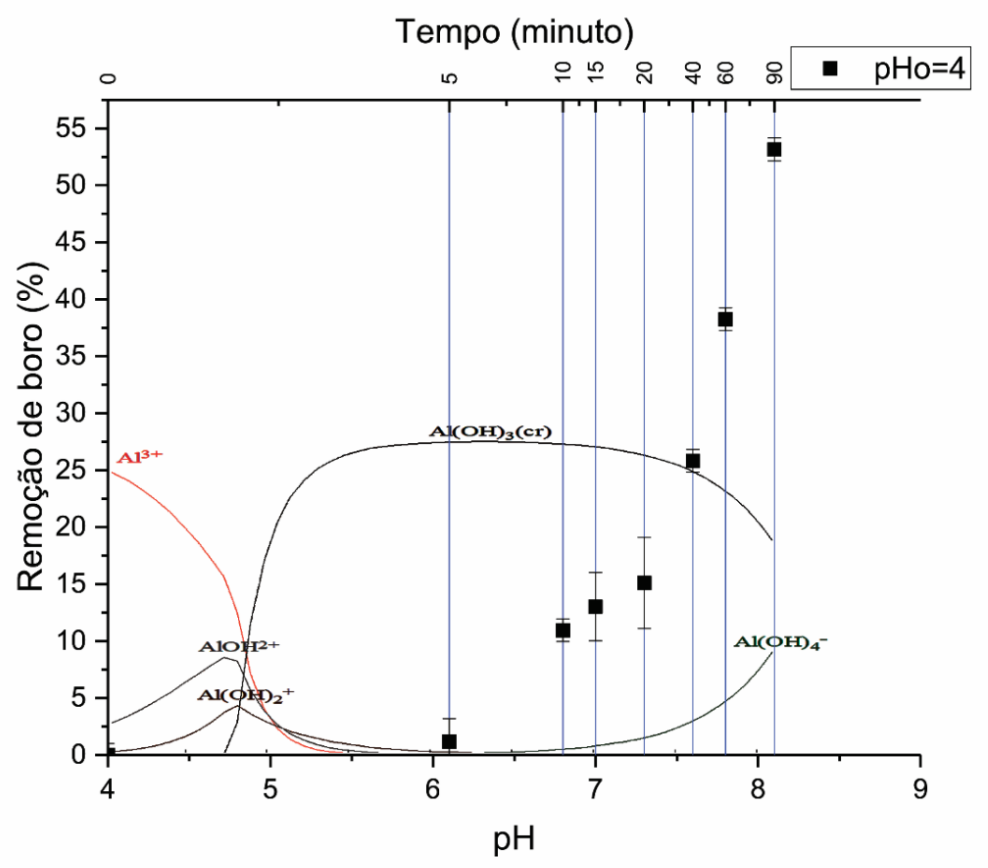

Figura 31 - Comportamento do $\mathrm{pH}$ ao longo do tempo em $\mathrm{pH}_{0}=4([\mathrm{NaCl}]=15 \mathrm{mM} ; \mathrm{RPM}$ $=250 ; \mathrm{d}=10 \mathrm{~mm} ; \mathrm{J}=6,25 \mathrm{~mA} / \mathrm{cm}^{2}$ ). Elaborada pelo autor.

- Mecanismo de remoção dominante em $\mathrm{pH}_{0}=5$

Na Figura 32, em $\mathrm{pH}_{0}=5$, observa-se, com base no cálculo dos equilíbrios termodinâmicos, a predominância dos cátions monoméricos durante os primeiros instantes do processo $(\mathrm{t}<5 \mathrm{~min})$. A predominância do hidróxido de alumínio ocorre a partir dos 5 minutos e continua até o término do processo de eletrocoagulação.

Nesse valor de $\mathrm{pH}$ inicial atinge-se a segunda melhor eficiência de remoção de boro. O mecanismo de remoção dominante, durante todo o processo, é a floculação por varredura. A fenomenologia é similar àquela detalhada em $\mathrm{pH}_{0}=4$. 


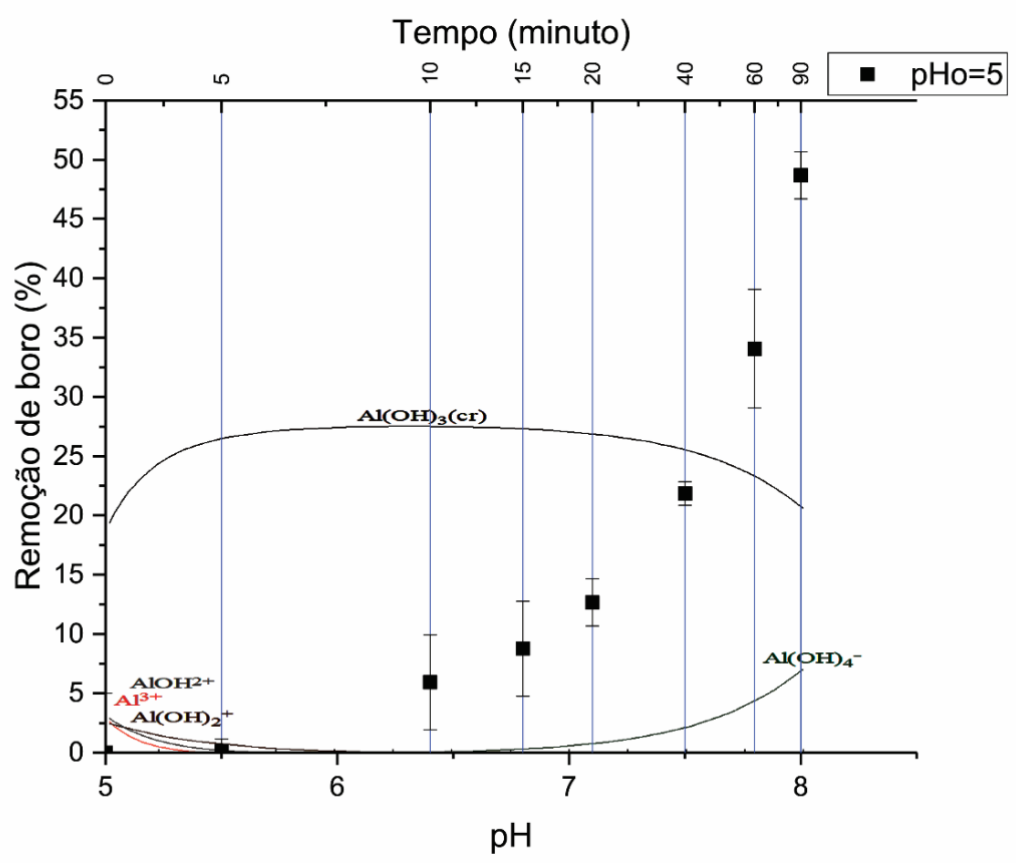

Figura 32 - Comportamento do $\mathrm{pH}$ ao longo do tempo em $\mathrm{pH}_{0}=5([\mathrm{NaCl}]=15 \mathrm{mM} ; \mathrm{RPM}$ $\left.=250 ; \mathrm{d}=10 \mathrm{~mm} ; \mathrm{J}=6,25 \mathrm{~mA} / \mathrm{cm}^{2}\right)$. Elaborada pelo autor.

- Mecanismo de remoção dominante em $\mathrm{pH}_{0} \geq 6$

Nas Figuras 33, 34 e 35, observa-se a ausência dos cátions monoméricos ao longo do processo de eletrocoagulação. A pior eficiência de remoção de boro ocorre em $\mathrm{pH}_{0}=8$. Esse resultado pode ser justificado em razão da dissolução do precipitado de hidróxido de alumínio para formar espécies aniônicas monoméricas de hidroxialumínio em solução (Chen et al., 2000). 


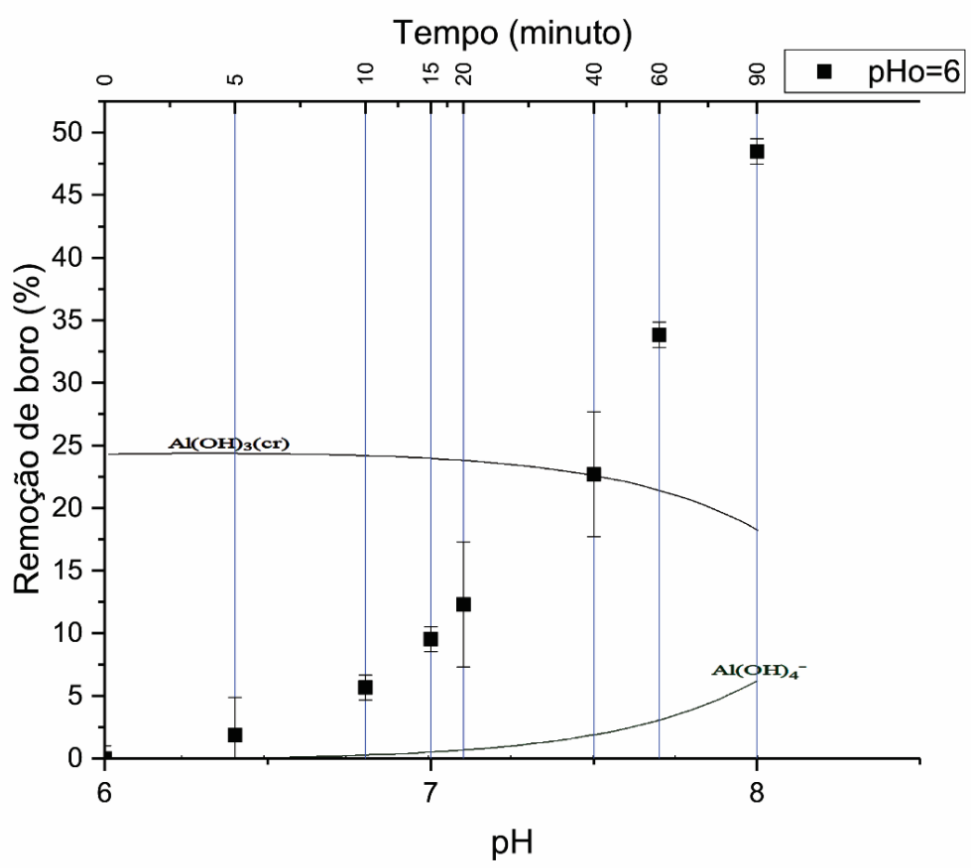

Figura 33 - Comportamento do $\mathrm{pH}$ ao longo do tempo em $\mathrm{pH}_{0}=6([\mathrm{NaCl}]=15 \mathrm{mM} ; \mathrm{RPM}$ $=250 ; \mathrm{d}=10 \mathrm{~mm} ; \mathrm{J}=6,25 \mathrm{~mA} / \mathrm{cm}^{2}$ ). Elaborada pelo autor.

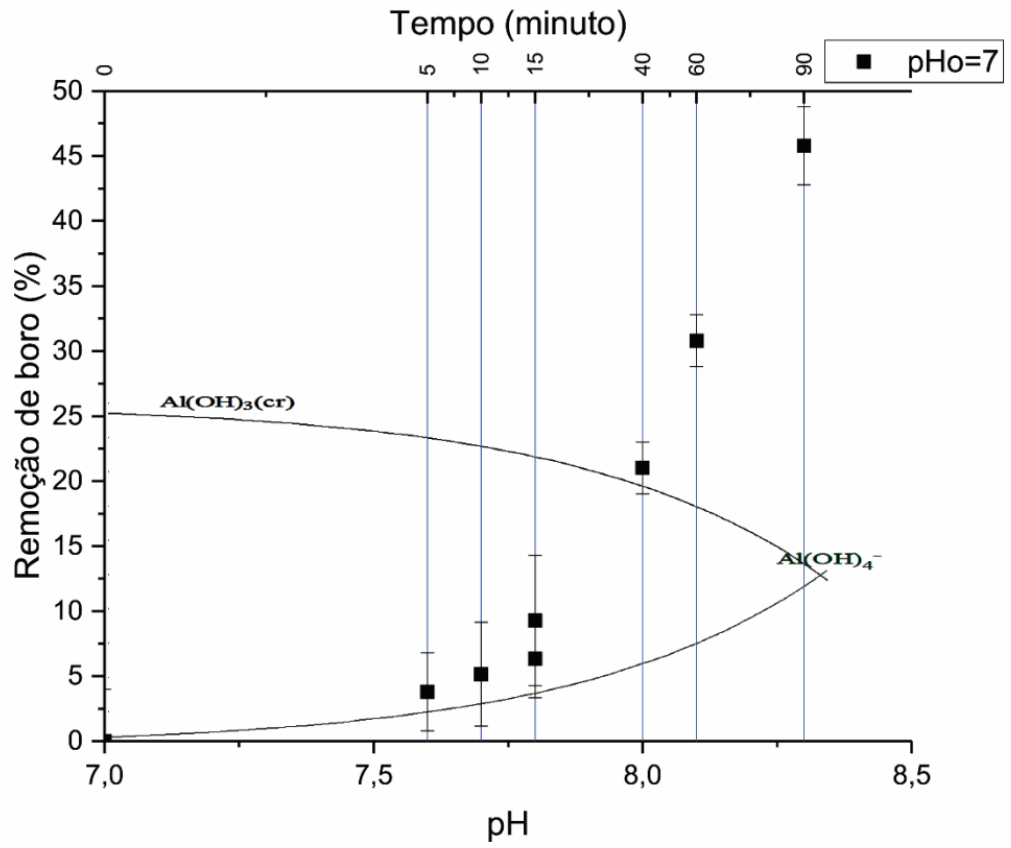

Figura 34 - Comportamento do $\mathrm{pH}$ ao longo do tempo em $\mathrm{pH}_{0}=7([\mathrm{NaCl}]=15 \mathrm{mM} ; \mathrm{RPM}$ $=250 ; \mathrm{d}=10 \mathrm{~mm} ; \mathrm{J}=6,25 \mathrm{~mA} / \mathrm{cm}^{2}$ ). Elaborada pelo autor. 


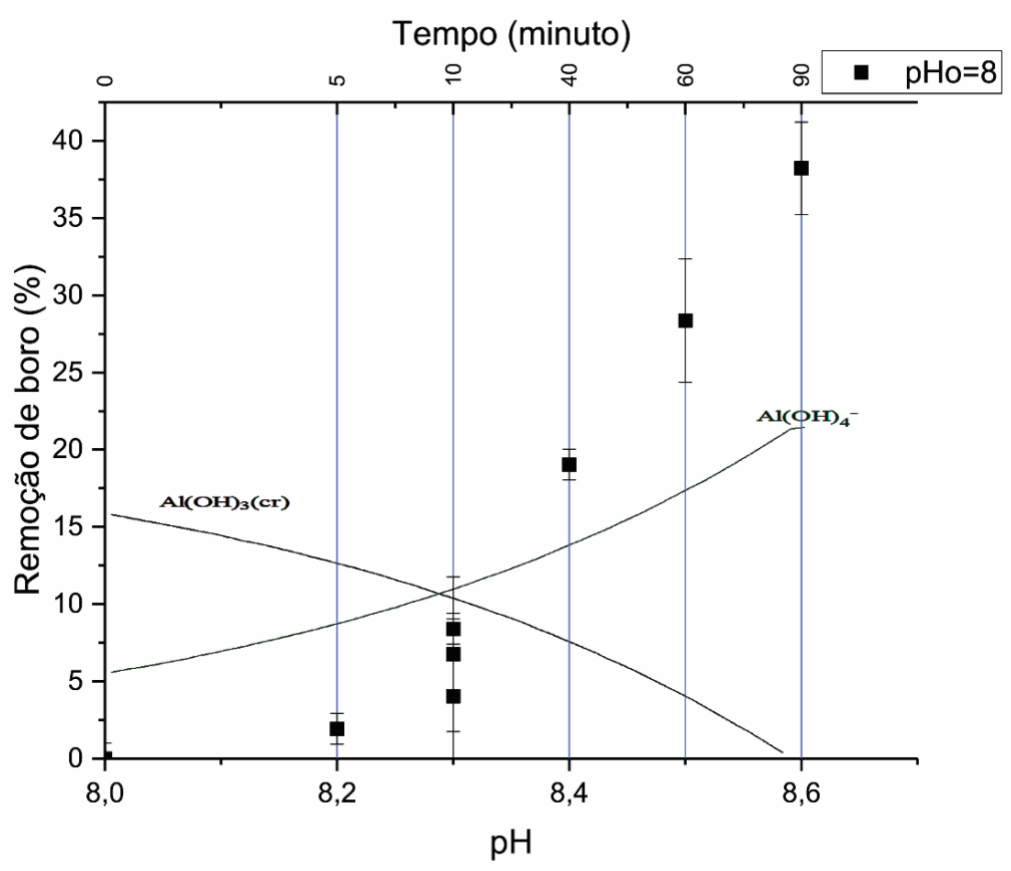

Figura 35 - Comportamento do $\mathrm{pH}$ ao longo do tempo em $\mathrm{pH}_{0}=8([\mathrm{NaCl}]=15 \mathrm{mM} ; \mathrm{RPM}$ $\left.=250 ; \mathrm{d}=10 \mathrm{~mm} ; \mathrm{J}=6,25 \mathrm{~mA} / \mathrm{cm}^{2}\right)$. Elaborada pelo autor.

\subsection{2.}

\section{Efeito da densidade de corrente}

Um parâmetro chave no processo de eletrocoagulação é a densidade de corrente, uma vez que essa exerce uma forte influência sobre a cinética de reação eletroquímica. A densidade de corrente está relacionada à extensão da dissolução anódica. Ao mesmo tempo, a taxa de geração de gases eletrolíticos e o tamanho das bolhas também dependem da densidade de corrente aplicada (Holt et al., 2005). Portanto, a densidade de corrente afeta diretamente a dosagem de coagulante, a remoção do poluente por flotação e a mistura da solução.

A densidade de corrente pode ser relacionada à quantidade de alumínio dissolvido pela lei de Faraday (Bard et al., 1980), conforme apresentada na eq. (34), que fornece a perda de massa teórica do anodo de alumínio.

$m=\frac{I \times t \times 26,98}{289500}$

Onde m é a massa de alumínio dissolvido, em grama, I é a intensidade de corrente, em ampère, e t é o tempo de processo, em segundo. 
Neste estudo, o efeito da densidade de corrente na remoção de boro (\%) em função dos valores de $\mathrm{pH}$ inicial $(3,4,5,6,7$ e 8), conforme apresentado na Figura 36, foi investigado para diferentes valores de densidade de corrente $\left(6,25 \mathrm{~mA} / \mathrm{cm}^{2}, 12,50 \mathrm{~mA} / \mathrm{cm}^{2}\right.$ e $\left.18,75 \mathrm{~mA} / \mathrm{cm}^{2}\right)$, mantendo fixo o tempo de eletrólise $(\mathrm{t}=90 \mathrm{~min})$.

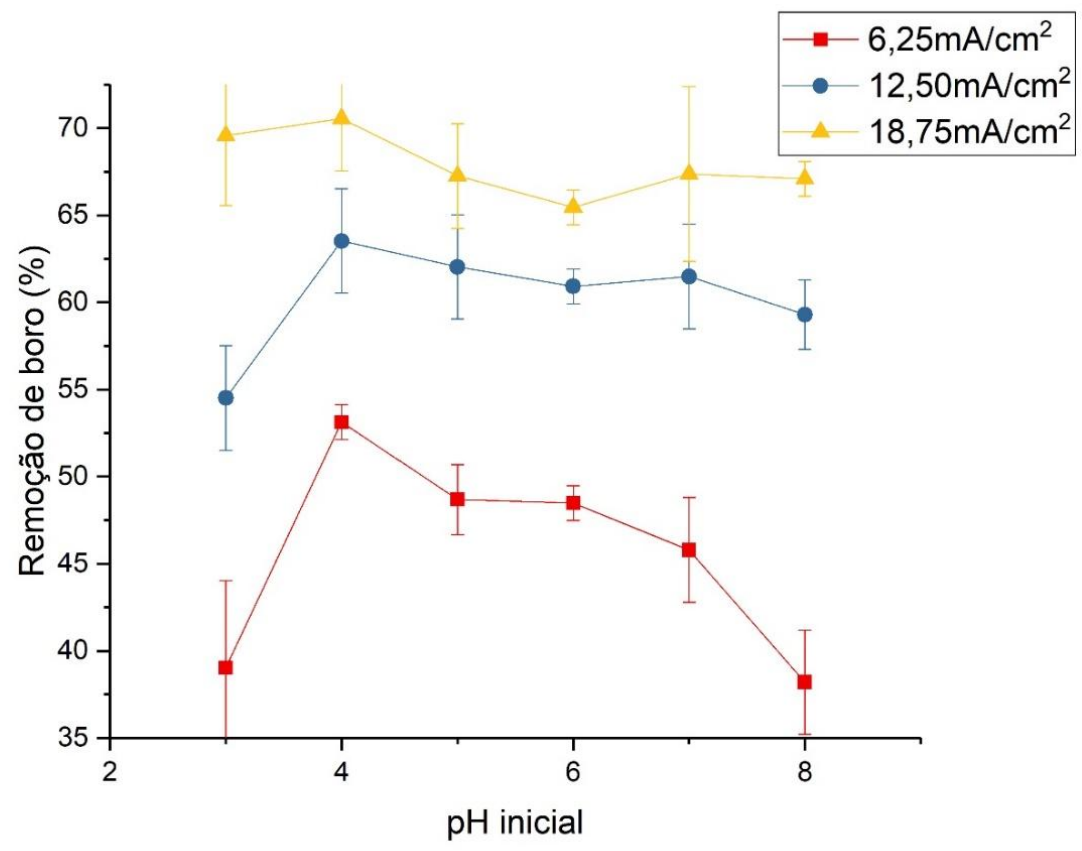

Figura 36 - Efeito da densidade de corrente na remoção de boro (\%) em função dos diferentes valores de $\mathrm{pH}$ inicial $([\mathrm{NaCl}]=15 \mathrm{mM} ; \mathrm{RPM}=250 ; \mathrm{d}=10 \mathrm{~mm} ; \mathrm{t}=90 \mathrm{~min})$. Elaborada pelo autor.

Pode-se verificar, a partir da Figura 36, que a eficiência de remoção de boro aumenta juntamente com a densidade de corrente. Esses resultados convergem com aqueles obtidos por Ezechi et al. (2012). Esse comportamento pode ser justificado em razão da maior geração do cátion $\mathrm{Al}^{3+}$ devido à crescente dissolução anódica e, por consequência, o aumento dos produtos de hidrólise.

Ulu et al. (2014) estudaram a influência de diversos parâmetros no crescimento dos flocos ao longo do processo de eletrocoagulação. Os resultados obtidos pelos autores indicaram que o aumento da densidade de corrente acelera o crescimento dos flocos, tornando-os maiores em tamanho. Portanto, a presença de flocos maiores em tamanho e em quantidade, devido à elevada dissolução 
anódica, favoreceria a taxa de colisão entre o contaminante e o floco, favorecendo a floculação por varredura.

Observa-se também na Figura 36 que, embora o incremento no valor das densidades de corrente seja constante, o aumento da eficiência de remoção de boro não é constante. Nota-se que a remoção de boro apresenta um aumento mais significativo de $\mathrm{J}=6,25 \mathrm{~mA} / \mathrm{cm}^{2}$ para $\mathrm{J}=12,50 \mathrm{~mA} / \mathrm{cm}^{2}$ se comparada de $\mathrm{J}=$ $12,50 \mathrm{~mA} / \mathrm{cm}^{2}$ para $\mathrm{J}=18,75 \mathrm{~mA} / \mathrm{cm}^{2}$. A fundamentação desse resultado encontrase na resistência ôhmica da solução, pois à medida que se aumenta a densidade de corrente, também se aumenta o efeito Joule. Existe um valor crítico para a densidade de corrente e, uma vez atingido esse valor, a qualidade do efluente não sofrerá mudanças significativas para outros aumentos na corrente aplicada (Chen, 2004).

Em muitas situações, a quantidade de alumínio dissolvido a partir do anodo é superior à calculada teoricamente pela lei de Faraday, essa dissolução em excesso de alumínio tem como fonte a dissolução química (Mollah et al., 2001). Nesse estudo, os catodos também eram de alumínio, portanto, suscetíveis à dissolução química. $\mathrm{O}$ ataque químico em ambos os eletrodos pode ocorrer devido à alcalinidade e à acidez produzida em suas vizinhanças.

A dissolução total de alumínio (contribuição da dissolução química em ambos os eletrodos e da eletrodissolução no anodo) em função dos valores de $\mathrm{pH}$ inicial $(3,4,5,6,7$ e 8) é apresentada nas Figuras 37, 38 e 39, para diferentes valores de densidade de corrente $\left(6,25 \mathrm{~mA} / \mathrm{cm}^{2}, 12,50 \mathrm{~mA} / \mathrm{cm}^{2}\right.$ e $\left.18,75 \mathrm{~mA} / \mathrm{cm}^{2}\right)$, mantendo fixo o tempo de eletrólise $(\mathrm{t}=90 \mathrm{~min})$. 


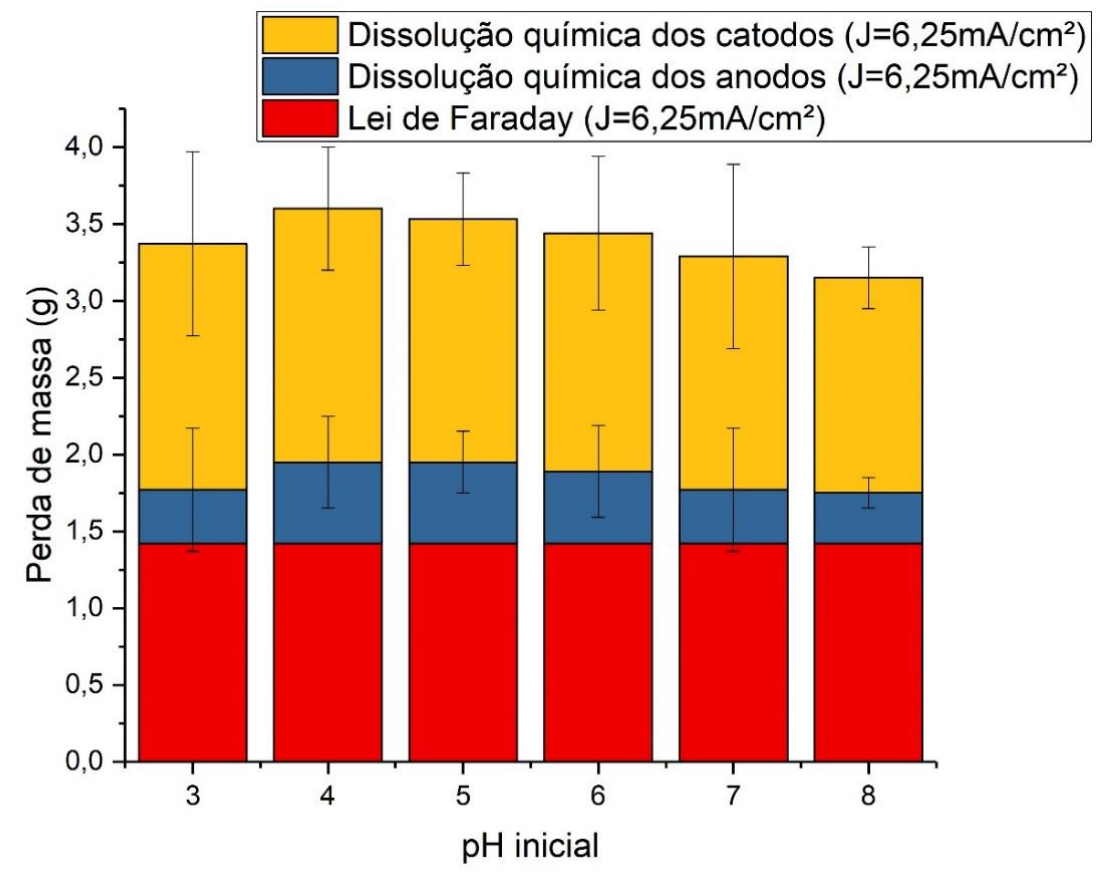

Figura 37 - Dissolução total de alumínio em função dos valores de $\mathrm{pH}$ inicial em densidade de corrente de $6,25 \mathrm{~mA} / \mathrm{cm}^{2}([\mathrm{NaCl}]=15 \mathrm{mM} ; \mathrm{RPM}=250 ; \mathrm{d}=10 \mathrm{~mm} ; \mathrm{t}=$ 90min). Elaborada pelo autor.

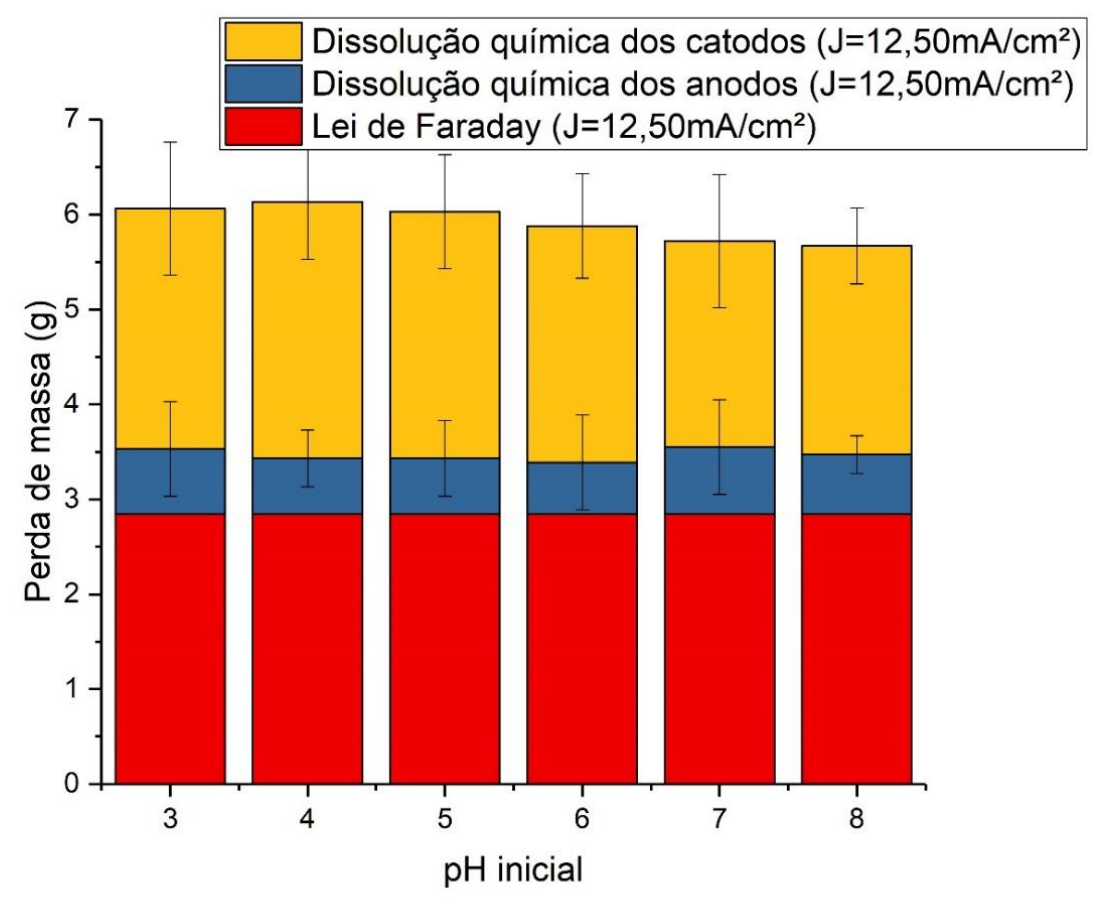

Figura 38 - Dissolução total de alumínio em função dos valores de $\mathrm{pH}$ inicial em densidade de corrente de $12,50 \mathrm{~mA} / \mathrm{cm}^{2}([\mathrm{NaCl}]=15 \mathrm{mM} ; \mathrm{RPM}=250 ; \mathrm{d}=10 \mathrm{~mm} ; \mathrm{t}=$ 90min). Elaborada pelo autor. 


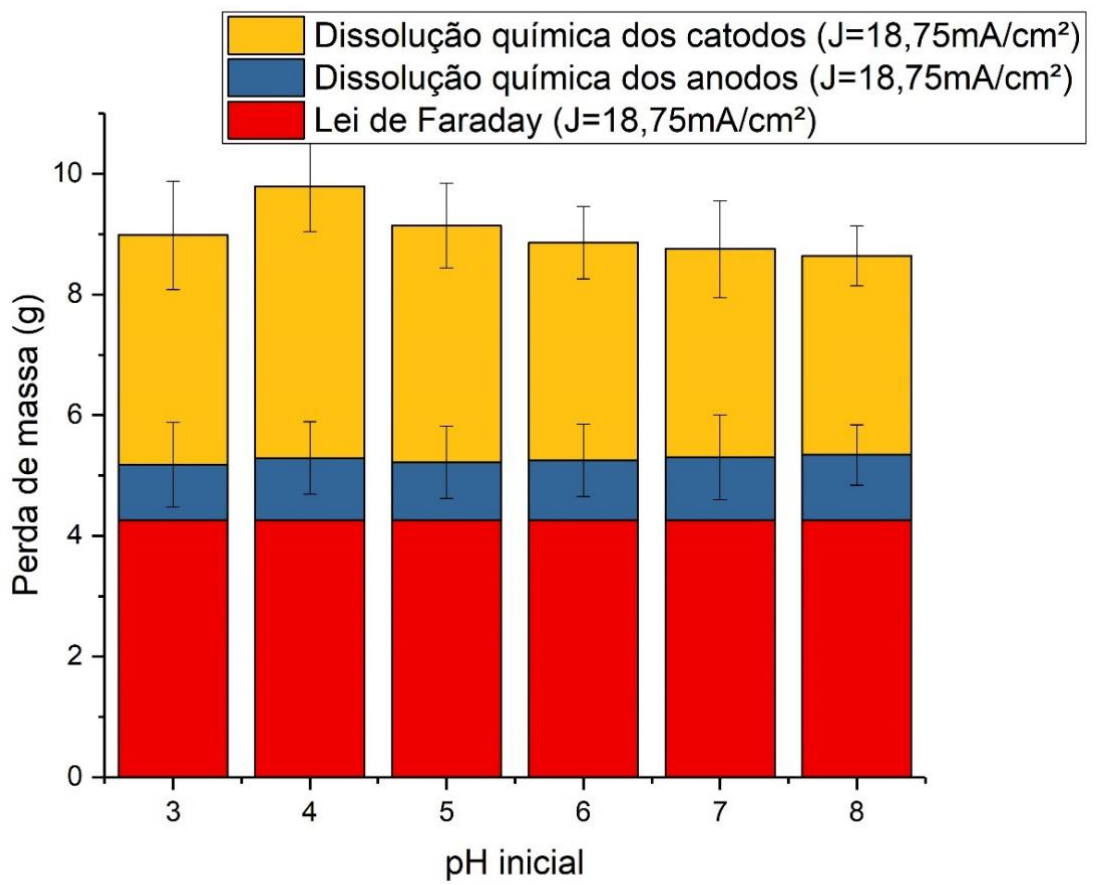

Figura 39 - Dissolução total de alumínio em função dos valores de $\mathrm{pH}$ inicial em densidade de corrente de $18,75 \mathrm{~mA} / \mathrm{cm}^{2}([\mathrm{NaCl}]=15 \mathrm{mM} ; \mathrm{RPM}=250 ; \mathrm{d}=10 \mathrm{~mm} ; \mathrm{t}=$ $90 \mathrm{~min})$. Elaborada pelo autor.

Esses resultados evidenciam que a quantidade de alumínio dissolvido a partir do anodo é sempre superior à calculada teoricamente pela lei de Faraday, essa diferença advém da dissolução química do anodo. Observa-se que a dissolução química do catodo se manteve independente da densidade de corrente, portanto, o aumento da densidade de corrente diminui a contribuição da dissolução química do catodo na dissolução total de alumínio. Além disso, a dissolução total de alumínio é equivalente a duas vezes o valor calculado pela lei de Faraday para as condições experimentais desse trabalho.

\section{2. \\ Modelo cinético}

Conforme discutido anteriormente, a remoção por eletrocoagulação é o resultado de um processo em duas etapas, que envolve a coagulação e a floculação. Como na eletrocoagulação essas duas etapas ocorrem simultaneamente, e é compreensível que uma série de reações e processos complexos estejam envolvidos (Mollah et al., 2001). Embora a fase da coagulação 
dependa essencialmente da especiação do coagulante, foi relatado que a fase da floculação é função do grau de desestabilização alcançado na fase da coagulação e da taxa de colisão entre as partículas (Bratby, 2006). Tendo em conta a complexidade dessas reações, neste estudo, a remoção de boro pode ser descrita pela eq. (35).

$\frac{d[B]}{d t}=-k[B]^{x}\left[A l(O H)_{n}^{(3-n)}\right]^{y}$

Onde $[\mathrm{B}]$ é a concentração de boro, $\left[\mathrm{Al}(\mathrm{OH})_{n}{ }^{(3-n)}\right]$ é a concentração dos produtos de hidrólise do cátion $\mathrm{Al}^{3+}, \mathrm{k}$ é a constante cinética e $\mathrm{x}$ e y são as ordens parciais da reação.

Acredita-se que a remoção de boro é alcançada por uma combinação de processos envolvendo as espécies de $\mathrm{Al}(\mathrm{OH})_{\mathrm{n}}{ }^{(3-n)}$.

É notório que a determinação da constante cinética, $\mathrm{k}$, e das ordens parciais da reação, x e y, é uma tarefa de grande complexidade, uma vez que a especiação do cátion $\mathrm{Al}^{3+}$ é governada pelo $\mathrm{pH}$ e pela dose de coagulante. $\mathrm{Na}$ eletrocoagulação, o coagulante é gerado de forma contínua e o pH varia ao longo do processo. Essas condições produzem um sistema dinâmico (Holt et al., 2002).

$\mathrm{Na}$ tentativa de desenvolver um modelo cinético para as variações temporais da concentração de boro, assumiu-se que as taxas de geração e de consumo dos produtos de hidrólise do cátion $\mathrm{Al}^{3+}$ eram idênticas ao longo do processo de eletrocoagulação. Dessa forma, a concentração das espécies de $\mathrm{Al}(\mathrm{OH})_{\mathrm{n}}{ }^{(3-\mathrm{n})}$ pode ser considerada constante e a eq. (35) pode ser simplificada para a eq. (36).

$\frac{d[B]}{d t}=-k_{o b s}[B]^{x}$

Onde $\mathrm{k}_{\mathrm{obs}}$ é a constante cinética observada, [B] é a concentração de boro e $\mathrm{x}$ é a ordem parcial da reação.

Nessa aproximação, a constante cinética reflete a contribuição de várias reações, envolvendo as fases da coagulação e da floculação. Uma abordagem semelhante foi utilizada para estudar a cinética de oxidação eletroquímica (Szpyrkowicz et al., 2005). 
Diversos autores relataram que a remoção de uma ampla variedade de contaminantes por eletrocoagulação ocorre segundo uma cinética de pseudoprimeira ordem ou de pseudo-segunda ordem (Chou et al., 2010; Mameri et al., 1998; Linares-Hernández et al., 2010).

Dessa forma, toda a matriz experimental foi ajustada aos modelos de pseudo-primeira ordem $(x=1)$ e de pseudo-segunda ordem $(x=2)$, os valores de $\mathrm{R}^{2}$ foram utilizados para avaliar a qualidade dos ajustes. Na Tabela 7 , observa-se os valores das constantes cinéticas (valor da inclinação da reta de regressão) e de $\mathrm{R}^{2}$.

Tabela 7 - Valores das constantes cinéticas e de $R^{2}$ para os modelos cinéticos de pseudo-primeira ordem e de pseudo-segunda ordem. Elaborada pelo autor.

\begin{tabular}{|c|c|c|c|c|c|}
\hline \multirow[t]{2}{*}{$\begin{array}{c}\text { Densidade } \\
\text { de corrente } \\
\left(\mathrm{mA} / \mathrm{cm}^{2}\right)\end{array}$} & \multirow[t]{2}{*}{$\begin{array}{c}\mathrm{pH} \\
\text { inicial }\end{array}$} & \multicolumn{2}{|c|}{$\begin{array}{l}\text { Cinética de pseudo- } \\
\text { primeira ordem } \\
\ln [B]=\ln [B]_{0}-k_{o b s} t\end{array}$} & \multicolumn{2}{|c|}{$\begin{array}{l}\text { Cinética de pseudo- } \\
\text { segunda ordem } \\
\frac{1}{[B]}=\frac{1}{[B]_{0}}+k_{o b s} t\end{array}$} \\
\hline & & $\overline{\mathrm{K}_{\mathrm{obs}}}$ & $\overline{R^{2}}$ & $\overline{\mathrm{K}_{\mathrm{obs}}}$ & $\overline{R^{2}}$ \\
\hline 6,25 & 3 & 0,00506 & 0,9595 & 0,00015 & 0,9348 \\
\hline 6,25 & 4 & 0,00826 & 0,9923 & 0,00029 & 0,9761 \\
\hline 6,25 & 5 & 0,00744 & 0,9945 & 0,00024 & 0,9771 \\
\hline 6,25 & 6 & 0,00734 & 0,9969 & 0,00024 & 0,9794 \\
\hline 6,25 & 7 & 0,00674 & 0,9914 & 0,00020 & 0,9723 \\
\hline 6,25 & 8 & 0,00551 & 0,9978 & 0,00016 & 0,9944 \\
\hline 12,50 & 3 & 0,00875 & 0,9833 & 0,00029 & 0,9397 \\
\hline 12,50 & 4 & 0,01113 & 0,9983 & 0,00042 & 0,9646 \\
\hline 12,50 & 5 & 0,01071 & 0,9986 & 0,00040 & 0,9699 \\
\hline 12,50 & 6 & 0,01068 & 0,9957 & 0,00041 & 0,9632 \\
\hline 12,50 & 7 & 0,01080 & 0,9960 & 0,00039 & 0,9683 \\
\hline 12,50 & 8 & 0,00999 & 0,9954 & 0,00036 & 0,9612 \\
\hline 18,75 & 3 & 0,01334 & 0,9963 & 0,00054 & 0,9577 \\
\hline 18,75 & 4 & 0,01373 & 0,9987 & 0,00060 & 0,9738 \\
\hline 18,75 & 5 & 0,01264 & 0,9983 & 0,00052 & 0,9864 \\
\hline 18,75 & 6 & 0,01207 & 0,9984 & 0,00048 & 0,9876 \\
\hline 18,75 & 7 & 0,01272 & 0,9951 & 0,00052 & 0,9878 \\
\hline 18,75 & 8 & 0,01244 & 0,9973 & 0,00050 & 0,9646 \\
\hline
\end{tabular}


Pode-se verificar a partir da Tabela 7 que o modelo cinético que melhor descreve a remoção de boro é o de pseudo-primeira ordem. A Figura 40 apresenta o valor da constante cinética do modelo de pseudo-primeira ordem em função do pH inicial e da densidade de corrente. Observa-se que a constante cinética aumenta com o aumento da densidade de corrente. Em relação ao efeito do pH inicial, nota-se que a constante cinética apresenta o seu valor máximo em $\mathrm{pH}_{0}=4$.

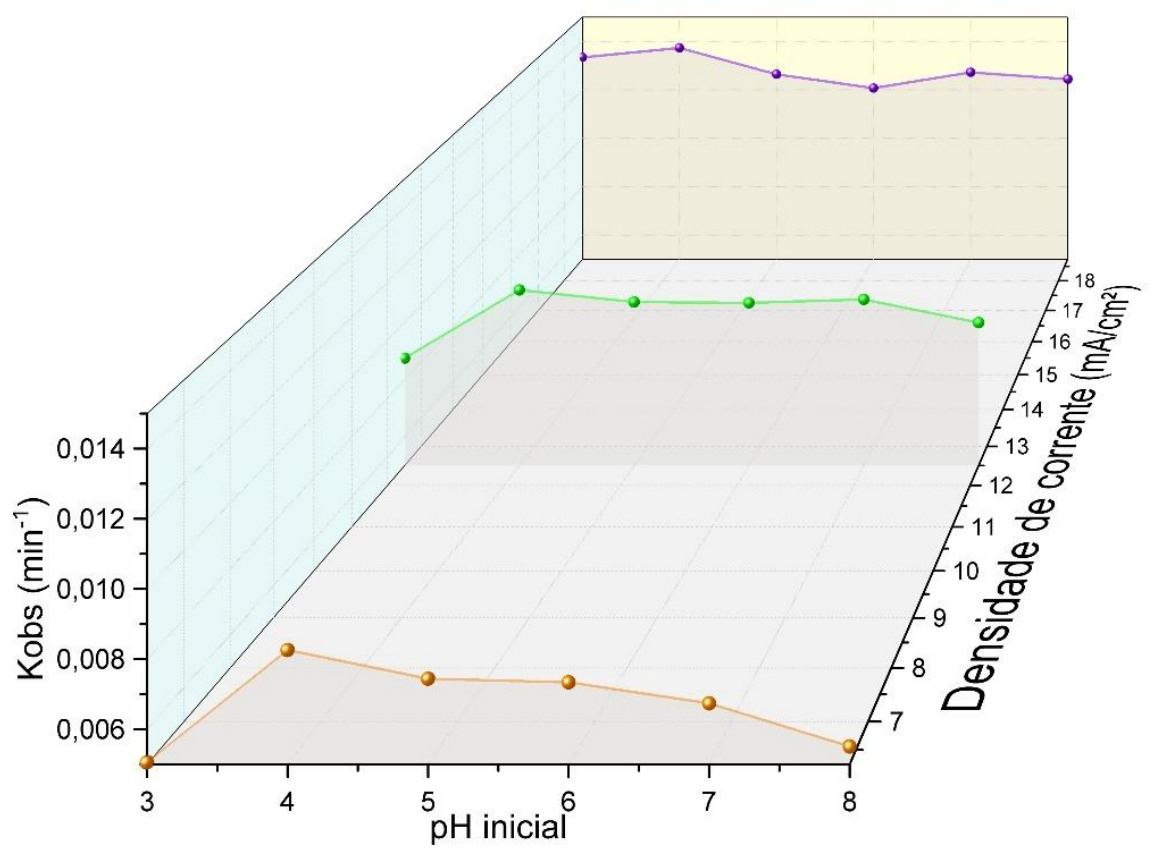

Figura 40 - Constante cinética em função do pH inicial e da densidade de corrente. Elaborada pelo autor.

\section{3.}

\section{Isotermas de adsorção}

Um dos atributos importantes de um adsorvente é a quantidade de substância que possa acumular ou que possa ser retirada de sua superfície. Uma forma de descrever essa acumulação é expressar a quantidade de substância adsorvida por quantidade de adsorvente $\left(\mathrm{q}_{\mathrm{e}}\right)$ em função da concentração de adsorvato $\left(\mathrm{C}_{\mathrm{e}}\right)$ em solução. Tal expressão é denominada de isoterma de adsorção (Letterman et al., 1999). 
Embora haja diversos modelos que retratam as isotermas de adsorção, os mais conhecidos são o modelo de Langmuir e o modelo de Freundlich, que serão utilizados neste trabalho.

A remoção de boro envolve a adsorção das partículas de ácido bórico nos produtos de hidrólise do cátion $\mathrm{Al}^{3+}$, principalmente o $\mathrm{Al}(\mathrm{OH})_{3}$ (Mollah et al., 2004). Com a intenção de determinar se a adsorção foi o mecanismo dominante para a remoção de boro por eletrocoagulação, estudos de equilíbrio da adsorção do boro foram processados com a utilização de modelos de isotermas de adsorção (Kinniburgh, 1986).

Vários estudos foram publicados sobre os modelos de isotermas de adsorção para descrever a remoção de boro usando vários adsorventes (Kavak, 2009). Esses estudos foram realizados variando a concentração inicial de boro com uma quantidade constante de adsorvente e medindo a quantidade de boro adsorvido no equilíbrio.

No processo de eletrocoagulação, o adsorvente ou o coagulante é dosado à solução de forma contínua, gerando um sistema extremamente dinâmico, de modo que o equilíbrio é alcançado progressivamente ao aumentar a concentração de adsorvente. Consequentemente, não é possível realizar experimentos em batelada para determinar o tempo de equilíbrio, como geralmente é feito em estudos de isotermas de adsorção (Vasudevan et al., 2009).

No entanto, é razoável supor que, na eletrocoagulação, o processo de adsorção é relativamente rápido e não representa a etapa controladora do processo, que corresponde à fase de floculação (Hahn et al., 1968).

Isso implica que, ao final do processo de eletrocoagulação, o equilíbrio para o boro adsorvido foi alcançado e, consequentemente, a concentração de boro em equilíbrio, $\mathrm{B}_{\mathrm{e}}$, é igual à concentração final de boro em solução, $\mathrm{B}_{\mathrm{t}}$.

A capacidade de adsorção foi obtida utilizando a eq. (37).

$q_{e}=\frac{\left(B_{0}-B_{e}\right) V}{M}$

Onde $\mathrm{q}_{\mathrm{e}}$ é a quantidade de boro adsorvido em equilíbrio por unidade de massa de adsorvente, em mg/g, $B_{0}$ e $B_{e}$ são as concentrações inicial e de equilíbrio 
de boro, respectivamente, em $\mathrm{mg} / \mathrm{L}, \mathrm{V}$ é o volume da solução, em $\mathrm{L}$, e $\mathrm{M}$ é a quantidade de adsorvente, em g.

A quantidade de adsorvente gerado, $\mathrm{M}$, foi considerada como a quantidade de cátions $\mathrm{Al}^{3+}$ gerados pela eletrodissolução dos anodos de alumínio e foi calculada através da lei de Faraday. Contudo, com o objetivo de incluir o efeito da dissolução química, o valor encontrado pela lei de Faraday foi multiplicado por dois para considerar a dissolução química em ambos os eletrodos de alumínio, conforme detalhado na seção 5.1.2.

Nesse estudo, os modelos utilizados foram os de Langmuir e de Freundlich, que descrevem o equilíbrio estabelecido entre a quantidade de boro adsorvido por unidade de massa de adsorvente $\left(\mathrm{q}_{\mathrm{e}}\right)$ e a concentração de boro na solução $\left(\mathrm{B}_{\mathrm{e}}\right)$, a uma temperatura constante.

O modelo de Langmuir considera a sorção em monocamada na superfície, com um número definido de lugares disponíveis (FOO et al., 2010), e obedece à eq. (38):

$q_{e}=\frac{q_{m} K_{L} B_{e}}{1+K_{L} B_{e}}$

Onde $\mathrm{q}_{\mathrm{m}}$ é a máxima quantidade de boro por unidade de peso dos precipitados de hidróxido de alumínio para formar uma monocamada na superfície, em mg/g, e $\mathrm{K}_{\mathrm{L}}$ é a constante relativa à afinidade dos lugares disponíveis na superfície com o boro, em $\mathrm{L} / \mathrm{mg}$.

O modelo de Freundlich, por sua vez, considera que a sorção se dá em superfícies heterogêneas (FOO et al., 2010), conforme a eq. (39):

$q_{e}=K_{F} B_{e}^{\frac{1}{n}}$

Onde $\mathrm{K}_{\mathrm{F}}$ é um indicador da capacidade de adsorção $(\mathrm{L} / \mathrm{g})$ e $\mathrm{n}$ representa a intensidade de adsorção (adimensional).

Os estudos para determinar as isotermas de adsorção foram realizados em diferentes valores de concentração inicial de boro $(12,50 \mathrm{mg} / \mathrm{L}, 25 \mathrm{mg} / \mathrm{L}, 50 \mathrm{mg} / \mathrm{L}$ e $100 \mathrm{mg} / \mathrm{L})$, no valor do $\mathrm{pH}$ ótimo determinado em experimentos anteriores $\left(\mathrm{pH}_{0}=\right.$ 
4) e em uma densidade de corrente de $12,50 \mathrm{~mA} / \mathrm{cm}^{2}$. Todos os experimentos foram realizados à temperatura constante de $25^{\circ} \mathrm{C}$.

O gráfico da regressão não linear dos modelos Langmuir e Freundlich é exibido na Figura 41. A qualidade do ajuste dos modelos foi avaliada utilizando o valor de $\mathrm{R}^{2}$ ajustado. Os valores de $\mathrm{R}^{2}$ ajustado e os parâmetros das isotermas de Langmuir e de Freundlich são apresentados na Tabela 8.

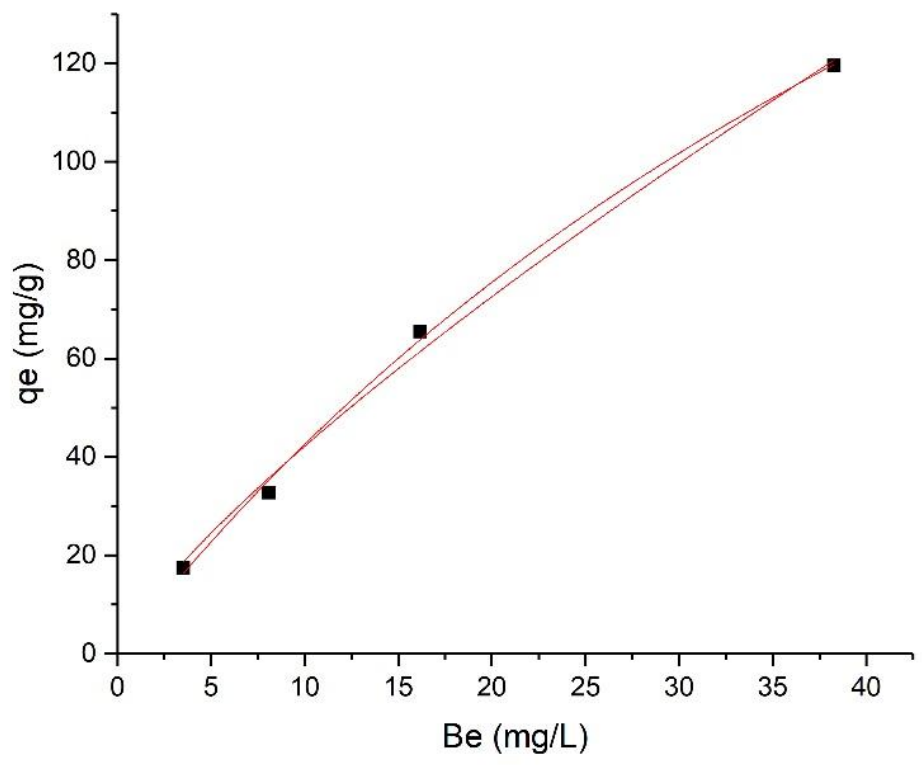

Figura 41 - Gráfico da regressão não linear dos modelos Langmuir e Freundlich. Elaborada pelo autor.

Tabela 8 - Valores de $R^{2}$ ajustado e os parâmetros das isotermas de Langmuir e de Freundlich. Elaborada pelo autor.

\begin{tabular}{|c|c|c|}
\hline \multicolumn{3}{|c|}{ Langmuir } \\
\hline $\mathrm{K}_{\mathrm{L}}(\mathrm{L} / \mathrm{mg})$ & $\mathrm{q}_{\mathrm{m}}(\mathrm{mg} / \mathrm{g})$ & $\mathrm{R}^{2}$ ajustado \\
\hline 0,01459 & 334,1933 & 0,99482 \\
\hline \multicolumn{3}{|c|}{ Freundlich } \\
\hline $\mathrm{K}_{\mathrm{F}}(\mathrm{L} / \mathrm{mg})$ & $\mathrm{n}$ & $\mathrm{R}^{2}$ ajustado \\
\hline 6,95493 & 1,2774 & 0,98631 \\
\hline
\end{tabular}


Os valores apresentados na Tabela 8 mostram que o modelo de Langmuir se ajusta muito bem aos dados experimentais obtidos.

$\mathrm{O}$ valor de $\mathrm{q}_{\mathrm{m}}$ obtido pelo modelo de Langmuir reflete a elevada capacidade de adsorção máxima $\left(\mathrm{q}_{\mathrm{m}}=334 \mathrm{mg} / \mathrm{g}\right)$ do precipitado de hidróxido de alumínio gerado ao longo do processo de eletrocoagulação quando comparado a outros adsorventes, conforme apresentado na Tabela 9.

Tabela 9 - Constante $\mathrm{q}_{\mathrm{m}}$ da isoterma de Langmuir para a adsorção de boro em diferentes adsorventes. Elaborada pelo autor.

\begin{tabular}{|c|c|c|}
\hline Adsorvente & $\mathbf{q}_{\mathbf{m}}(\mathbf{m g} \mathbf{g})$ & Referência \\
\hline Celulose & 11,9 & Inukai et al., 2004 \\
\hline Metacrilato de metila-divinilbenzeno & 23,24 & Biçak et al., 2001 \\
\hline Quitosana & 35,13 & Wei et al., 2011 \\
\hline
\end{tabular}

É importante destacar que o modelo de Freundlich também apresentou um bom ajuste dos dados. O valor de $\mathrm{n}$ é maior que a unidade, indicando que as espécies presentes são favoravelmente adsorvidas sob as condições experimentais testadas.

Dessa forma, isso sugere a ocorrência da adsorção em monocamada, assim como condições heterogêneas na superfície, onde ambas condições podem coexistir sob as condições experimentais testadas. Como já discutido, o processo de eletrocoagulação é extremamente complexo, portanto é razoável supor uma superfície heterogênea do adsorvente.

\section{4. \\ Avaliação microscópica da superfície dos eletrodos de alumínio utilizados no processo de eletrocoagulação}

As Figuras 42 e 43 apresentam as análises por Microscopia Eletrônica de Varredura (MEV) da superfície do catodo e do anodo, respectivamente, com aumento de 200 vezes. 


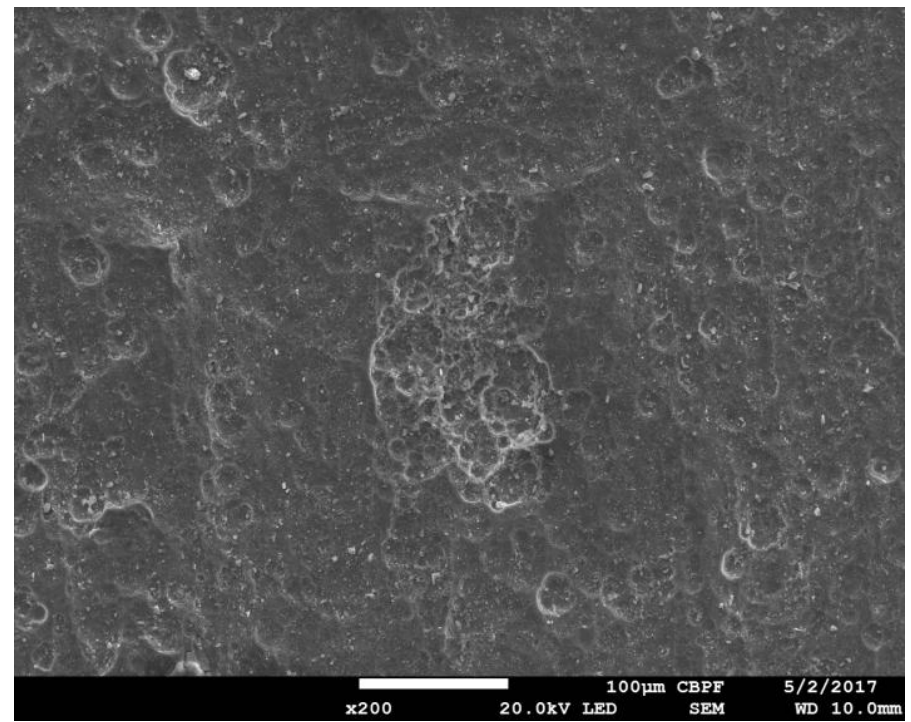

Figura 42 - Análise por MEV da superfície do catodo, com aumento de 200 vezes. Elaborada pelo autor.

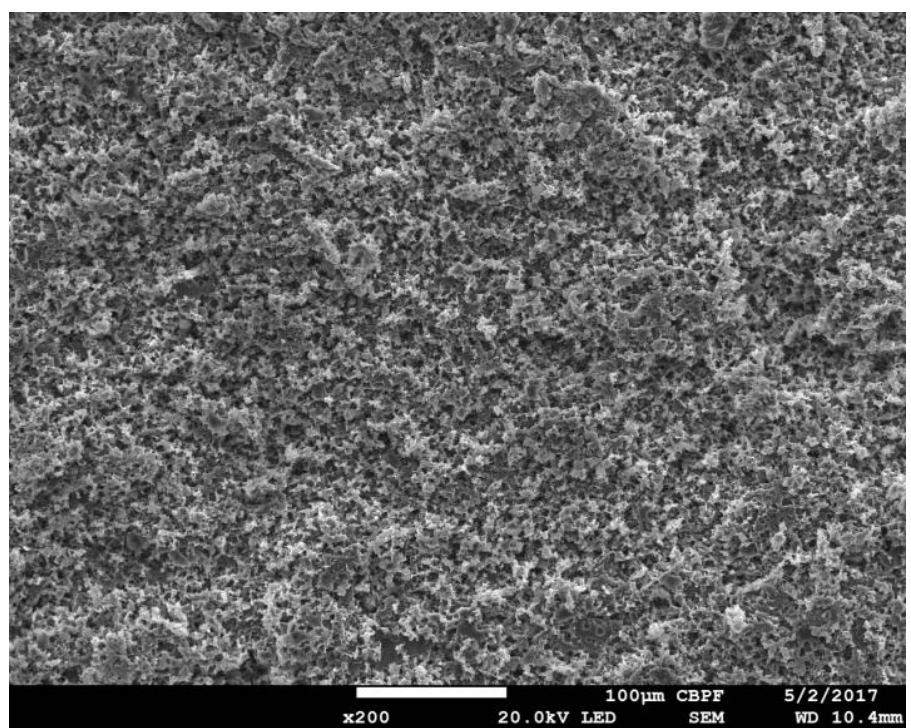

Figura 43 - Análise por MEV da superfície do anodo, com aumento de 200 vezes. Elaborada pelo autor.

Enquanto que na superfície do catodo observa-se a presença de corrosão do tipo localizada, no anodo observa-se a corrosão do tipo uniforme na superfície do eletrodo. Esse resultado também foi relatado por Smoczyński et al. (2013) no tratamento de efluentes da indústria de laticínios. Esse comportamento converge com os resultados de perda de massa dos eletrodos obtidos experimentalmente. 
A Figura 44 apresenta a morfologia da superfície do catodo em uma região onde ocorreu a dissolução química do alumínio, com aumento de 2000 vezes.

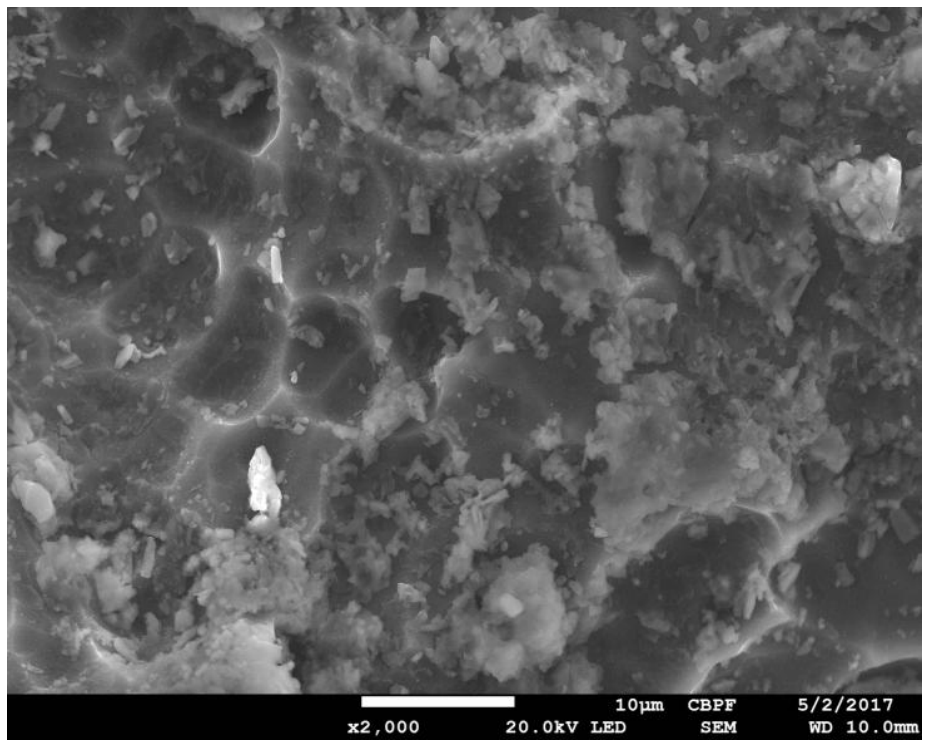

Figura 44 - Análise por MEV da superfície do catodo em uma região onde ocorreu a dissolução química do alumínio, com aumento de 2000 vezes. Elaborada pelo autor.

Na Figura 44 visualiza-se o aspecto característico da corrosão do tipo localizada do alumínio. Esse mesmo aspecto foi relatado por Mouedhen et al. (2008), que investigaram o comportamento dos eletrodos de alumínio no processo de eletrocoagulação.

A técnica de Espectroscopia de Energia Dispersiva (EDS) foi utilizada para determinar qualitativamente os elementos químicos presentes na superfície dos eletrodos de alumínio.

A Figura 45 apresenta o resultado da análise por EDS da superfície do catodo em uma região onde não houve a dissolução química do alumínio. Observa-se a presença predominante de alumínio e de oxigênio, comprovando a existência de uma camada de óxido de alumínio sobre a superfície do eletrodo. 


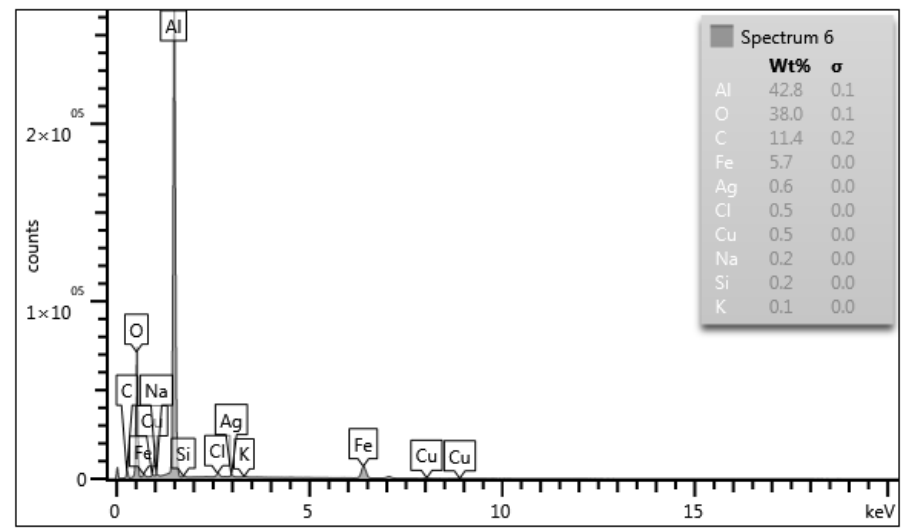

Figura 45 - Análise por EDS da superfície do catodo em uma região onde não houve a dissolução química do alumínio. Elaborada pelo autor.

As Figuras 46 e 47 apresentam, respectivamente, as análises por EDS da superfície do catodo em uma região onde houve a dissolução química do alumínio e da superfície do anodo. Observa-se, em ambos os casos, a presença predominante de alumínio e a menor presença de oxigênio, comprovando a baixa incidência de uma camada de óxido de alumínio sobre a superfície do eletrodo.

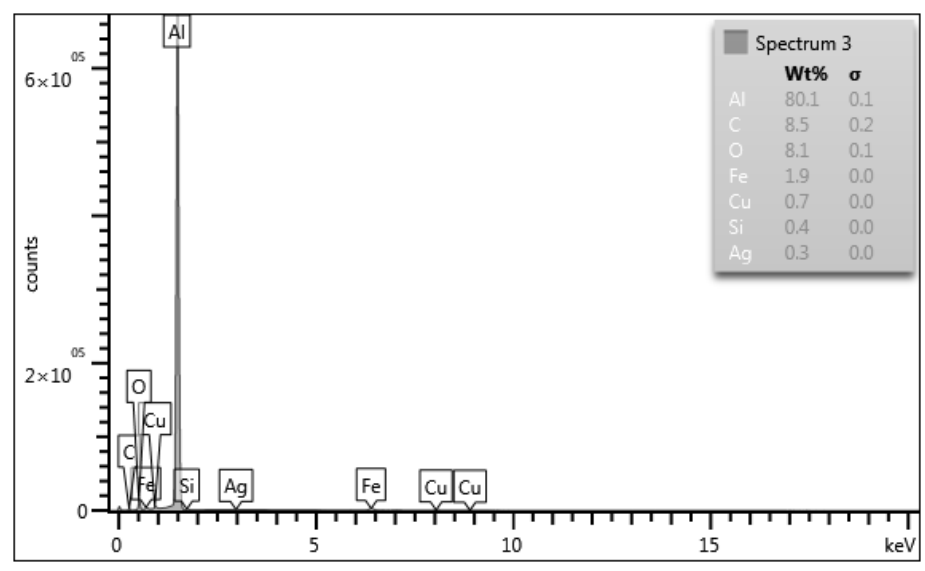

Figura 46 - Análise por EDS da superfície do catodo em uma região onde houve a dissolução química do alumínio. Elaborada pelo autor. 


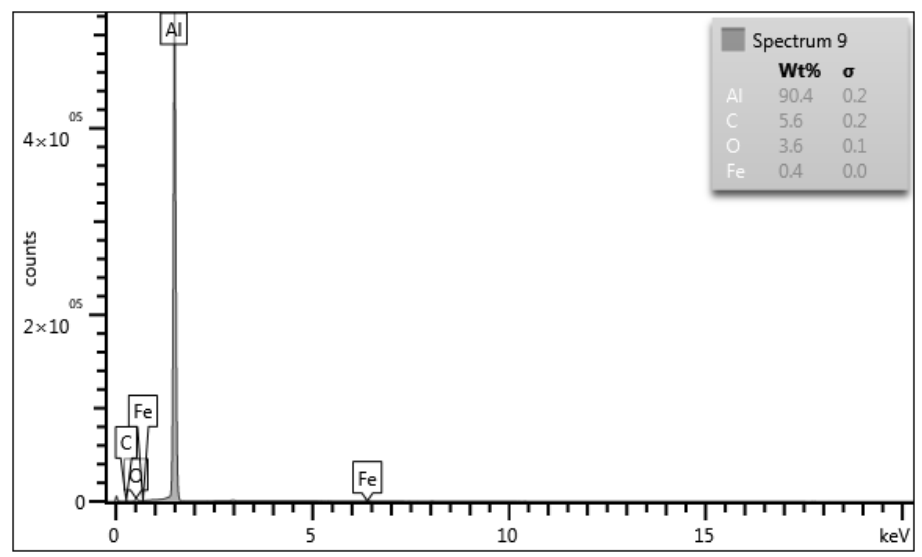

Figura 47 - Análise por EDS da superfície do anodo. Elaborada pelo autor.

\section{5 .}

\section{Caracterização do lodo produzido no processo de eletrocoagulação}

A produção de lodo no processo de eletrocoagulação é proporcional às características do efluente, aos sólidos presentes, à matéria desestabilizada pela coagulação e à concentração de coagulante, sendo esta última relacionada à densidade de corrente aplicada e ao tempo de eletrólise (Kobya et al., 2006).

Neste estudo, o lodo produzido ao longo do processo de eletrocoagulação foi analisado por Microscopia Eletrônica de Varredura (MEV), por Difração de Raios-X (DRX) e por Espectroscopia por Perda de Energia de Elétrons (EELS).

A Figura 48 apresenta a morfologia e a composição elementar do lodo produzido no processo de eletrocoagulação. A análise por MEV indica a presença de uma morfologia heterogênea na superfície. A análise por EDS mostra que o lodo é composto, sobretudo, por alumínio e oxigênio. Esses resultados reforçam que os precipitados obtidos ao longo do processo de eletrocoagulação são, como esperado, flocos de hidróxido de alumínio amorfo (Mollah et al., 2001). 


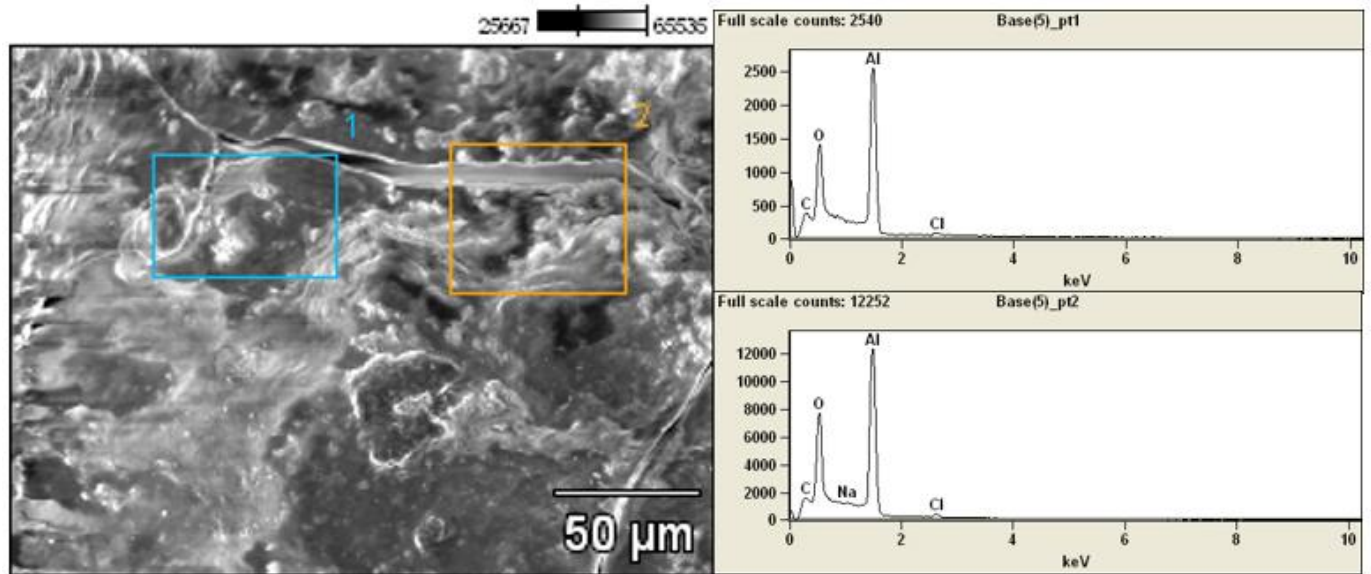

Figura 48 - Morfologia e composição elementar do lodo produzido no processo de eletrocoagulação. Elaborada pelo autor.

A Figura 49 apresenta a análise por DRX do lodo obtido no processo de eletrocoagulação. Observa-se picos largos característicos de um material amorfo. A fase de alumínio predominante é a boehmita, $\mathrm{AlO}(\mathrm{OH})$. A técnica de preparo das amostras para análise de Difração de Raios-X envolvia a secagem dessas em mufla a $100^{\circ} \mathrm{C}$ por 120 minutos. Sabe-se que o hidróxido de alumínio, $\mathrm{Al}(\mathrm{OH})_{3}$, sofre decomposição térmica nessa faixa de temperatura, tendo como produto a boehmita (Sato, 1987). Portanto, o resultado da análise por DRX converge com o resultado obtido por EDS, isto é, o lodo gerado é composto de hidróxido de alumínio amorfo.

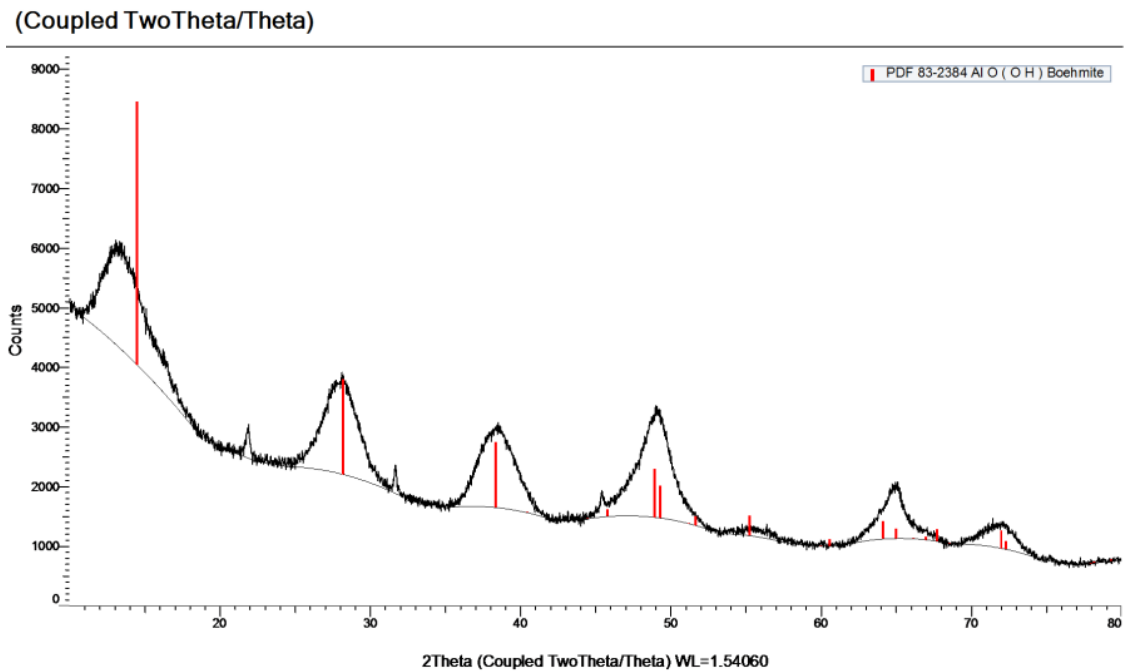

Figura 49 - Difratograma do lodo obtido no processo de eletrocoagulação. Elaborada pelo autor. 
Nota-se que os resultados apresentados por EDS e DRX não são capazes de detectar a presença de boro no lodo obtido por eletrocoagulação, uma vez que o boro é um elemento de baixo número atômico. Portanto, fez-se o uso da técnica de Espectroscopia por Perda de Energia de Elétrons (EELS). A EELS tem sido utilizada como um complemento para a EDS por possibilitar melhor informação, assim como a detecção de elementos leves (Von Harrach et al., 2010).

A Figura 50 apresenta a análise por EELS do lodo gerado no processo de eletrocoagulação. Através dessa técnica foi possível a detecção do boro no lodo, além da detecção de alumínio e de oxigênio. Esse resultado converge com as demais análises e, em especial, confirma a presença do boro.

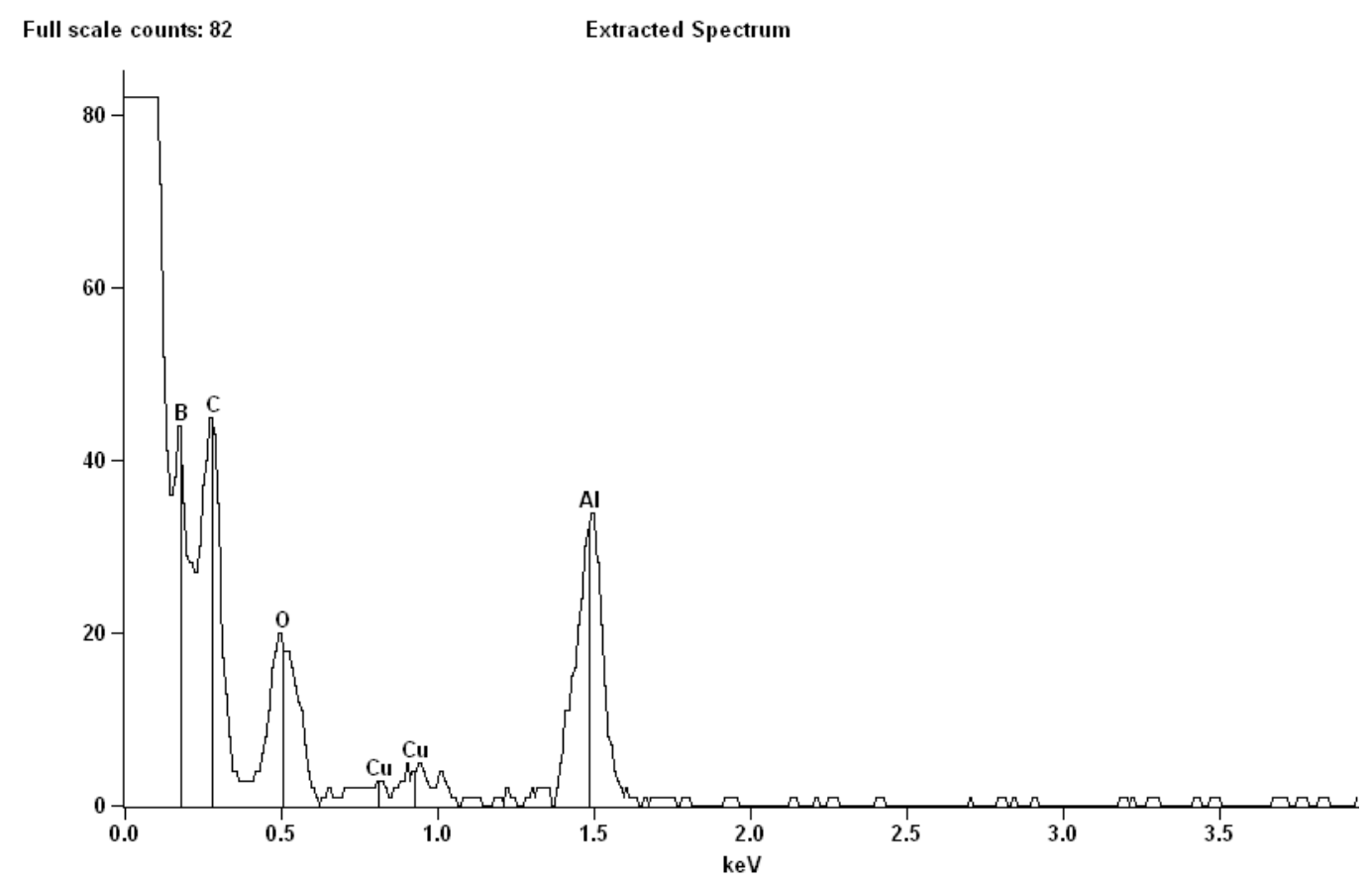

Figura 50 - Espectro de EELS do lodo obtido no processo de eletrocoagulação. Elaborada pelo autor.

\section{6.}

\section{Otimização das condições experimentais}

\subsection{1.}

\section{Modelagem e análise estatística}

A Tabela 10 apresenta os coeficientes do modelo matemático de segunda ordem estimado pelo software Statistica 12 (StatSoft), bem como o erro padrão dos coeficientes, os respectivos valores de t-Student e as significâncias de cada 
coeficiente da regressão através do valor-p. Os coeficientes estatisticamente significativos, considerando um intervalo de confiança de $95 \%(\mathrm{p}<0,05)$, foram destacados em negrito.

Tabela 10 - Coeficientes da regressão linear, erro padrão dos coeficientes, valores de te probabilidade de significância estatística $(p)$ dos coeficientes do modelo referente à remoção de boro. Densidade de corrente (X1), em mA/ $\mathrm{cm}^{2}, \mathrm{pH}$ inicial (X2) e tempo (X3), em minuto. Elaborada pelo autor.

\begin{tabular}{|c|c|c|c|c|}
\hline Termo & Coeficiente & $\begin{array}{c}\text { Erro Padrão } \\
\text { do } \\
\text { Coeficiente }\end{array}$ & Valor-T & Valor-P \\
\hline Constante & $-21,0500$ & 0,04370 & $-4,82$ & 0,0000 \\
\hline $\mathrm{X} 1$ & 0,3950 & 0,00401 & 0,99 & 0,3260 \\
\hline$\overline{X 2}$ & 6,5000 & 0,01240 & 5,24 & 0,0000 \\
\hline $\mathrm{X3}$ & 0,6249 & 0,00053 & 11,86 & 0,0000 \\
\hline$X 1 * X 1$ & $-0,0047$ & 0,00014 & $-0,33$ & 0,7410 \\
\hline$X 2^{*} \times 2$ & $-0,6040$ & 0,00105 & $-5,74$ & 0,0000 \\
\hline $\mathrm{X} 3{ }^{*} \times 3$ & $-0,0024$ & 0,00000 & $-6,18$ & 0,0000 \\
\hline$X 1 * X 2$ & 0,0095 & 0,00030 & 0,32 & 0,7530 \\
\hline$X 1^{*} X 3$ & 0,0199 & 0,00002 & 11,13 & 0,0000 \\
\hline$X 22^{\star} \times 3$ & $-0,0005$ & 0,00005 & $-0,10$ & 0,9200 \\
\hline
\end{tabular}

O modelo obtido somente com as parcelas que foram estatisticamente significativas pelo teste de probabilidade de significância $(\mathrm{p}<0,05)$, o qual relaciona a variável resposta com as variáveis independentes, apresenta-se a seguir de acordo com a eq. (40):

$$
\begin{aligned}
& \text { Remoção de boro }(\%)=-21,0500+6,5000 X_{2}+0,6249 X_{3}- \\
& 0,6040 X_{2}^{2}-0,0024 X_{3}^{2}+0,0199 X_{1} X_{3}
\end{aligned}
$$

Os valores positivos dos coeficientes indicam um aumento no valor da resposta quando a variável segue em direção ao seu nível máximo estudado. Enquanto que os valores negativos indicam um efeito de aumento da resposta quando a variável segue em direção ao seu nível mínimo. Para as interações, valores positivos indicam que a resposta aumentará se as duas variáveis forem em direção ao mesmo nível, inferior ou superior. E valores negativos indicam um aumento na resposta se as variáveis forem em direções contrárias, ou seja, uma 
variável em direção ao nível superior e a outra em direção ao nível inferior (Myers et al., 2016).

De acordo com a Tabela 10, verificou-se que as três variáveis independentes foram consideradas significativas em algum modo (em termos lineares, quadráticos ou de interação) para a remoção de boro. No caso do $\mathrm{pH}$ inicial, o coeficiente linear positivo e o coeficiente quadrático negativo sugerem um valor intermediário da variável no intuito de maximizar a remoção de boro. Embora a variável tempo apresente uma situação semelhante, essa apresenta um coeficiente de interação positivo com a variável densidade de corrente, assim indicando que a máxima remoção de boro ocorre a valores máximos de tempo e densidade de corrente.

O modelo de análise de variância assume que as observações são independentes e normalmente distribuídas (Myers et al., 2016). A validade da suposição de normalidade pode ser verificada por meio de um gráfico de probabilidade normal para os resíduos, conforme apresentado pela Figura 51.

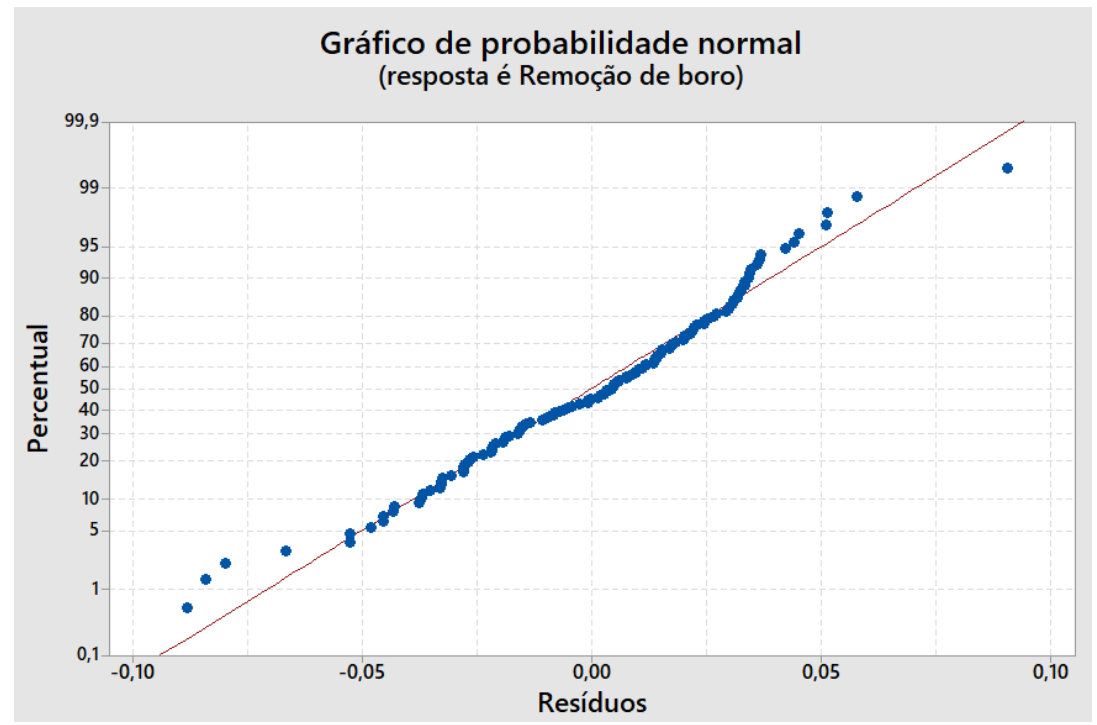

Figura 51 - Gráfico de probabilidade normal dos resíduos para a variável resposta. Elaborada pelo autor.

De acordo com a Figura 51, verifica-se que há indícios de que os erros são normalmente distribuídos, pois a maioria dos pontos está localizada de forma 
aproximada ao longo da reta, inferindo a confiabilidade dos pontos experimentais obtidos.

O coeficiente de determinação calculado $\left(R^{2}\right)$ representa o quanto da variância experimental pode ser explicada pelo modelo proposto (Myers et al., 2016). Diante disto, para a remoção de boro, algo em torno de $97 \%$ da variância pode ser explicado pelo respectivo modelo construído.

Enquanto que o valor-p obtido para a regressão descritiva da remoção de boro foi $<0,001$, demonstrando a significância estatística da regressão (valor $\mathrm{p}<$ $0,05)$.

\subsection{2.}

\section{Análise das superfícies de resposta}

Para o estudo da superfície de resposta normalmente fixa-se o valor de uma variável independente e confrontam-se os valores das outras variáveis independentes para a determinação da região ótima, na qual se encontra os valores máximos ou mínimos, dependendo do objetivo, da variável resposta (Khuri et al., 2010). Os gráficos de superfície de resposta e contorno, elaborados no software Statistica 12 (StatSoft), foram ilustrados através das Figuras 52 a 57.

De acordo com as Figuras 52 e 53, fixou-se o tempo em seu valor máximo (90 minutos), e as variáveis densidade de corrente e $\mathrm{pH}$ inicial foram confrontadas com a região ótima para a resposta. Neste caso, foi possível observar que a remoção de boro é intensificada à medida que a densidade de corrente se aproxima do seu nível máximo e a melhor faixa de $\mathrm{pH}$ inicial encontra-se entre 5 e 6. 
Superfície de resposta para o percentual de remoção de boro Tempo fixo em 90 minutos

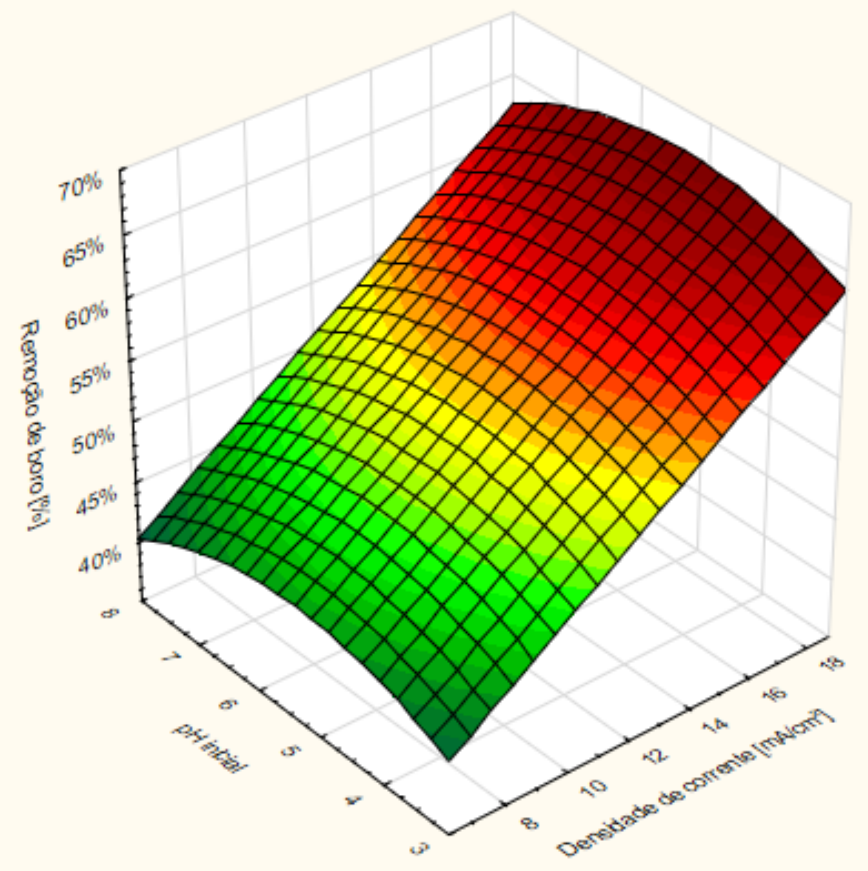

Uू

Figura 52 - Superfície de resposta para o percentual de remoção de boro x pH inicial $\mathrm{x}$ densidade de corrente, mantendo o tempo fixo em 90 minutos. Elaborada pelo autor.

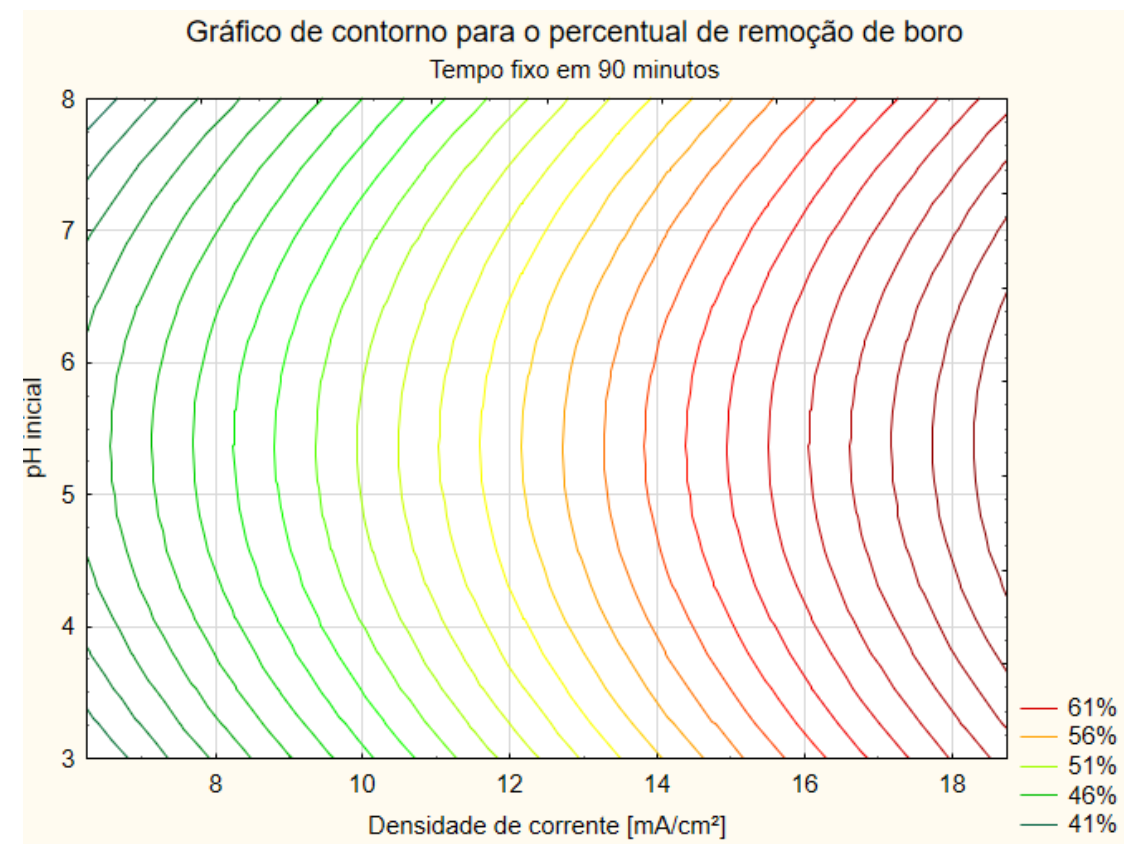

Figura 53 - Gráfico de contorno para o percentual de remoção de boro x pH inicial $\mathrm{x}$ densidade de corrente, mantendo o tempo fixo em 90 minutos. Elaborada pelo autor. 
Nas figuras 54 e 55, o $\mathrm{pH}$ inicial foi mantido constante em 5,5, e as variáveis densidade de corrente e tempo foram correlacionadas com a região ótima para a remoção de boro. Notou-se com essas condições que a remoção de boro tende a aumentar quando o valor da densidade de corrente e do tempo se aproximam dos seus níveis máximos.

\section{Superfície de resposta para o percentual de remoção de boro $\mathrm{pH}$ inicial fixo em 5,5}

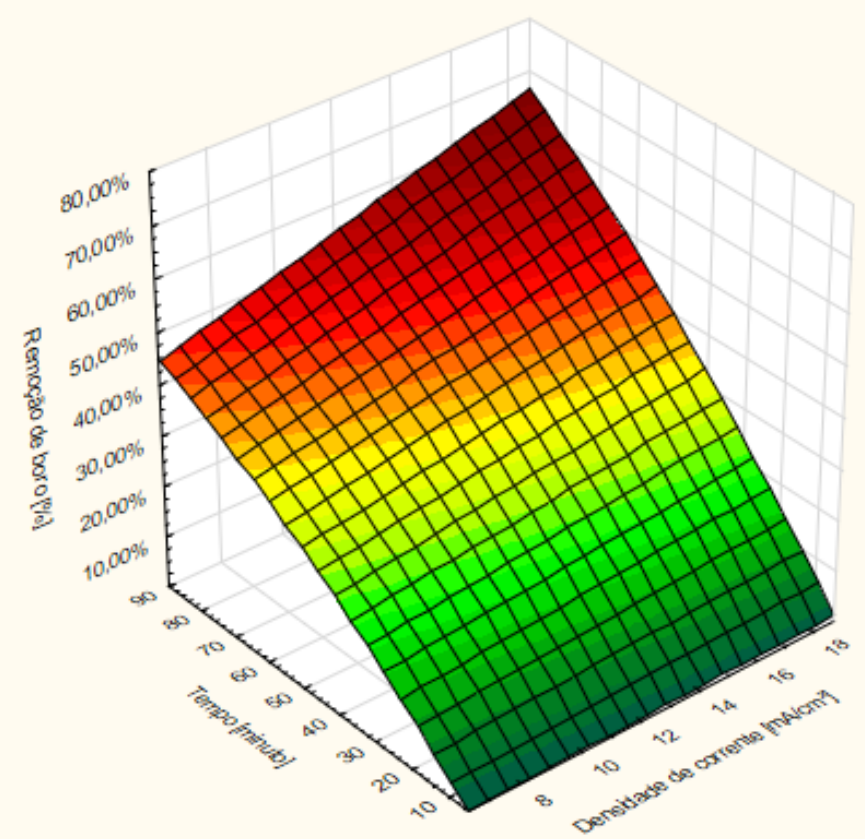

Figura 54 - Superfície de resposta para o percentual de remoção de boro $\mathrm{x}$ tempo $\mathrm{x}$ densidade de corrente, mantendo o pH inicial fixo em 5,5. Elaborada pelo autor. 


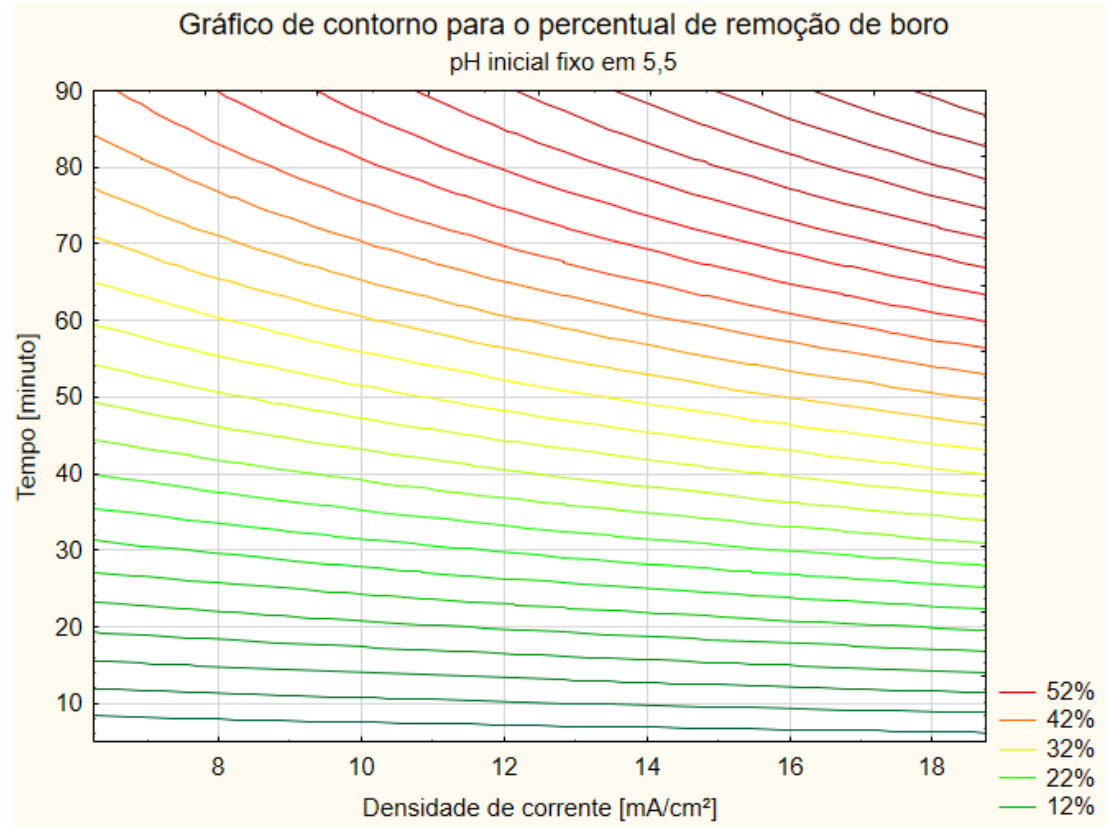

Figura 55 - Gráfico de contorno para o percentual de remoção de boro $\mathrm{x}$ tempo $\mathrm{x}$ densidade de corrente, mantendo o pH inicial fixo em 5,5. Elaborada pelo autor.

Nas Figuras 56 e 57, fixou-se a densidade de corrente em seu valor máximo $\left(18,75 \mathrm{~mA} / \mathrm{cm}^{2}\right)$ e as variáveis $\mathrm{pH}$ inicial e tempo foram correlacionadas com a região ótima para o aumento da eficiência de remoção de boro. Observou-se de forma similar que à medida que o tempo se aproxima do seu nível máximo e a faixa de $\mathrm{pH}$ inicial encontra-se entre 5 e 6 , a eficiência de remoção de boro tende a aumentar. 


\section{Superfície de resposta para o percentual de remoção de boro}

Densidade de corrente fixa em $18,75 \mathrm{~mA} / \mathrm{cm}^{2}$

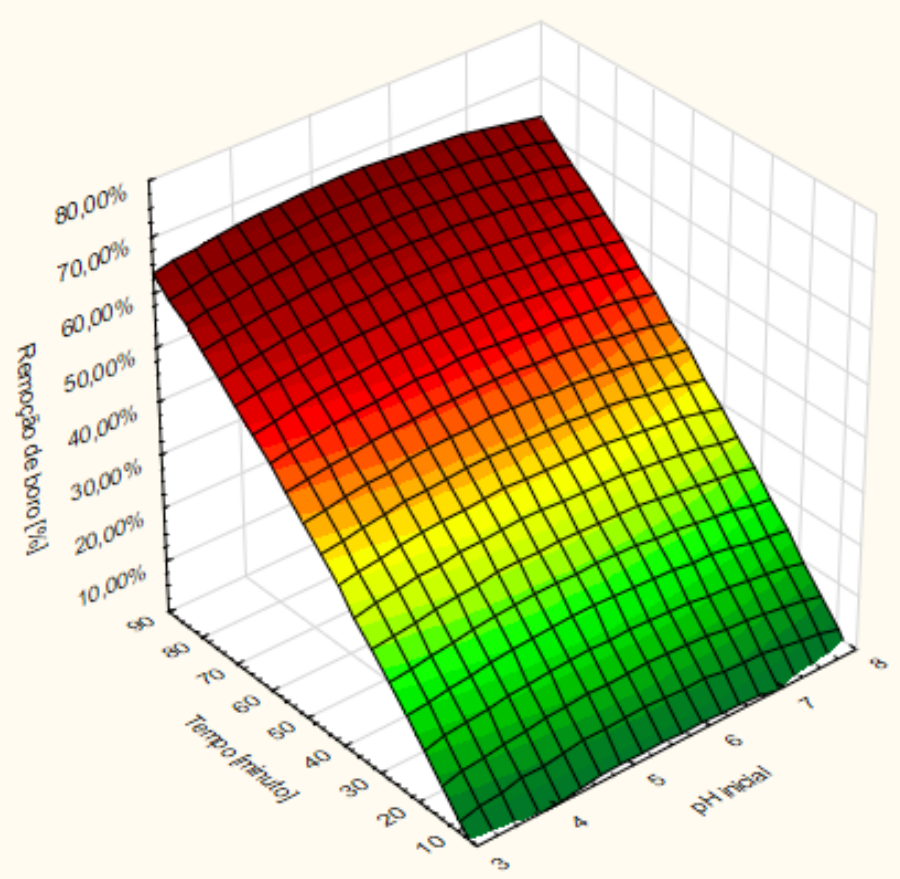

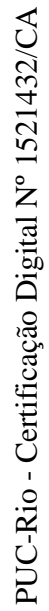

Figura 56 - Superfície de resposta para o percentual de remoção de boro $\times$ tempo x pH inicial, mantendo a densidade de corrente fixa em $18,75 \mathrm{~mA} / \mathrm{cm}^{2}$. Elaborada pelo autor.

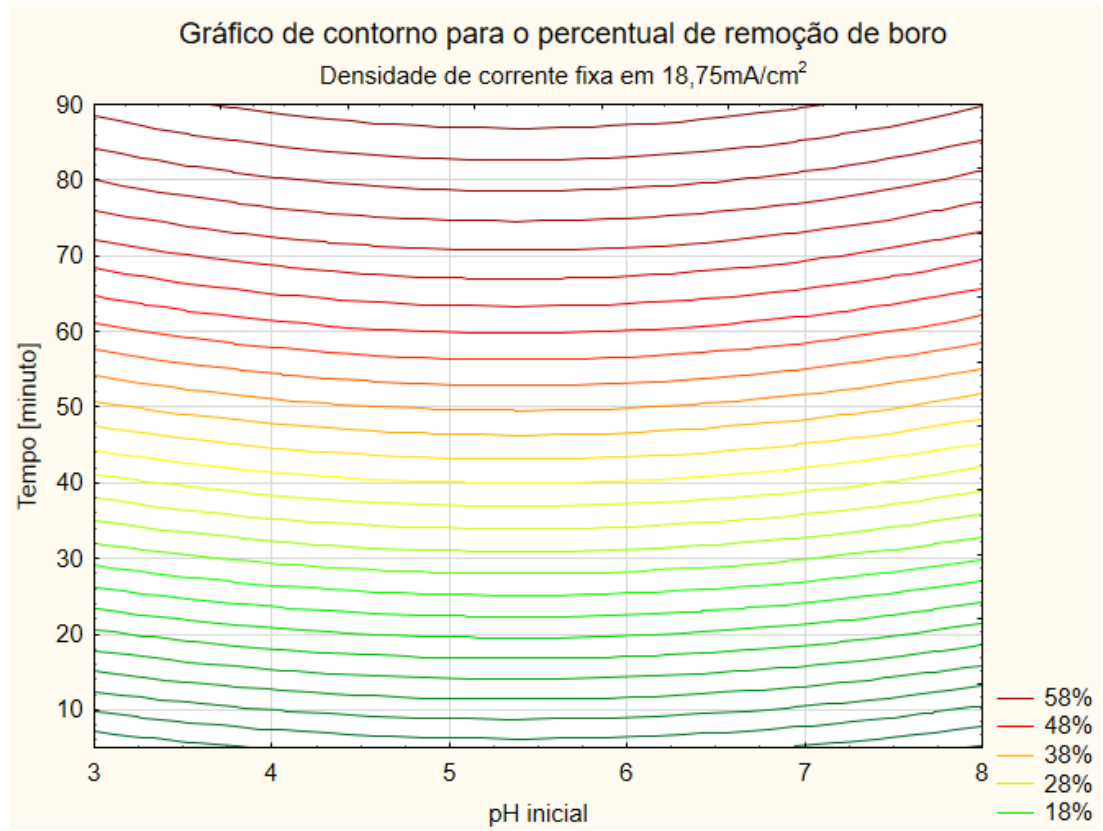

Figura 57 - Gráfico de contorno para o percentual de remoção de boro $\times$ tempo x pH inicial, mantendo a densidade de corrente fixa em $18,75 \mathrm{~mA} / \mathrm{cm}^{2}$. Elaborada pelo autor. 


\subsection{3.}

\section{Condições ótimas}

Os valores ótimos das variáveis operacionais obtidos a partir da metodologia de superfície de resposta para a remoção de boro foram: densidade de corrente de $18,75 \mathrm{~mA} / \mathrm{cm}^{2}$, tempo de eletrólise de 90 minutos e $\mathrm{pH}$ inicial de 5,5 .

Embora a eletrocoagulação seja um processo complexo que envolve diversos processos físico-químicos, diante dos resultados obtidos nesse estudo de otimização constata-se que o desenvolvimento de um modelo matemático por análise de regressão possibilitou a avaliação do efeito das variáveis independentes (densidade de corrente, $\mathrm{pH}$ inicial e tempo) e as suas interações na remoção de boro. 


\section{6 Conclusões}

Observou-se que a maior porcentagem de remoção de boro foi alcançada em $\mathrm{pH}_{0}=4$. Observou-se que a remoção de boro em 5 minutos é mínima, portanto, o mecanismo de remoção dominante, durante todo o processo, é a floculação por varredura. É provável que ocorra uma ação conjunta, inicialmente, com a desestabilização das partículas de ácido bórico através das interações com os cátions monoméricos presentes na solução e, posteriormente, com a adsorção dessas partículas no precipitado de hidróxido de alumínio.

A pior eficiência de remoção de boro ocorreu em $\mathrm{pH}_{0}=8$, esse resultado pode ser justificado em razão da dissolução do precipitado de hidróxido de alumínio para formar espécies aniônicas monoméricas de hidroxialumínio em solução.

A eficiência de remoção de boro aumentou juntamente com a densidade de corrente. A quantidade de alumínio dissolvido a partir do anodo foi sempre superior à calculada teoricamente pela lei de Faraday, essa diferença advém da dissolução química do anodo. Observou-se que a dissolução química do catodo se manteve independente da densidade de corrente, portanto, o aumento da densidade de corrente diminui a contribuição da dissolução química do catodo na dissolução total de alumínio. Além disso, a dissolução total de alumínio foi equivalente a duas vezes o valor calculado pela lei de Faraday para as condições experimentais desse trabalho.

O modelo cinético que melhor descreveu a remoção de boro é o de pseudoprimeira ordem. Observou-se que a constante cinética aumenta com o aumento da densidade de corrente. Em relação ao efeito do $\mathrm{pH}$ inicial, notou-se que a constante cinética apresenta o seu valor máximo em $\mathrm{pH}_{0}=4$.

O modelo de Langmuir se ajustou muito bem aos dados experimentais obtidos. O valor de $\mathrm{q}_{\mathrm{m}}$ obtido pelo modelo de Langmuir reflete a elevada capacidade de adsorção máxima $\left(\mathrm{q}_{\mathrm{m}}=334 \mathrm{mg} / \mathrm{g}\right)$. É importante destacar que o modelo de Freundlich também apresentou um bom ajuste dos dados. Os valores 
elevados das constantes $\mathrm{K}_{\mathrm{F}}$ e $\mathrm{n}$ mostram uma fácil adsorção. $\mathrm{O}$ valor de $\mathrm{n}$ é maior que a unidade, indicando que as espécies presentes são favoravelmente adsorvidas sob as condições experimentais testadas. Dessa forma, isso sugere a ocorrência da adsorção em monocamada, assim como condições heterogêneas na superfície, onde ambas condições podem coexistir sob as condições experimentais testadas.

As análises por MEV mostraram na superfície do catodo a presença de corrosão do tipo localizada, no anodo observou-se a corrosão do tipo uniforme da superfície do eletrodo. O resultado da análise por EDS da superfície do catodo em uma região onde não houve a dissolução química do alumínio mostrou a presença predominante de alumínio e de oxigênio, comprovando a existência de uma camada de óxido de alumínio sobre a superfície do eletrodo.

A análise por MEV indicou a presença de uma morfologia heterogênea na superfície do lodo produzido no processo de eletrocoagulação. A análise por EDS mostrou que o lodo é composto, sobretudo, por alumínio e oxigênio. Esses resultados reforçam que os precipitados obtidos ao longo do processo de eletrocoagulação são, como esperado, flocos de hidróxido de alumínio amorfo. A análise por DRX do lodo apresentou picos largos característicos de um material amorfo. A fase de alumínio predominante foi a boehmita, $\mathrm{AlO}(\mathrm{OH})$. Através da análise por EELS do lodo gerado no processo de eletrocoagulação foi possível a detecção do boro, além da detecção de alumínio e de oxigênio.

Através dos gráficos de superfície de resposta e contorno foi possível observar que a remoção de boro é intensificada à medida que a densidade de corrente e tempo de eletrólise se aproximam dos seus níveis máximos e a melhor faixa de pH inicial encontra-se entre 5 e 6 . Embora a eletrocoagulação seja um processo complexo envolvendo diversos processos físico-químicos, diante dos resultados obtidos nesse estudo de otimização constatou-se que o desenvolvimento de um modelo matemático por análise de regressão possibilitou a avaliação do efeito das variáveis independentes (densidade de corrente, $\mathrm{pH}$ inicial e tempo) e as suas interações na remoção de boro. 


\section{7 \\ Referências bibliográficas}

ADAIR, Rick. Boron. The Rosen Publishing Group, 2007.

AHN, Channing C. (Ed.). Transmission electron energy loss spectrometry in materials science and the EELS atlas. John Wiley \& Sons, 2006.

AKYOL, Abdurrahman. Treatment of paint manufacturing wastewater by electrocoagulation. Desalination, v. 285, p. 91-99, 2012.

ALY, Anwar A.; HASAN, Yousef NY; AL-FARRAJ, Abdullah S. Olive mill wastewater treatment using a simple zeolite-based low-cost method. Journal of environmental management, v. 145, p. 341-348, 2014.

AMANI-GHADIM, A. R. et al. Optimization of electrocoagulation process for removal of an azo dye using response surface methodology and investigation on the occurrence of destructive side reactions. Chemical Engineering and Processing: Process Intensification, v. 64, p. 68-78, 2013.

ANDERSON, Mark J.; WHITCOMB, Patrick J. Design of experiments. John Wiley \& Sons, Inc., 2000.

AOUDJ, S. et al. Electrocoagulation process applied to wastewater containing dyes from textile industry. Chemical Engineering and Processing: Process Intensification, v. 49, n. 11, p. 1176-1182, 2010.

ARGUST, Peter. Distribution of boron in the environment. Biological trace element research, v. 66, n. 1, p. 131-143, 1998.

ATKINS, Peter. The elements of physical chemistry: with application in biology. 2001.

AUBERT, H.; PINTA, M. Trace elements in soils. Elsevier Scientific, Amsterdam, 1997.

AYYILDIZ, H. F.; KARA, H. Boron removal by ion exchange membranes. Desalination, v. 180, n. 1-3, p. 99-108, 2005.

BARD, Allen J. et al. Electrochemical methods: fundamentals and applications. New York: wiley, 1980.

BARKLEY, Naomi P.; FARRELL, Clifton; WILLIAMS, Tracie. Electro-pure alternating current electrocoagulation. US Environmental Protection Agency, Superfund Innovative Technology Evaluation, 1993. 
BAYAR, Serkan et al. The effect of stirring speed and current density on removal efficiency of poultry slaughterhouse wastewater by electrocoagulation method. Desalination, v. 280, n. 1, p. 103-107, 2011.

BAYRAMOGLU, Mahmut; EYVAZ, Murat; KOBYA, Mehmet. Treatment of the textile wastewater by electrocoagulation: economical evaluation. Chemical Engineering Journal, v. 128, n. 2, p. 155-161, 2007.

BELONGIA, B. M. et al. Treatment of alumina and silica chemical mechanical polishing waste by electrodecantation and electrocoagulation. Journal of the Electrochemical Society, v. 146, n. 11, p. 4124-4130, 1999.

BIÇAK, Niyazi et al. Modification of crosslinked glycidyl methacrylate-based polymers for boron-specific column extraction. Reactive and Functional Polymers, v. 47, n. 3, p. 175-184, 2001.

BOUGUERRA, W. et al. Boron removal by adsorption onto activated alumina and by reverse osmosis. Desalination, v. 223, n. 1-3, p. 31-37, 2008.

BOX, George EP; HUNTER, J. Stuart; HUNTER, William Gordon. Statistics for experimenters: design, innovation, and discovery. New York: WileyInterscience, 2005.

BRADY, R. Weil, The nature and properties of soils, 14. ed., Upper Saddle River: Prentice Hall, 2008.

BRATBY, John. Coagulation and flocculation in water and wastewater treatment. IWA publishing, 2006.

BUSCH, Markus et al. Boron removal in sea water desalination. International Desalination and Water Reuse Quarterly, v. 13, n. 4, p. 25, 2004.

BUTT, Hans- Jürgen; KAPPL, Michael. Electrostatic Double- Layer Forces. Surface and Interfacial Forces, p. 93-125, 2010.

CAÑIZARES, P. et al. Electrodissolution of aluminum electrodes in electrocoagulation processes. Industrial \& engineering chemistry research, v. 44, n. 12, p. 4178-4185, 2005.

CAÑIZARES, P. et al. Coagulation and electrocoagulation of wastes polluted with dyes. Environmental science \& technology, v. 40, n. 20, p. 6418-6424, 2006.

CARNIE, Steven L.; TORRIE, Glenn M. The statistical mechanics of the electrical double layer. Advances in Chemical Physics, Volume 56, p. 141-253, 2007.

CHEN, Guohua; CHEN, Xueming; YUE, Po Lock. Electrocoagulation and electroflotation of restaurant wastewater. Journal of environmental engineering, v. 126, n. 9, p. 858-863, 2000. 
CHEN, Guohua. Electrochemical technologies in wastewater treatment. Separation and purification Technology, v. 38, n. 1, p. 11-41, 2004.

CHEN, Xueming; CHEN, Guohua. Electroflotation. In: Electrochemistry for the Environment. Springer New York, 2010. p. 263-277.

CHEN, Xueming; CHEN, Guohua; YUE, Po Lock. Separation of pollutants from restaurant wastewater by electrocoagulation. Separation and purification technology, v. 19, n. 1, p. 65-76, 2000.

CHOU, Wei-Lung; WANG, Chih-Ta; HUANG, Kai-Yu. Investigation of process parameters for the removal of polyvinyl alcohol from aqueous solution by iron electrocoagulation. Desalination, v. 251, n. 1, p. 12-19, 2010.

CRESPILHO, Frank Nelson; REZENDE, Maria Olímpia Oliveira. Eletrodos de pasta de carbono modificados com ácidos húmicos: estudo e determinação de metais em meio aquoso. Quim. Nova, v. 27, n. 6, p. 964-969, 2004.

DANESHVAR, N. et al. Decolorization of CI Acid Yellow 23 solution by electrocoagulation process: Investigation of operational parameters and evaluation of specific electrical energy consumption (SEEC). Journal of hazardous materials, v. 148, n. 3, p. 566-572, 2007.

DANESHVAR, N.; SORKHABI, H. Ashassi; KASIRI, M. B. Decolorization of dye solution containing Acid Red 14 by electrocoagulation with a comparative investigation of different electrode connections. Journal of hazardous materials, v. 112, n. 1, p. 55-62, 2004.

DAVIDSON, Matthew G. et al. (Ed.). Contemporary boron chemistry. Royal Society of Chemistry, 2007.

DERYAGIN, B. V.; LANDAU, L. Bacteria sulfide mineral interactions with reference to flotation and flocculation. Acta Physicochem., URSS, v. 55, p. 333, 1941.

DI BERNARDO, L.; DANTAS, A. Di Bernardo. Métodos e Técnicas de Tratamento de Água. 2. ed. 2v. Rima, São Carlos, SP, 2005.

DOMINGUEZ, Joaquin R. et al. Aluminium sulfate as coagulant for highly polluted cork processing wastewaters: removal of organic matter. Journal of hazardous materials, v. 148, n. 1, p. 15-21, 2007.

DONINI, J. C. et al. The operating cost of electrocoagulation. The Canadian Journal of Chemical Engineering, v. 72, n. 6, p. 1007-1012, 1994.

DUAN, Jinming; GREGORY, John. Coagulation by hydrolysing metal salts. Advances in colloid and interface science, v. 100, p. 475-502, 2003. 
EDZWALD, J. K. Coagulation in drinking water treatment: particles, organics and coagulants. Water Science and Technology, v. 27, n. 11, p. 21-35, 1993.

EDWARDS, Marc; BENJAMIN, Mark M. Regeneration and reuse of iron hydroxide adsorbents in treatment of metal-bearing wastes. Journal (Water Pollution Control Federation), p. 481-490, 1989.

EL-TAWEEL, Yehia A. et al. Removal of Cr (VI) ions from waste water by electrocoagulation using iron electrode. Egyptian journal of Petroleum, v. 24, n. 2, p. 183-192, 2015.

EMAMJOMEH, Mohammad M.; SIVAKUMAR, Muttucumaru. Review of pollutants removed by electrocoagulation and electrocoagulation/flotation processes. Journal of environmental management, v. 90, n. 5, p. 1663-1679, 2009.

EVERETT, Douglas H. Basic principles of colloid science. Royal society of chemistry, 2007.

EZECHI, EZERIE HENRY; ISA, MOHAMED HASNAIN; KUTTY, Shamsul Rahman Mohamed. Removal of boron from produced water by electrocoagulation. In: 10th WSEAS International Conference on Environment, Ecosystems and Development (EED'12). 2012. p. 87-92.

FAUST, Samuel D.; ALY, Osman M. Chemistry of water treatment. CRC Press, 1998.

FOO, KY; HAMEED, B. H. Insights into the modeling of adsorption isotherm systems. Chemical Engineering Journal, v. 156, n. 1, p. 2-10, 2010.

FORMOSINHO, Sebastião J.; ARNAUT, Luís G. Cinética química: estrutura molecular e reactividade química: estructura molecular e reactividade química. Imprensa da Universidade de Coimbra/Coimbra University Press, 2003.

FOX, K. K. et al. The use of measured boron concentration data from the GREAT-ER UK validation study (1996-1998) to generate predicted regional boron concentrations. Science of the total environment, v. 251, p. 305-316, 2000 .

FREY, Michelle M. et al. Cost to utilities of a lower MCL for arsenic. JournalAmerican Water Works Association, v. 90, n. 3, p. 89-102, 1998.

GHOSH, D.; MEDHI, C. R.; PURKAIT, M. K. Treatment of fluoride containing drinking water by electrocoagulation using monopolar and bipolar electrode connections. Chemosphere, v. 73, n. 9, p. 1393-1400, 2008.

GOLDER, A. K.; SAMANTA, A. N.; RAY, S. Removal of Cr 3+ by electrocoagulation with multiple electrodes: bipolar and monopolar configurations. Journal of Hazardous Materials, v. 141, n. 3, p. 653-661, 2007. 
GOLDSTEIN, Joseph et al. Scanning electron microscopy and X-ray microanalysis: a text for biologists, materials scientists, and geologists. Springer Science \& Business Media, 2012.

GOODRIDGE, F.; SCOTT, K. A guide to the design of electrolytic plant. Electrochemical Process Engineering, 1995.

GOODWIN, J. Colloids and Interfaces with Surfactants and Polymers - An Introduction, John Wiley \& Sons: Chichester, 2004.

GREENWOOD, N. N. et al. (ed.). Comprehensive Inorganic Chemistry. Pergamon Press, Oxford-New York, v. 1, p. 680-689, 1973.

GUPTA, Umesh C. et al. Boron toxicity and deficiency: a review. Canadian Journal of Soil Science, v. 65, n. 3, p. 381-409, 1985.

GÜRSES, Ahmet; YALÇIN, Mehmet; DOĞAR, Cetin. Electrocoagulation of some reactive dyes: a statistical investigation of some electrochemical variables. Waste Management, v. 22, n. 5, p. 491-499, 2002.

HAHN, Hermann H.; STUMM, Werner. Kinetics of coagulation with hydrolyzed AI (III): The rate-determining step. Journal of colloid and interface science, v. 28, n. 1, p. 134-144, 1968.

HANSEN, Henrik K. et al. Electrocoagulation in wastewater containing arsenic: Comparing different process designs. Electrochimica Acta, v. 52, n. 10, p. 34643470, 2007.

HEBBLETHWAITE, R. L.; EMBERSON, P. Rising from the ashes. Landscape Des, v. 10, p. 31-34, 1993.

HERMANEK, Stanislav. Boron chemistry: introduction. Chemical Reviews, v. 92, n. 2, p. 175-175, 1992.

HIEMENZ, Paul C.; HIEMENZ, Paul C. Principles of colloid and surface chemistry. New York: M. Dekker, 1986.

HILAL, N.; KIM, G. J.; SOMERFIELD, C. Boron removal from saline water: a comprehensive review. Desalination, v. 273, n. 1, p. 23-35, 2011.

HINZ, Katja et al. Interaction of $\mathrm{Nd}$ (iii) and $\mathrm{Cm}$ (iii) with borate in dilute to concentrated alkaline $\mathrm{NaCl}, \mathrm{MgCl} 2$ and $\mathrm{CaCl} 2$ solutions: solubility and TRLFS studies. New journal of chemistry, v. 39, n. 2, p. 849-859, 2015.

HOLT, P. K.; BARTON, G. W.; MITCHELL, C. A. Electrocoagulation as a wastewater treatment. The third annual australian environmental engineering research event, v. 1000, p. 41-46, 1999.

HOLT, P. K.; BARTON, G. W.; MITCHELL, C. A. The role of current in determining pollutant removal in a batch electrocoagulation reactor. In: 6th 
World Congress of Chemical Engineering Conference Media CD, Melbourne, Australia. 2001.

HOLT, P. K. et al. A quantitative comparison between chemical dosing and electrocoagulation. Colloids and Surfaces A: Physicochemical and Engineering Aspects, v. 211, n. 2, p. 233-248, 2002.

HOLT, P. K. Electrocoagulation: unravelling and synthesising the mechanisms behind a water treatment process. 2002.

HOLT, P. K.; BARTON, G. W.; MITCHELL, C. A. The future for electrocoagulation as a localised water treatment technology. Chemosphere, v. 59, n. 3, p. 355-367, 2005.

HOSMANE, Narayan S. (Ed.). Boron science: new technologies and applications. CRC press, 2011.

HOWE, Paul D. A review of boron effects in the environment. Biological trace element research, v. 66, n. 1-3, p. 153-166, 1998.

HUNTER, Robert J. Introduction to modern colloid science. Oxford University Press, 1993.

HUNTER, Robert J. Zeta potential in colloid science: principles and applications. Academic press, 2013.

HUSSIN, Farihahusnah et al. Removal of lead by solar-photovoltaic electrocoagulation using novel perforated zinc electrode. Journal of Cleaner Production, v. 147, p. 206-216, 2017.

INUKAI, Yoshinari et al. Removal of boron (III) by N-methylglucamine-type cellulose derivatives with higher adsorption rate. Analytica Chimica Acta, v. 511, n. 2, p. 261-265, 2004.

ISA, Mohamed Hasnain et al. Boron removal by electrocoagulation and recovery. Water research, v. 51, p. 113-123, 2014.

IVANISHVILI, A. I.; PRZHEGORLINSKII, V. I.; KALINICHENKO, T. D. A comparative evaluation of the efficiency of electrocoagulation and reagent methods of clarifying waste water. Soviet Journal of Water Chemistry and Technology, v. 9, n. 5, p. 118-119, 1987.

JACOB, Cyril. Seawater Desalination: Boron Removal by Ion Exchange Technology. Desalination. 205: 47-52. 2007.

JAHIRUDDIN, M. et al. Factors regulating the distribution of boron in water in the River Dee catchment in north east Scotland, Science of the Total Environment, 210, 53-62, 1998.

JOLLY, William L. Modern inorganic chemistry. McGraw-Hill College, 1984. 
KABDAŞLI, I. et al. Electrocoagulation applications for industrial wastewaters: a critical review. Environmental Technology Reviews, v. 1, n. 1, p. 2-45, 2012.

KATAL, Reza; PAHLAVANZADEH, Hassan. Influence of different combinations of aluminum and iron electrode on electrocoagulation efficiency: Application to the treatment of paper mill wastewater. Desalination, v. 265, n. 1, p. 199-205, 2011.

KAVAK, Duygu. Removal of boron from aqueous solutions by batch adsorption on calcined alunite using experimental design. Journal of Hazardous Materials, v. 163, n. 1, p. 308-314, 2009.

KHURI, André I.; MUKHOPADHYAY, Siuli. Response surface methodology. Wiley Interdisciplinary Reviews: Computational Statistics, v. 2, n. 2, p. 128-149, 2010.

KILIÇ, Mehtap Gülsün; HOŞTEN, Çetin; DEMIRCI, Şahinde. A parametric comparative study of electrocoagulation and coagulation using ultrafine quartz suspensions. Journal of hazardous materials, v. 171, n. 1, p. 247-252, 2009.

KIM, Jonathan P.; LEMMON, Joan; HUNTER, Keith A. Size-distribution analysis of sub-micron colloidal particles in river water. Environmental technology, v. 16, n. 9, p. 861-868, 1995.

KINNIBURGH, David G. General purpose adsorption isotherms. Environmental Science \& Technology, v. 20, n. 9, p. 895-904, 1986.

KLUG, Harold Philip et al. X-ray diffraction procedures. New York: Wiley, 1954.

KOBYA, M. et al. Treatment of potato chips manufacturing wastewater by electrocoagulation. Desalination, v. 190, n. 1-3, p. 201-211, 2006.

KOVATCHEVA, Valeria K.; PARLAPANSKI, Marin D. Sonoelectrocoagulation of iron hydroxides. Colloids and Surfaces A: Physicochemical and Engineering Aspects, v. 149, n. 1, p. 603-608, 1999.

KRAUSKOPF, K. B. Geochemistry of micronutrients. Micronutrients in agriculture, 1972.

LEMARCHAND, E.; SCHOTT, J.; GAILLARDET. J. Boron isotopic fractionation related to boron sorption on humic acid and the structure of surface complexes formed. Geochim Cosmochim Acta 2005.

LETTERMAN, Raymond D. et al. Water quality and treatment. McGraw-Hill, 1999.

LEVENSPIEL, Octave. Chemical reaction engineering. Industrial \& engineering chemistry research, v. 38, n. 11, p. 4140-4143, 1999. 
LINARES-HERNÁNDEZ, Ivonne et al. A combined electrocoagulationelectrooxidation treatment for industrial wastewater. Journal of hazardous materials, v. 175, n. 1, p. 688-694, 2010.

LIU, Huijuan; ZHAO, Xu; QU, Jiuhui. Electrocoagulation in water treatment. In: Electrochemistry for the Environment. Springer New York, 2010. p. 245262.

MAHESH, S. et al. Electrochemical degradation of pulp and paper mill wastewater. Part 1. COD and color removal. Industrial \& engineering chemistry research, v. 45, n. 8, p. 2830-2839, 2006.

MAMERI, N. et al. Defluoridation of septentrional Sahara water of North Africa by electrocoagulation process using bipolar aluminium electrodes. Water research, v. 32, n. 5, p. 1604-1612, 1998.

MANE, P. P., et al., Modeling boron rejection in pilot-and full-scale reverse osmosis desalination processes. Journal of membrane science, 2009. 338(1-2): p. 119-127.

MATIS, K. A.; ZOUBOULIS, A. I. Electrolytic flotation: an unconventional technique. Flotation Science and Engineering, p. 385-413, 1995.

MATTESON, Michael J. et al. Electrocoagulation and separation of aqueous suspensions of ultrafine particles. Colloids and Surfaces A: Physicochemical and Engineering Aspects, v. 104, n. 1, p. 101-109, 1995.

MAXIMOVA, Natalia; DAHL, Olli. Environmental implications of aggregation phenomena: current understanding. Current opinion in colloid \& interface science, v. 11, n. 4, p. 246-266, 2006.

McNeill, L.S., and M. Edwards. "Predicting as removal during metal hydroxide precipitation." Journal of American Water Works Assoc. 89 (1997): 75-86.

MEL'NIK, L. A.; BUTNIK, I. A.; GONCHARUK, V. V. Sorption-membrane removal of boron compounds from natural and waste waters: Ecological and economic aspects. Journal of Water Chemistry and Technology, v. 30, n. 3, p. 167-179, 2008.

MISSAOUI, Khaoula et al. Boron removal by electrocoagulation using full factorial design. Journal of Water Resource and Protection, v. 5, n. 09, p. 867, 2013.

MLAKAR, Matej; LEVSTEK, Marjetka; STRAŽAR, Marjeta. Physico-chemical treatment of liquid waste on an industrial plant for electrocoagulation. Water Science and Technology, p. wst2017390, 2017.

MOLLAH, M. Yousuf A. et al. Electrocoagulation (EC)-science and applications. Journal of hazardous materials, v. 84, n. 1, p. 29-41, 2001. 
MOLLAH, Mohammad YA et al. Fundamentals, present and future perspectives of electrocoagulation. Journal of hazardous materials, v. 114, n. 1, p. 199-210, 2004.

MONTASER, Akbar et al. AN INTRODUCTION TO ICP SPECTROMETRIES FOR ELEMENTAL ANALYSIS. 1992.

MONTGOMERY, Douglas C. Design and analysis of experiments. John Wiley \& Sons, 2017.

MOORE, John A. et al. An assessment of boric acid and borax using the IEHR evaluative process for assessing human developmental and reproductive toxicity of agents. Reproductive Toxicology, v. 11, n. 1, p. 123-160, 1997.

MORENO C, Hector A. et al. Electrochemical reactions for electrocoagulation using iron electrodes. Industrial \& Engineering Chemistry Research, v. 48, n. 4, p. 2275-2282, 2009.

MORGAN, V. Boron geochemistry. Mellors Comprehensive Treatise on Inorganic and Theoretical Chemistry, v. 5, n. Suppl 1, p. 52-72, 1980.

MOUEDHEN, G. et al. Behavior of aluminum electrodes in electrocoagulation process. Journal of hazardous materials, v. 150, n. 1, p. 124-135, 2008.

MUETTERTIES, Earl L. The Chemistry of Boron and its Compounds. New York: John WIley \& Sons, Inc., 1967.

MURRAY, F. Jay. A human health risk assessment of boron (boric acid and borax) in drinking water. Regulatory Toxicology and Pharmacology, v. 22, n. 3, p. 221-230, 1995.

MYERS, Raymond H.; MONTGOMERY, Douglas C.; ANDERSON-COOK, Christine M. Response surface methodology: process and product optimization using designed experiments. John Wiley \& Sons, 2016.

NABLE, R. O.; BAÑUELOS, G. S.; PAULL, J. G. Boron toxicity. Plant and Soil, 193(1-2), 181-198. 1997.

NEWMAN, John; THOMAS-ALYEA, Karen E. Electrochemical systems. John Wiley \& Sons, 2012.

NINHAM, B. W. On progress in forces since the DLVO theory. Advances in colloid and interface science, v. 83, n. 1, p. 1-17, 1999.

NOVIKOVA, S. P.; SHKORBATOVA, T. L.; SOKOL, E. Ya. Purification of effluents from the production of synthetic detergents by electrocoagulation. Soviet J. Water Chem. Technol, v. 4, n. 4, p. 353-357, 1982. 
OHSHIMA, Hiroyuki. DLVO Theory of Colloid Stability. Biophysical Chemistry of Biointerfaces, p. 420-430.

OHSHIMA, Hiroyuki; FURUSAWA, Kunio (Ed.). Electrical phenomena at interfaces: fundamentals: measurements, and applications. CRC Press, 1998.

OLESIK, John W. Elemental analysis using ICP-OES and ICP/MS. Analytical Chemistry, v. 63, n. 1, p. 12A-21A, 1991.

ÖZTÜRK, Neşe; KAVAK, Duygu. Adsorption of boron from aqueous solutions using fly ash: batch and column studies. Journal of hazardous materials, v. 127, n. 1, p. 81-88, 2005.

PARK, Jong Kil; LEE, Kun Jai. Diffusion coefficients for aqueous boric acid. Journal of Chemical and Engineering Data, v. 39, n. 4, p. 891-894, 1994.

PARKS, Jeffrey L., and Marc Edwards. "Boron removal via formation of magnesium silicate solids during precipitative softening." Journal of Environmental Engineering 133 (February 2007): 149-156.

PARKS, Jeffrey L.; EDWARDS, Marc. Boron in the environment. Critical Reviews in Environmental Science and Technology, v. 35, n. 2, p. 81-114, 2005.

PEREZ, Nestor et al. Electrochemistry and corrosion science. Boston: Kluwer Academic Publishers, 2004.

KEMP, Peter Hayden. The chemistry of borates: a review. Borax Consolidated Limited, 1956.

PILIPENKO, A. T.; GREBENYUK, V. D.; MELNIK, La. Extraction of boron compounds from natural water and industrial effluents. Soviet Journal of Water Chemistry and Technology, v. 12, n. 3, p. 1-18, 1990.

PLETCHER, D. K.; WALSH, F. C. Industrial Electrochemistry. 3. ed., Cambridge, Chapman and Hall, 1990, 653 p.

POLAT, Hürriyet et al. A new methodology for removal of boron from water by coal and fly ash. Desalination, v. 164, n. 2, p. 173-188, 2004.

POURBAIX, Marcel; BURBANK, Jeanne. Atlas D-Equilibres Electrochimiques. 1964.

POWER, Philip P.; WOODS, William G. The chemistry of boron and its speciation in plants. Plant and Soil, v. 193, n. 1, p. 1-13, 1997.

PRETORIUS, W. A.; JOHANNES, W. G.; LEMPERT, G. G. Electrolytic iron flocculant production with a bipolar electrode in series arrangement. Water S. A., v. 17, n. 2, p. 133-138, 1991. 
REDLICH, O. J. D. L.; PETERSON, D. L. A useful adsorption isotherm. Journal of Physical Chemistry, v. 63, n. 6, p. 1024-1024, 1959.

REICHELT, Rudolf. Scanning electron microscopy. In: Science of microscopy. Springer New York, 2007. p. 133-272.

REMY, Patricia et al. Removal of boron from wastewater by precipitation of a sparingly soluble salt. Environmental Progress \& Sustainable Energy, v. 24, n. 1, p. 105-110, 2005.

REVIE, R. Winston; UHLIG, Herbert H. Thermodynamics: Pourbaix diagrams. Corrosion and Corrosion Control: An Introduction to Corrosion Science and Engineering, Fourth Edition, p. 43-51, 2008.

ROSS, V. F.; EDWARDS, J. O. The Chemistry of Boron and Its Compounds. In: MUETTERTIES, Earl. L. The Chemistry of Boron and its Compounds. 155207. Wilmington: John Wiley and Sons, Inc., 1967.

RUBINSTEIN, Israel (Ed.). Physical Electrochemistry: Science and Technology. CRC Press, 1995.

SAHIN, S. Mathematical model of boron adsorption by ion exchange. ACH, models in chemistry, v. 133, n. 1-2, p. 143-150, 1996.

SAHU, Omprakash; MAZUMDAR, Bidyut; CHAUDHARI, P. K. Treatment of wastewater by electrocoagulation: a review. Environmental science and pollution research, v. 21, n. 4, p. 2397-2413, 2014.

SATO, Taichi. Thermal decomposition of aluminium hydroxides. Journal of Thermal Analysis and Calorimetry, v. 32, n. 1, p. 61-70, 1987.

SHARMA, G. et al. Solar-powered electrocoagulation system for water and wastewater treatment. Desalination and Water Treatment, v. 32, n. 1-3, p. 381388, 2011.

SHAW, D. T. Introduction to Colloid and Interface Science. Butterworth, Oxford, 1992.

SHAW, Duncan J.; COSTELLO, Bernard. Introduction to colloid and surface chemistry. Butterworth, Oxford, 1993.

SAWYER, Donald T.; SOBKOWIAK, Andrzej; ROBERTS, Julian L. Electrochemistry for chemists. Wiley, 1995.

SIMONNOT, Marie-Odile et al. Boron removal from drinking water with a boron selective resin: is the treatment really selective?. Water Research, v. 34, n. 1, p. 109-116, 2000.

SMOCZYŃSKI, Lech et al. Electrocoagulation of Model Wastewater Using Iron Elect. Ecological Chemistry and Engineering. A, v. 20, n. 10, 2013. 
SONG, Shuang et al. Ozone assisted electrocoagulation for decolorization of CI Reactive Black 5 in aqueous solution: An investigation of the effect of operational parameters. Separation and purification technology, v. 55, n. 2, p. 238-245, 2007.

SPOSITO, Garrison. The environmental chemistry of aluminum. CRC Press, 1995.

SZPYRKOWICZ, Lidia et al. Influence of anode material on electrochemical oxidation for the treatment of tannery wastewater. Water research, v. 39, n. 8, p. 1601-1613, 2005.

TUREKIAN, K. K., WEDEPOHL, K. H. Distribution of the elements in some major units of the earth's crust. Geol Soc Am Bull, 1961;72(2):175e92.

UDUMAN, Nyomi et al. A parametric study of electrocoagulation as a recovery process of marine microalgae for biodiesel production. Chemical Engineering Journal, v. 174, n. 1, p. 249-257, 2011.

ULU, Feride et al. Removal of humic substances by electrocoagulation (EC) process and characterization of floc size growth mechanism under optimum conditions. Separation and Purification Technology, v. 133, p. 246-253, 2014.

VASUDEVAN, Subramanyan et al. Remediation of phosphate-contaminated water by electrocoagulation with aluminium, aluminium alloy and mild steel anodes. Journal of Hazardous Materials, v. 164, n. 2, p. 1480-1486, 2009.

VASUDEVAN, Subramanyan et al. Removal of iron from drinking water by electrocoagulation: adsorption and kinetics studies. Korean journal of chemical engineering, v. 26, n. 4, p. 1058-1064, 2009.

VASUDEVAN, Subramanyan; LAKSHMI, Jothinathan; SOZHAN, Ganapathy. Electrochemically assisted coagulation for the removal of boron from water using zinc anode. Desalination, v. 310, p. 122-129, 2013.

VEPSÄLÄINEN, Mikko; PULLIAINEN, Martti; SILLANPÄ̈̈, Mika. Effect of electrochemical cell structure on natural organic matter (NOM) removal from surface water through electrocoagulation (EC). Separation and Purification Technology, v. 99, p. 20-27, 2012.

OVERBEEK, J. Th G.; VERWEY, E. J. W. Theory of the Stability of Lyophobic Colloids: The interaction of Sol Particles Having an Electric Double Layer. 1948.

VETTER, K. J. Electrochemical Kinetics. Academic Press, London, 1967, 789 p.

VIK, Eilen A. et al. Electrocoagulation of potable water. Water Research, v. 18, n. 11, p. 1355-1360, 1984. 
VON HARRACH, H. Sebastian et al. Comparison of the detection limits of EDS and EELS in S/TEM. Microsc. Microanal, v. 16, n. 2, p. 1313, 2010.

WANG, Boyang; GUO, Xianghai; BAI, Peng. Removal technology of boron dissolved in aqueous solutions-a review. Colloids and Surfaces A: Physicochemical and Engineering Aspects, v. 444, p. 338-344, 2014.

WANG, Chih-Ta; CHOU, Wei-Lung; KUO, Yi-Ming. Removal of COD from laundry wastewater by electrocoagulation/electroflotation. Journal of hazardous materials, v. 164, n. 1, p. 81-86, 2009.

WANG, Xiansheng et al. Removal of malachite green from aqueous solutions by electrocoagulation/peanut shell adsorption coupling in a batch system. Water Science and Technology, v. 75, n. 8, p. 1830-1838, 2017.

WEAST, Robert C. A ready-reference book of chemical and physical data. CRC handbook of chemistry and physics, p. B-82, 1985.

WEI, Yu-Ting; ZHENG, Yu-Ming; CHEN, J. Paul. Design and fabrication of an innovative and environmental friendly adsorbent for boron removal. Water research, v. 45, n. 6, p. 2297-2305, 2011.

WHITTIG, L. D.; ALLARDICE, W. R. X-ray diffraction techniques. Methods of Soil Analysis: Part 1-Physical and Mineralogical Methods, $n$. methodsofsoilan1, p. 331-362, 1986.

WOLSKA, J.; BRYJAK, M. Methods for boron removal from aqueous solutions - A review. Desalination, 310, 18-24, 2013. Disponível em: $<10.1016 / j$.desal.2012.08.003>. Acesso em:

XU, Yonglan; JIANG, Jia-Qian. Technologies for boron removal. Industrial \& Engineering Chemistry Research, v. 47, n. 1, p. 16-24, 2008.

YILMAZ, A. Erdem et al. The investigation of parameters affecting boron removal by electrocoagulation method. Journal of hazardous materials, v. 125, n. 1, p. 160-165, 2005.

YILMAZ, A. Erdem et al. Boron removal from geothermal waters by electrocoagulation. Journal of hazardous materials, v. 153, n. 1, p. 146-151, 2008.

ZAROUAL, Zaina et al. Contribution to the study of electrocoagulation mechanism in basic textile effluent. Journal of Hazardous materials, v. 131, n. 1, p. 73-78, 2006.

ZEEBE, Richard E. et al. A theoretical study of the kinetics of the boric acidborate equilibrium in seawater. Marine Chemistry, v. 73, n. 2, p. 113-124, 2001. 